



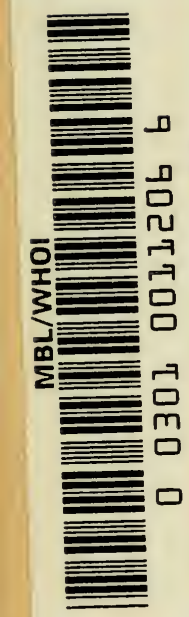



THE PROBLEMS OF EVOLUTION 


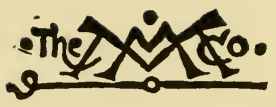

THE MACMILLAN COMPANY

NEW YORK - BOSTON - CHICAGO - DALLAS

ATLANTA - SAN FRANCISCO

MACMILLAN \& CO., Limited

LONDON - BOMBAY - CALCUTTA

MELBOURNE

THE MACMILLAN COMPANY

OF CANADA, LMITED

TORONTO 


\title{
THE PROBLEMS OF EVOLUTION
}

\author{
BY \\ ARTHUR WARD LINDSEY \\ PROFESBOR OF ZOOLOGY \\ IN \\ DENIBON UNTVERSTTY
}

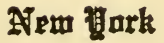

THE MACMILLAN COMPANY 1931 
Coprright, 1931,

BY THE MACMILLAN COMPANY

ALL RIGHTS RESERVED-NO PART OF THIS BOOK MAY BE REPRODUCED

IN ANY FORM WITHOUT PERMISSION IN WRITING FROM THE PUBLISHER

Set up and electrotyped Published February, 1931

SET UP AND ELECTROTYPED BY T. MOREY \& SON

PRINTED IN THE ONITED STATES OF AMERICA. 


\section{TO}

\section{EDWIN GRANT CONKLIN}




\section{PREFACE}

The preparation of this small volume has been the result of long dissatisfaction with the existing treatment of the processes of evolution. Published theories and discussions representing a wide range of opinion are almost universally weak in the treatment of certain problems which are clearly fundamental. The logical solution of these problems is of the greatest importance, and even though a final solution is at present impossible, the problems commend themselves to the attention of biologists.

The problems of evolution arise mostly from the interpretation of observed facts. While the facts themselves cannot be a subject of serious disagreement, their significance in this field is often a matter of dispute. Philosophical inquiries here, as elsewhere in scientific fields, are often sufficiently removed from the facts to give a misleading plausibility to theories of doubtful or limited value, and a plausible theory is all too likely to assume such importance in the minds of its supporters that it may obscure other factors with which the problem is associated.

This difficulty may be met in two ways. On the 
one hand we may attempt to deal with theories in close connection with observed facts, although the body of facts which can be gathered in support of a theory is limited and the capacity of the human mind for their interpretation is often less than we might wish. It is possible to draw thoroughly sound conclusions from apparently sufficient evidence in many cases, only to find them worthless when extended ever so slightly beyond the field in which they were formulated. On the other hand one may admit the futility of present attempts at detailed correlation of our enormous store of observations and resort to logical fundamentals as a possible source of useful working hypotheses. The former method must be followed; without it the entire fabric of evolutionary thought must remain forever without adequate scientific foundations. But if the foundations are to be sound when they are finally completed, our efforts must be properly directed; this they have not always been, and it is the purpose of this work to inquire into the trend of evolutionary thought and to seek the proper background for future study.

It has long been evident that we are making little progress in our absolute knowledge of evolution, and since our experimental methods have undergone very little change they seem to be the most promising field for correction. Experimental evolution has been so much concerned with en- 
vironmental relationships that any attempt to criticize or correct leads inevitably into Lamarckian problems and terminology. We must continue to investigate environmental relationships, but they may be studied in a spirit wholly different from the controversial approach of the past, and here lies the chief claim of this study. It is presented as a non-partisan discussion of the existing state of evolutionary theory in the hope of finding a more logical approach for experimental work. It has a Lamarckian flavor, but is neither Lamarckian nor Darwinian in intent; I am interested only in the sound investigation of evolutionary processes, regardless of the names by which they may be called.

Such conclusions as I present here must necessarily be the result of years of thought and of many men's work. It is impossible to acknowledge or even to realize the extent of one's obligation to the many who collaborate through the medium of their published works, but that the debt is great I both realize and gratefully acknowledge.

I wish to extend my thanks for permission to use quotations from copyrighted works to the publishing houses of Henry Holt and Company, Charles Scribner's Sons, Charles C. Thomas, and the University of Chicago Press. My gratitude is also due once more to my wife, Winifred Wood Lindsey, for assistance in reading proof and for the 
many less tangible but infinitely valuable services which she has rendered in this project, as in all of my work.

The final stages of organizing this book and the actual preparation of the text were carried on at Princeton University during a semester's leave of absence from Denison in the fall and winter of 1929. During this period the members of the staff of the department of Biology at Princeton were uniformly willing and generous in giving any assistance which I cared to ask. To them I extend my sincere thanks. To Dr. E. G. Conklin, who was at all times actively interested in my project and ready to share his time, his wealth of information and experience, and his keen appreciation of the facts and problems of this field, I cannot adequately express my gratitude in thanks; in appreciation of his generous help it is my pleasure and privilege to dedicate this volume to him.

A. W. Lindsey.

Granville, OHio, January, 1931. 


\section{CONTENTS}

CHAPTER I. INTRODUCTION • • • • . 1

Scope of work. Heritage and environment. Life: vitalistic and mechanistic concepts. Necessity of mechanistic point of view in scientific inquiry. Environment as initial source of change. Present autonomy of heritage. Complexity of environment. Direction of inquiry.

CHAPTER II. Individuals ANd Species -

The species problem. Nature of species as a unit. Species and evolution. Heritage and environment in species and individuals. Individual characters and the characters of species.

CHAPTER III. Sources of Change - • .

Materials and forces in natural entities. Internal and external forces. Change of environment. Fluctuations of heritage. Scientific attitude toward variation: Darwin, Lamarck, Bateson. Osborn's tetrakinetic theory. Modifications, recombinations, and mutations. Adaptation: process and result. Adaptability a fundamental property of protoplasm. Mutilations. Fundamental similarity of all acquired characters. Individual characters a part of species complex. Difference between modifications and hereditary characters. Adaptation of species. Selection. Permanence of modifications. Cause of mutations.

\section{CHAPTER IV. GeNetics}

Basic concepts of genetics. Chromosomes, nucleus, and cytoplasm in heredity. Action of genes. Cytoplasmic inheritance. Germ plasm and soma. The body as environment. Relations of body and external environment. Environment and germ cells. Stability of genes. Modern xi 
attitude to this question. Duration of gene activity. Sphere of gene activity. Use and disuse.

CHAPTER V. Theories of Evolution .

Faith the ultimate basis. Vitalism and mechanism. Natural selection. Germinal selection. Intraselection. Coincident selection. Validity of selection theories. Isolation, geographic and biological. Results of isolation. Impotence of selection and isolation to explain evolution. Mutations. Mutations and selection. Orthogenesis. Cause of mutations. Preadaptation. Inadequacy of germinal theories. Lamarckian theory. Kinetogenesis. Parallel induction. Insufficiency of all theories.

CHAPTER VI. Evolution in Nature . . .

Usefulness of mutations. X-ray mutations. Mutations and environment. Acquired characters. Hypothetical analysis of trend of evolution. Existing species based on acquired characters, on hereditary characters. Experimental results: eye defects in rabbits; Daphnia; mice; Simocephalus; flax. Possible methods of evolution in a complex species. Difficulties of interpretation of natural cases. Palaeontology. What is a new character? Emergent evolution. Complexity of evolutionary processes.

CHaPter VII. The Organic Tendency • •

Autonomy of the individual. Opportunism in evolution. Mind. Results of mental control. Favorable orientation. Instinct. Self-maintenance the tendency of living things. Changes the outcome of interacting heritage and environment. Environment a perpetual source of change. Effects of environment on organism. Tendency of organism to become independent. Universal necessity for adaptive adjustment. Necessity for experimental evidence.

\section{CHAPTER VIII. Our Future Course .}

Both heritage and environment essential. Environment may be only directive but is a possible source of hereditary change. Some factors of heritage depend on 


\section{CONTENTS}

xiii

PAGE

external conditions for expression. Nature of individual response. Possibility of chromosomal modification. Use and disuse in chromosomes. Somatic and germinal chromosomes. Continuity of germ plasm. Modifications and the internal environment. Modifications and preadaptation. Reversibility. Conditions for experiment.

INDEX • 



\section{THE PROBLEMS OF EVOLUTION}

\section{I \\ INTRODUCTION}

We are reminded by a recent writer that "the problems of evolution are much broader than the origin of biological species," ${ }^{1}$ and with this warning in mind I must confess to a limitation of my subject and of my present interest. Admittedly evolution is inclusive of universal processes, not all of which are concerned with living things, but the origin of species has a peculiar interest to the biologist. This particular problem still offers promise of solution on a basis of established scientific principles, and even though a fragment of the whole subject, it is a fragment of the utmost importance. Its solution would, if nothing else, release a vast amount of energy for the pursuit of other scientific inquiries!

The scientific world has been thoroughly interested in problems of organic evolution for approximately three-quarters of a century. During that

${ }^{1}$ Conger, G. P., New Views of Evolution, p. 77, 1929. 
time it has been necessary to devote a considerable amount of effort to the adequate establishment of the fact of its occurrence, but the method of evolution has also been the subject of extensive discussion. The matter has been handled controversially to such a degree that expressions of opinion are much more plentiful than sound discussions, but here and there in the literature, especially in recent years, a new and valuable trend in the discussion of phylogenetic processes may be noted. Apparently our knowledge has reached a point where rational analysis is being diligently attempted.

The expressed conclusions of writers on this subject are so different that they can hardly result in an early agreement, but they strike at the heart of existing difficulties in so many cases that the prospect of progress is bright. We have been concerned for years with the gathering of new data and have clung so tenaciously to the old theories and the old theoretical controversies that any departure from the established mode of treatment is promising, granting only that it partakes of an open-minded point of view and does not introduce a new bias among those already existing. Such a work as this cannot pretend to be an ultimate solution, any more than the contributions of many other scientists, but the time seems ripe for a soundly logical analysis of the problems of phylogenesis and this is an attempt at such analysis. In 
most ways it is not novel; most of the ideas contained in it have been expressed in some form elsewhere. But novelty is not the only valid reason for writing. The reason for this work is a sincere belief that it approaches fundamental problems of evolution without prejudice, that it paves the way for a rational examination of details, and that it furnishes a rational basis for experimentation which has hitherto been obscured by mistaken attitudes.

At the outset a word should be said of the possible fields of inquiry in evolution, for it is possible to find unnecessary prejudice even in methods of approach. One writer ${ }^{2}$ summarily dismisses the results of philosophical inquiry when conducted without close association with laboratory investigation. To the extent that an inquiry may be purely philosophical I heartily agree with his attitude, but it suggests to me that there are two distinct courses to be followed in phylogenetic studies. We may, on the one hand, confine ourselves to the examination of various lines of descent, determining the spatial and chronological relationships of the various included species and the environmental conditions under which they arose, and construct phylogenetic trees of great practical value and interest in the field of science. On the other hand, we may interest ourselves in the broader aspects

${ }^{2}$ Sewertzoff, A. N., Acta Zoologica, Vol. X, pp. 59-141, 1929. 
of phylogeny in an effort to determine the general laws which govern the occurrences in the organic world as evolution progresses. In the latter case, of course, we risk departing rather too widely from the solid ground of a specific problem in phylogeny but any inquiry worthy of attention must be founded upon a background of biological facts which should serve as an adequate guaranty of its scientific soundness and protect it against the stigma of philosophic insecurity.

It is unnecessary in a study of this kind, which is avowedly an attempt to approach the problems of species formation and general organic evolution in the broadest possible way, to delve into the past history of the subject in detail. Anyone who is interested in it will undoubtedly be thoroughly acquainted with that history so that a general survey may be dispensed with.

One conspicuous controversy has come down to us from the past which, in final analysis, colors every consideration of our problem that has yet appeared. This controversy is best labelled with the familiar term, inheritance of acquired characters. Of it so much has been written that again it is unnecessary to go into the details of past treatment, but it establishes the point of departure for the critical portion of our study of evolutionary processes. It has raged for many years through the proposal of all existing theories of 
evolutionary method, and all existing theories may be disposed on one or the other side. They neither decide nor abate the controversy.

If this quarrel between the proponents of environment as the important shaping factor in the origin of species and those of the heritage appealed to me as valid, I should have nothing further to say, for in that case our present knowledge would be insufficient to decide the matter and further argument would be as profitless as that of the past. Rather, it appears that we have been barking up the wrong tree and that the promising field for investigation is not the relative merits of these two factors but their universal and exceedingly intricate coördination. This point of view is not original, but since it came to me without direct suggestion from others I derive a firm conviction of its soundness from the similar conclusions that I find scattered through the literature. It presents difficulties of its own. Perhaps it will not lead us yet to an ultimately tenable conclusion, but as an initial step it seems inevitable.

This point of view is slow to gain a hearing. Conklin ${ }^{3}$ years ago emphasized the inseparability of heritage and environment. Rabaud states an undeniable truth in saying: "Dès maintenant, nous pouvons affirmer que ni le milieu ni l'organisme considérés isolément ne portent en eux de

${ }^{3}$ Heredity and Environment, First Edition, 1915. 
résultat prédeterminé," 4 yet the Hagedoorns ${ }^{5}$ find it necessary to warn us that scientists have not approached the problem with open minds in applying the results of their researches and show little evidence of doing so now. And still when we have recognized and admitted that the heritage and the environment are inseparable, we are scarcely nearer to a solution of our problem than before. We witness their interaction only in the individual and the difficulty has always been to determine if, and how, the transition might occur from the somatic characters admittedly produced in the individual to the hereditary characters which appear normally in all individuals of a species. We are left with several fundamental concepts to clarify; among them the relationship of individual and species, and the consequent association of heritage and environment in the two entities, are prominent.

Once we acquire a satisfactory attitude toward these fundamental questions, the difficulties presented by the apparently sound theories of evolutionary method are lessened. It becomes obvious that whether we deal with orthogenesis, mutation, natural selection, or any of the minor methods of change, a uniform analysis on the basis of interacting heritage and environment is possible. Whereas these theories have overemphasized one or another

Biologica, Vol. III, p. 171, 1913.

The Relative Value of the Processes Causing Evolution, 1921. 
factor, a rigidly logical interpretation makes it impossible to fall into such an error, although it leaves us ultimately the difficult course proposed by Rabaud: to investigate that which results in the interaction of heritage and environment.

At this point we come dangerously close to the eternal question, what is life? It would be folly to add to the discussions of this subject which have already appeared; beyond it there is still a profitable field for inquiry on the basis of known chemical and biological principles. Without knowing exactly what life is, the complexities of heritage and environment furnish an adequate background for the realization that their interaction is sufficient to explain the orderly phenomena of life and the complexity of the organic world. This, in itself, is neither a unique nor a difficult concept, but when we introduce the principle of evolutionary change we encounter the difficulties with which the subject of evolution is fraught. It is easier to see that a thing occurs than to determine how it occurs, be it life or evolution.

Fortunately biological investigations provide an abundance of material from which to draw conclusions relating to our problem. In addition to observations and experiments relating directly to the problems of evolution, other branches of biological science disclose many cases in which definite conditions produce definite results and changing con- 
ditions produce changed results. In physiology, particularly in the field of endocrinology, there are striking evidences of the exactness of cause and effect in the organism and in its environmental relations. In experimental embryology there are many disclosures of hereditary response to modifications of environment, both external and internal. In grafting experiments there are still further significant results to be considered, both in embryos and in adult organisms. All of these things bear definitely upon the problem of evolutionary method and aid in the establishment of a sound foundation upon which to approach the less satisfactory accumulation of evidence with regard to evolutionary processes themselves.

It is rare to find a distinctly original attempt to explain the problems of life, possibly because hundreds of men working over a long period of years are not likely to cling to concepts of no value beyond the acquisition of the facts necessary to prove their uselessness. One such attempt is now prominent in the literature, viz., Augusta Gaskell's What is Life? ${ }^{6}$ This is a brilliant and thoughtprovoking work. It paves the way to a more definite inquiry into fundamentals than has yet been made. But unfortunately it is entirely without assurance that the inquiry will be more successful than those of the past. When Mrs. Gaskell makes

6 What is Life? 1928. 
such statements as this: "The new verdict is that it would seem almost certain that the strain which resulted in 'man' was a separate one from the beginning. It is extremely improbable that there should have developed a common ancestor from which (as many think, at a late date) both man and the apes evolved-," she evades an overwhelming mass of significant facts which neither biologist nor palaeontologist can agree to discard. Apparently two points of view are possible, the one conditioned by an accumulation of laboriously acquired information which must be considered in reaching a conclusion, the other free from any preconceived notions which might exert control over its results. One is reminded of Osborn's statement about the ancient Greeks: "Not pausing to test their theories by research, they did not suffer the disappointments and delays which come from our own efforts to wrest truths from Nature. Combined with great freedom and wide range of ideas, independence of thought, and tendencies to rapid generalization, they had genuine gifts of scientific deduction, which enabled them to reach truth, as it were, by inspiration." ?

If the principle of an élan vital should some day be established, whether as an independent force comparable to energy in the physical world or as the Z-system of electrons postulated by Mrs. Gas-

${ }^{7}$ From the Greeks to Darwin, p. 30, 1894. 
kell, the problems of evolution will be greatly modified, but with the knowledge at present available I fail to see how it could overthrow completely the intricate web of relationships now so convincingly demonstrated in the field of evolution. For the present everything points toward the adequacy of a physico-chemical concept of the organism as a basis for inquiry into this subject.

Whatever life may be, the living being and its functions are almost infinitely complex. Seemingly organisms act by the exercise of intangible forces resident within them, but it is increasingly evident as time goes on that the foundation for every action is tangible, and that only our ignorance of details conceals from us the whys of behavior. The skin of the frog darkens or becomes pale, but it is not due to some mysterious power of the animal. Darkening is brought about by cold and dampness and is due to a specific stimulant from certain parts of the pituitary gland which causes expansion of the melanophores. ${ }^{8}$ The digestive glands respond to the stimulus of food under normal conditions, but secretin extracted from the lining of the intestine will induce secretion of pancreatic juice regardless of other conditions. ${ }^{8}$ Far from being a completely discriminating unit, the organism is very largely a result of complex interaction of substances governed by a

${ }^{8}$ Hogben, L. T., The Comparative Physiology of Internal Secretion, 1927. 
likewise complex association of conditions. This is true even of intelligent man with his relatively great power to control the conditions of his own life.

It must be admitted that the physico-chemical basis has not yet been proved the sole explanation of life, but we may confidently predict that it is a universal foundation for the manifestation of life. Vital processes have never yet been demonstrated independently of such a foundation and, until they are, the problems of evolution should be susceptible of solution to the same extent as most of our problems of science. When we explain a natural phenomenon, we have merely resolved it into its component simpler phenomena; we push back the barriers of ignorance but never wholly remove them. In the case of evolution we first had to recognize its occurrence. Then it was necessary to bolster it up with adequate evidence in the various fields of science. And all the while we have been struggling to learn how it proceeds, but here our footing crumbles and long before we get to $w h y$, we have such a difficult task on hand that we are still struggling. The problem of life itself is very near this why. Given life, be it the result of an élan vital, a Z-system, or merely of a peculiarly intricate physico-chemical organization, we have a satisfactory foundation for the investigation of the how of evolution. 
A number of phenomena are characteristic of living matter. Ordinarily we think of its ability to appropriate to itself selectively the materials of its environment and to shape them definitely into its own body, its ability to adjust itself to the conditions of its environment, its ability to reproduce itself, and the physiological properties by which these things are brought about. Yet inorganic matter affords a number of phenomena which show us that these properties may, after all, be only a result of intricacy which makes possible the association of a certain complex of actions. We may mix substances dry without result, moisten them and secure a reaction. We may mix other things and secure reactions only by heating them or striking them. Association of elements may be accidental to the extent that they are distributed by natural forces beyond our ken. One may be wholly independent of another until the proper conditions obtain and they may then unite. The resulting compound is different from what existed before. It may be able to avail itself of other conditions and other neighboring materials to form still other things. Nor must a complete change always result. The mere presence of a substance may enable others to react or may prevent reaction; this phenomenon of catalysis is apparently a marked acceleration or slowing of reactions already possible, but under natural conditions 
they may actually not occur to a significant extent without its intervention. Through autocatalysis, moreover, a catalyst may even produce more of itself. And so in the organism we start with a chemical complex of great intricacy, associated with environmental conditions which are no less essential than the matter in the body. It carries on processes fundamentally like those of any chemical system, governed by similar conditions. It differs conspicuously in its maintenance of organized units - cells, individuals, colonies - and in its ability to reproduce those units. Here lie problems of life at present insurmountable, but they occur like all other vital phenomena as a reaction of the complex organism to the complex conditions of life, and so do not destroy our concept.

A reasonably full discussion of the complexities of living things would be a liberal education in biology, but there are a few principles which indicate a definite trend, not to say purpose, in the development of organisms to their present state. The primordial living substance which is a necessary concept in our modern ideas of evolution must have been very simple as compared with the simplest cell of the present. We must assume that it was a very labile protein compound; as to its organization we may safely predict an absence of the differentiation evident in existing cells, a closer approach to homogeneity. Since life, according 
to modern concepts, probably resulted from the proper association of inorganic materials at a remote period in the history of the world when a peculiar complex of conditions prevailed, this primordial living material was evidently a product of inorganic factors entirely. In other words, if the idea is valid that life had a beginning, barring the doctrine of special creation and vitalistic theories, it must have been a product of things which we now recognize as factors in its environment.

In order to fall within the category of living things, this substance must necessarily have had some capacity to maintain and reproduce itself, the former ability including a simple expression of the various phenomena of adaptation and metabolism. Maintenance and reproduction need not have been more than a complex form of autocatalysis. Thus the origin of a partially independent substance as a product of non-living factors entirely is not difficult to conceive. With its origin, the activity of living things began, consisting of an interaction between the living substance and its surroundings. Since then we have a source in living matter to consider as well as the inorganic factors associated with its existence, for the spontaneous origin of life has not been demonstrated and most living things have probably arisen from a single ultimate source. Life itself, so far as we have been able to determine, is the manifest activ- 
ity resulting from the interaction. The organism is a mechanism for the storage and transformation of energy, but the source of its energy is the world about it; without frequent replenishment it soon runs down and dies. The idea of a vital principle may be superimposed upon this interpretation but in the present state of our knowledge may not displace it; such an idea is, moreover, fatal to a scientific inquiry.

Obviously the changing world environment which brought about the conditions favorable to the origin of life must, in time, have given rise to other conditions less favorable for its maintenance. The whole history of the world is one of changing climates and geological events which have exposed its various regions to a succession of different conditions. The partially independent living substance, if it were to persist through changing environmental conditions, must necessarily have had adequate latitude of response to enable it to meet them, and likewise the environment surrounding an organism could not change beyond the organism's capacity for adjustment without destroying it. These facts still apply to all existing organisms.

But according to our ideas of evolution the complex population of the modern world has evolved from a simple primordium. As the years have passed the living substance has gained tolerance for conditions which would have been fatal to it 
in a previous state, and changes forced upon living things have met with a response in ever-increasing diversity of life. It is primarily a tale of gradually increasing independence of environment; a change of acidity in the surrounding medium which would be fatal to many Protozoa is incidental to others, and a change of temperature which stiffens the most active insect into immobility merely stimulates homoiothermal man. As fixed conditions have persisted, many organisms have developed a narrowly limited dependence upon them, but the major tendency in evolution has been toward greater and greater freedom. This does not mean that true independence is even a possibility. Terrestrial organisms are as dependent upon adequate water as aquatic creatures, but they have developed the ability to conserve their more limited supply enough to invade the driest parts of the earth. They encounter a much greater fluctuation of temperature than aquatic organisms, and in their highest groups, the mammals and birds, they have met this condition by developing the ability to maintain a constant temperature regardless of that of their surroundings.

The organism has gained complexity. If we could have been on hand to see its entire history the later steps might be intelligible in the light of the earlier, but since we are a late product of the entire chain of events, and a very complex one, we 
may only attempt to resolve the aggregate into its simpler components in a logical way. The cell, the simplest unit now available as a living thing, is, itself, complex, and when it lives in the free state it is scarcely less so than other organisms. The simplest multicellular organism seems much more intricate but it accomplishes the same ends as its simpler brother; its elaborate structure is a matter of method rather than result. All living things of the present share this quality, hence the heritage, that which reacts with the environment in the maintenance of the phenomenon called life, is complex in proportion to the degree of selfdetermination that it has wrested from its surroundings and in relation to the nature of its ultimate dependence upon them.

The details of organic complexity are, as has been said, the substance of biological science. It is characteristic of past treatment of evolution that we have recognized their importance in the existence and transformation of living things even, in many cases, to the exclusion of any serious consideration of the other factors necessary to their existence, namely, environmental conditions. But we cannot expect to understand the organism or its evolution without giving adequate attention to every significant fact.

The complexity of the environment is no less than that of the organism, but certain of its char- 
acteristics are more important for the purposes of our inquiry than any details. The recognition of three phases of environment is by no means new, ${ }^{9}$ and by no means difficult to grasp. In its life the organism encounters a number of physical and chemical factors which cannot fail to influence it. The importance of water and carbon dioxide, for example, is beautifully expressed by Henderson. ${ }^{10}$ Since the perfection of the hydrogen ion method of determining acidity, this condition has been shown to exert an important influence on the distribution of organisms. Temperature, especially daily and seasonal fluctuations thereof, is an unavoidable part of any environment which must be of importance to the organism. The nature of the soil, air or water pressure incidental to bathymetric distribution, the inorganic constituents of the environment, motion of the air, all of these things influence life and constitute the physical or non-living environment to which organisms must adjust themselves.

The physical environment is very important to the green plants, since they depend for their food upon inorganic materials. To them water and carbon dioxide are the fundamental necessities of life. Together with inorganic salts and the radiant

9 Osborn, H. F., “Tetraplasy," Jn. Acad. Nat. Sci. Phil., Special Volume, pp. 275-309, 1912; Osborn, H. F., Origin and Evolution of Life, p. 18, et seq., 1917.

10 The Fitness of the Environment, 1913. 
energy of sunlight they incorporate these compounds into the food supply of most of the organic world and any factors tending to modify the available supply of these several materials inevitably bring about adjustments of the flora. Trees do not grow on prairie areas, in some places because the prevailing winds are too dry to permit their development, favoring only the growth of low xerophytic vegetation. Elsewhere great altitude brings about rapid fluctuations of temperature and a short growing season; here again a characteristic flora prevails.

Animals respond to the physical environment no less certainly than plants, although their response involves less fundamental needs. A conspicuous evidence of animal response is the adjustment of the circulation to low pressure at high altitude and the peculiar effect of the sudden release of the human body from high pressure. Anyone who has attempted normal activity soon after moving to an altitude of ten thousand feet above sea level will realize that he is not adjusted to the prevailing conditions, but after a few weeks the increase of red corpuscles compensates for the low concentration of oxygen in the air. And after the appearance of a popular account of the last submarine disaster few people can be unaware of the necessity for bringing divers gradually back to surface pressure after they have worked at a considerable 
depth. Although pressure is not the only physical factor which affects animals, its effects are among the most striking.

The animals and such plants as depend upon other organisms for food give striking evidence of another phase of their surroundings which may be called the organic environment. Green plants are not independent of organic associations, but their dependence seems less vitally associated with other organisms than that of animals. Many green plants live normally in woods, but any environment which provides shade, moisture, and proper soil conditions is favorable to their existence. Trees are not essential beyond the fact that in nature forests alone usually guarantee the proper conditions. Animals and colorless plants, on the other hand, must have organic food. They are utterly dependent upon other organisms, ultimately on the green plants, and so far even man has failed to abolish this dependence in any cass. A host of adaptations are associated with this dependence. Aggressive and defensive structures, concealing adaptations, and even many adaptations directly associated with the physical environment have to do with an animal's food-securing habits or his defense against those of other creatures. Organic environment also leads to the beneficial associations, as symbiosis and social organization, and to the one-sided benefits of parasitism, 
in all of which the relations of individuals are conspicuous.

Finally, in that environment provides the surrounding conditions for a given action, we recognize that the body itself maintains the proper environment for many of its processes. Instead of depending upon fluctuating atmospheric temperatures, birds and mammals maintain a constant body temperature which is favorable for their vital processes and maintains a constant rate of metabolism, other things being equal. When external conditions or individual activities demand greater loss of heat, the sweat glands become more active, more blood reaches the surface, and the body cools itself. The accumulation of waste products in the tissues results in more rapid beating of the heart and more rapid respiration, so that elimination is hastened. Every organ of the body responds best to certain conditions, and the normal body provides optimum conditions for the performance of its various organs, thus constituting an internal environment. It is impossible, of course, thus rigidly to separate organic responses, for everything that the organism does is a product of the coördinated body; the internal environment plays a part in every action and the activities of every organism are closely linked with all three phases of its environment.

From the moment of conception an organism 
exists by virtue of the power of its heritage of living substance to react to the factors of the complex environment. To the extent that heritages are similar and the conditions of their environments coincide, we may expect the resulting organisms to resemble each other. The mechanism of heredity guarantees to each individual of a species approximately similar heritage, but within the limits characteristic of the species it also guarantees diversity. With the exception of identical twins, the chance that two individuals will receive identical heritages is exceedingly remote. And the infinite variation of conditions on the surface of the earth makes it practically impossible for two individuals to live under exactly the same conditions. With even slightly different heritages and slightly different environments, the products of interaction, living individuals, cannot fail to be different. Variation is, to this extent, axiomatic. Identical organisms are a practical impossibility although in theory they may exist.

When we undertake a consideration of the species and of the problems of phylogenetic change, our difficulties multiply. The considerations already stated are not obscure; it is increasingly evident to biologists that individuals must be looked upon as a reaction product, and the principle stated above applies chronologically as well as spatially. If an individual of one generation receives a heritage 
identical with one of a previous generation, it will be identical with its ancestor only if it encounters an identical environment. If the environment undergoes fluctuation, the individuals of successive generations will differ. But since we have never been able to witness such a change, the question still confronts us: can such variable responses bring about a change in the mass of individuals which constitute a species, beyond the initial range of variation? Logically, since the species is the sum of all its individuals, this must depend upon the ability of individual heritages to pass beyond the bounds of previous possibilities. What occurs in the individual belongs to the species, regardless of whether it belongs to all other individuals or not.

In view of these indubitable facts it is not strange that the acquisition by species of the adaptations which appear in individuals in response to the environment was long taken for granted. The idea is exceedingly plausible. Nevertheless the investigations of biologists have continued negative. We still do not know with absolute certainty what is the relation of individual adaptations to the characters of species.

In pursuing an inquiry into this subject, it is possible to find some precedent for a method of treatment. The sources of the antagonistic points of view are generally regarded as Lamarck's and Darwin's theories of evolutionary method, the one 
emphasizing environment and the other heritage in the evolution of species. But since Darwin, in his assumption that characters must be useful or harmful in order to have evolutionary value, recognized environmental relationships, and since Lamarck, in that he regarded environment as influencing the animal through its nervous system, recognized the activity of the heritage, I have never yet been able to find the fundamental disagreement in their views. However, there are differences, and the work of neither man is above criticism, so they may well continue to stand as the exponents of the opposed schools.

A more promising approach by far seems the inquiry, first of all, into the nature of species and individuals, their association, and the relationship in each of heritage and environment. The possibility of change, both in individuals and in species, then engages our attention. Sources of change, methods by which it is brought about, the nature of change in organisms in relation both to organism and to environment, are all pertinent to our problem. When once these things are disposed in an orderly manner we have a sound basis for the consideration of the various theories of evolution already proposed and for inquiry into the nature of evolutionary processes from the point of view adopted in this work. As I have already said, I do not regard it as a final solution, but I feel that 
it points the logical way for scientific investigation of the problem, not in terms of physics and chemistry, but in terms of biology. When we have reduced our knowledge to biological essentials there will still be room for the solution of these essentials in terms of other sciences. 


\section{II}

\section{INDIVIDUALS AND SPECIES}

The species problem has had a place in most studies of evolution, in addition to the numerous discussions in which it has occupied the center of the stage. Fortunately it has been so thoroughly handled that the usual points need scarcely be considered in detail; a few characteristics alone will be adequate for our needs.

The many recorded attempts to reach an agreement on the distinctive characteristics of species as biological units have said, as a rule, one of two things: that the species is a natural entity, ${ }^{1}$ or that only individuals exist in nature and the species is merely a concept for human convenience. ${ }^{2}$ We gain nothing by pursuing the inquiry. If entity means to the individual a material object which can be perceived, then obviously he will take the latter point of view, but if the broader idea of reality permitted by the accepted meaning of the word satisfies him, then nothing need prevent his

1 Powers, J. H., Am. Nat., Vol. XLIII, pp. 598-610, 1909; Bateson, Wm., Problems of Genetics, pp. 16, 21, 1913; Lindsey, A. W., Denison U. Bull., Jn. Sci. Lab., Vol. xx, pp. 289-305, 1924.

${ }^{2}$ Montgomery, T. H., Proc. Acad. Nat. Sci. Phil., 1902, p. 193; Bessey, Chas. E., et al., Am. Nat., Vol. XLII, p. 218 et seq., 1908; Williston, S. W., Am. Nat., Vol. XLII, p. 187, 1908. 
taking the former. Whichever course may be followed, the difficulties of systematic treatment which have inspired most discussions remain the same. Species differ in their nature. The same criteria are frequently inadequate for their separation in two unrelated groups. Morphological and physiological differences, fertility, mutability, all play a part in taxonomy. Their relative values must depend upon their effectiveness in special cases, and the taxonomist's idea of species is likely to be influenced by the useful characteristics of the group in which he works.

Attempts have been made from time to time to clarify the term species by simplifying its application. Elementary species, which are approximately the same as the pure lines and pure-line equivalents of biology, are possibly of some use in experimental work, but they are more definitely limited than the species of taxonomy only in degree. In certain characters they are uniform. The recognition of elementary species does not, moreover, solve the species problem. They are not independent natural entities but only components of natural species, which remain to be explained. For this reason the term species is used in these pages to designate natural species.

The relationship of individual and species has another aspect which can best be brought out by a broader consideration of living units. 
The simplest biological unit which is known to carry on independent life is the cell. Regardless of the fact that bacteria present certain characteristics which distinguish them from the vast majority of cells, this statement still applies to living matter generally. Until proof to the contrary is available we may regard bacteria as true cells of a special, perhaps a more primitive, type. The cells with which we are concerned elsewhere in the organic world, however, are definitely organized and complex in themselves. They are made up of various subsidiary units. The nucleus is one, but it in turn includes lesser units such as the chromosomes, and beyond these limits we are justified in believing that the genes may also be definite entities. The cytoplasm presents a variable host of minor units, granules, mitochondria, and others. Nevertheless, since these minor particles are incapable of existing independently, we may accept the cell as the ultimate living unit.

Were cells always to exist as independent organisms, as in the Protophyta and Protozoa, we would lack one valuable bit of evidence, but when they band together intimately and inseparably in the multicellular organism the case is different. Here we have a concrete entity, a unit which can be seen, heard, felt, smelled, and tasted. There is no obstacle to its acceptance as a natural entity, regardless of one's interpretation of the word, al- 
though it is composed of lesser units whose reality is also generally admitted.

The relation of a species to included individuals is, of course, not identical with the relation of an individual to its component cells, but are individuals an end in themselves? They may exist alone, to be sure. An asexual or parthenogenetic individual is even a sufficient unit for a time. If perpetual life were possible it might remain so, but the life of the individual under any circumstances is limited. Asexual or sexual, it must sooner or later die or merge its existence with that of the offspring which it produces. It is inevitably associated in some way with other individuals of its kind. These may be very different from itself, whence the difficulties arising from polymorphism, or they may be essentially the same, but the association always occurs. The aggregate of these associated individuals is the species.

The reality of the species is necessarily different from that of the individual, yet it, too, is an aggregation of units. The unit individuals are constantly changing, and they are not usually connected with each other or wholly dependent upon each other like the cells of the body. From year to year and from generation to generation no species ever embraces exactly the same constituents, yet it continues to exist. Until reduced to a very limited compass, such as the last dozen passenger 
pigeons, it is difficult to comprehend, but this is no proof that it is imaginary.

The old analogy of the stream is sound. We have no doubt of the existence and reality of the Mississippi River, yet it is beyond our power to see it as a whole. We may see a small part of it by standing on its banks, but at no successive moments does that small part have exactly the same characteristics. So too the species exists as an ever changing aggregation of individuals, their limits beyond our view, their changes constant and usually elusive, but always within a boundary which our fragmentary knowledge permits us to realize, as we map the course of a stream.

Which is more real, the Mississippi River or a pint of water dipped from it? It does not matter that it differs in flood and in drought, nor that it is always in motion; the river exists. Likewise the species, although it is a troublesome thing to fix, exists always as an aggregation of individuals, sometimes of various kinds in form or functions, fluctuating both in space and in time, but always associated either structurally or functionally and always part of a reproductive sequence.

Since we accept the reality of evolution, we must recognize the inconstancy of species through time. In this respect there can be no definite boundaries of species, save only the abrupt limit established by extinction. Consequently the requirements of 
systematic science are of a special kind. We must catalogue our materials. We must develop a reasonably definite idea of the various species making up the organic world, and in doing so we cannot conveniently express a fluctuating unit. It is this need for stability which has caused most of the trouble with the idea of species.

Gregory has attempted the expression of an undefined taxonomic unit by proposing the term circulus for the groups of individuals centering about a definite association of characters. ${ }^{3}$ The concept is valid, but it amounts to no more than another definition of the species concept of all time, hence a new term is unwelcome. For the purposes of taxonomy Montgomery's proposal that the species is a mental cross-section of a line of evolution appeals to me as the most valuable idea yet expressed. ${ }^{4}$ Elsewhere ${ }^{5}$ I have considered more fully the practical aspects of this matter in taxonomy; this much is adequate for my present purpose.

Given an entity, the species, made up of many lesser entities, the individuals, we have an adequate foundation for the consideration of problems of evolution, but it is desirable to clarify these concepts still further by the consideration of another step in the association of organisms. In a number of cases, notably among the insects, the relation of

${ }^{3}$ Mason, F., Creation by Evolution, 1928. 'Op. cit. ${ }^{5} O p$. cit. 
individuals within a species has taken a new trend in the formation of societies. This matter is exceedingly complex; in brief it shows that the individual may give way as the unit to a more complex association. The honey-bee colony is a familiar and clear-cut example. In it we find three types or castes, the queens, drones, and workers. The queens and drones are incapable of securing food or rearing young, yet they alone can produce young; the workers are incapable of normal reproduction, but they alone can rear young, supply food to the colony, and carry on the many necessary accessory tasks. The colony here is the unit of which the species is formed. No one would question its reality or call it a mere concept for the convenience of the beekeeper. The relationships of the individuals within it are no more like those of cells in a metazoön than like those of the individuals comprising a species, but they make up a unit sufficiently restricted to be seen at a glance, to be appreciated without the necessity of associating isolated facts. The limited existence, the dependence, of individual honey-bees is reminiscent of the condition of fragments of cells or of isolated tissue cells, but the fact that the colony is an aggregation of structurally separate individuals more closely approaches the nature of species.

The series of units here described show important and significant characteristics. Cells may live as 
individuals, but those of most organisms exist only as components of individuals. Individual honeybees may exist only as members of colonies. Colonies may be permanent, and may reproduce themselves as definitely as do individuals, yet they exist only as parts of the species. In most species the association is simpler: individuals exist only as parts of species. In any case we have species only through the existence of individuals. In such associations it is useless to argue the relative importance of the various categories. They are different, but interdependent. An individual cannot exist without belonging to a species nor a species without including individuals, and when two factors are essential, neither can be said to surpass the other in importance. Their importance, obviously, must differ in kind, but evaluation of degree is not admissible.

Herein lies an important point of view for the evolutionist. Species were long regarded as fixed and invariable beyond certain limits. The idea of organic evolution arose from the realization that such was not the case, but that species were variable to the extent of merging with each other, and that they had undoubtedly arisen in the past by development from preëxisting species. This realization led even to denial of the importance of species formation as a problem of evolution; one writer, at least, has recognized evolution as a con- 
tinuous process of change inherent in living things and species as merely stations along its course. ${ }^{6}$ The point of view is easily harmonized with all sound ideas of evolution and need not affect our approach. Species are the units of evolution, and as such must be the chief concern of the evolutionist, but in the very nature of their existence he must appreciate their impermanence. He must work also with individuals and must appreciate to the full their significance in his problem.

Here is a vital point in his progress. He must not fall into the sociological error of opposing individuals to species in estimating values. He must not fall into the biological error of regarding the phenomena of individual existence as independent of the characteristics of species. And he must not fall into the philosophical error of satisfying himself with concepts whose reality cannot be demonstrated within the bounds of science. If he succeeds in observing this trio of don'ts we may expect his results to be sound, even though they may be meager in the present state of our knowledge.

The nature of living beings has been briefly stated in the preceding chapter. We are unable to say that life is produced from non-living materials at the present time, or even to predict with reasonable certainty the possibility or impossibility of such additions to the living world. The old princi-

${ }^{6}$ Cook, O. F., Ann. Rept. Smiths. Inst., 1904, pp. 397-412, 1905. 
ple that all life arises from preëxisting life is sufficiently established to condition our studies of living things. Consequently we may conclude that all organisms begin life with a heritage characteristic of their ancestral line. From the moment of conception they have certain possibilities. Granting that the reproductive body meets a favorable environment, be it spore, fertilized ovum, or any of the numerous other forms in which the organism may first become independent of its parents, the heritage will proceed to develop according to its inherent possibilities. Once developed into an adult organism, it continues to exist by virtue of the constant interchange which it is able to maintain with its environment. This idea has been especially well expressed by Dendy ${ }^{7}$ in the following words: "It appears, then, that an organism really inherits from its parents two things: (1) a certain amount of protoplasm loaded with potential energy, with which to begin operations, and (2) an appropriate environment. . . . Therefore, when we say that an organism inherits a particular character from its parents, all we mean is that it inherits the power to produce that character under influence of certain environmental stimuli."

The essential nature of both factors is evident throughout all stages of development, although it is impossible in many cases to say what stimulus

${ }^{7}$ Am. Nat., Vol. XLIX, p. 161, 1915. 
is responsible for a given response, and in every case to say just how the hereditary substance is able to respond. We know, for example, that a temperature of approximately $39^{\circ} \mathrm{C}$. is a necessary condition for all of the development of the unhatched chick. We know that a surrounding medium containing oxygen is essential to both life and development of most organisms, and that water and carbon dioxide are also generally necessary. We know that exact relationships with a host species are necessary for the development and existence of many parasites. We know that the failure of one step in development may be fatal to the organism or may render it abnormal. Here are conditions representative of every phase of environment: a physical condition, chemical factors, organic surroundings, and internal associations within the body of the individual. All are essential, responsible for some phase of development. Rosenheim has shown that some conditions at high altitude, probably the intense light, result in the production of flavones in the sap of edelweiss which appear in greatly reduced quantities in plants raised at London. ${ }^{8}$ Henderson's thorough analysis of environment shows many ways in which water and carbon dioxide are important to organisms; ${ }^{9}$ it is sufficient to note that they are fundamental

8 Biochem. Journ., Vol. XII, pp. 283-289, 1918.

- Fitness of the Environment, 1913. 
constituents of the food supply of a vast majority of living things. Petrunkevitch ${ }^{10}$ calls attention to the fact that a number of parasitic worms, including Taenia solium, while they must tolerate a considerable variation of chemical environment in their normal hosts, cannot be raised in other animals. And it is commonly known that congenital thyroid deficiency so interferes with normal development that cretinism results.

When we examine some of the discoveries of experimental embryology a certain independence of the heritage also becomes evident. At the outset of development in sexual organisms, with the exception of a few cases of natural parthenogenesis, union of the ovum with a spermatozoön is a necessary preface to the formation of a new individual. But Loeb ${ }^{11}$ found many years ago that a slight increase in salt concentration in sea water was adequate to produce artificial parthenogenesis in the eggs of the sea urchin, development continuing to the production of swimming larvae, and in $\mathbf{1 9 1 6}$ he wrote that he had "seven parthenogenetic frogs over a year old, produced by merely puncturing the eggs with a fine needle." These frogs are said to have been as large as normal frogs of the same age and in no way different from frogs produced in the natural way.

10 Organic Adaptation, 1924.

11 The Mechanistic Conception of Life, p. 7, 1912. 
Harrison ${ }^{12}$ reports that limb buds of the salamander, Amblystoma punctatum, when transplanted to parts of the body other than their normal location, frequently express their potentiality as they would under normal conditions, by developing into legs of normal appearance.

Such observations indicate that there is some latitude in the conditions which may activate a given factor in the heritage, but we need only note the extensive modifications produced in developing embryos by relatively slight abnormalities of environment to realize that the correlation is, in general, very delicately adjusted. Morgan's monumental volume, Experimental Embryology, records more cases than are necessary to establish the point. ${ }^{13}$

Development which appears to proceed normally under abnormal conditions is relatively rare, and in such cases as those cited above, close scrutiny shows that the degree of normality attained is due to the persistence of adequate normal environment in spite of the artificial modification. The salamanders' transplanted limb buds may continue their development into limbs corresponding to their original destiny, but not to the extent of taking the place of normal legs in the individual body. This much may be accomplished through their reception from the blood stream, and from

13 Experimental Embryology, pp. xi $+766,1927$. 
other than the usual nerves, of the same things which would normally enable them to complete their development. Bones, muscles, and nerves are not peculiar to any one part of the body, hence the substances required for their development are everywhere present. Those features of their development which are associated with a given location, however, may be abnormal in transplanted limbs; they receive an abnormal innervation, if any, and have abnormal external relationships, hence they have accomplished only a part of the normal course of development. And it is worthy of note that a relatively small percentage of the transplanted limb buds are free from conspicuous abnormality.

We may accept as fact the conclusion that everything which appears in the organism is a product of definite interacting factors in the heritage and in the environment, and if either factor departs from the normal, we may expect the result likewise to depart from the normal.

Since the individuals thus brought into existence constitute species, it is an accurate conclusion also to say that the species is the result of interacting heritage and environment, but here additional complexity enters. Taxonomically we may accept the idea of a "mental cross-section of a line of evolution" and so limit our species to a fixed time level in the present or to definite geological horizons 
for the convenience of classification, but phylogenetically the species includes not only the individuals extant at a given time, but all of the succession of generations occurring before it loses its identity in the production of other species. In this succession there can be no sharp boundaries. We are dealing with entities which may be sharply limited in space but are inevitably diffuse in time.

Genetics has taught us that the mechanism of heredity guarantees a maximum diversity of individuals constituting a species. The assemblage of unit characters for which determiners are carried by the chromosome complex of the species includes many different expressions of the same fundamental character. Illustrations are common enough. Hair color in man may be black, brown, red, or blonde; skin varies in pigmentation from African black to Caucasian fairness; eyes may be anything from deep brown to pale blue. In the normal course of sexual reproduction the various characters are redistributed in such a thorough way that the chance of two individuals receiving identical heritages is negligible. Twins of the identical or monochorial type apparently do so because they are developed from equipotential portions of a single developing zygote, separated at an early stage in embryonic life. Their approximate identity emphasizes the more common differences of individual heritage. 
Not only do the individuals of a given generation receive an extensive assortment of character combinations, but also, because of their distribution over a considerable area, they are certain to encounter different environmental conditions. The species embraces all of the variety of individuals resulting from the combination of these diverse fundamentals. It is a product of heritage and environment, but in such a degree of diversity as cannot be exemplified by a single individual or even by a group of moderate size.

In a given location at different seasons the environment may vary so much that individuals of the same species may resemble each other no more than individuals of closely related species. These differences may be associated with conditions of light, moisture, or temperature. Henneguy, in speaking of this phenomenon, mentions Pieris octavia-seramus, a butterfly of the Transvaal, as one striking case. Of its wet and dry season forms he says: "La forme seramus, de la saison humide, présente une paire d'ailes antérieures dont la face supérieure est colorée en rouge, souvent avec bordures et taches noires, et dont la face inférieure est presque aussi vivement colorée. La forme octavia, de la saison sèche, a les ailes d'un bleu vif taché de rouge en dessus et d'un noir verdâtre en dessous." 14

This type of variation is of relatively little im${ }^{14}$ Les insectes, p. 516, 1904. 
portance in our consideration of species save in showing that variable conditions in nature may be definitely responsible for the appearance of different individual characteristics. The fact that different conditions obtain in different regions is more important. When the gradual dispersal of a species brings it into contact with these variable conditions they may play a part in the production of geographic races. The part which they play must be considered later; it is a disputed one, but the races concerned are real and important.

Many species of wide distribution encounter different environmental conditions in various parts of their range, and may show marked diversity of individual characters correlated with regional occurrence. John B. Smith, one of the early students of North American Noctuidae, described many species of these obscurely colored moths which have since been shown to associate with each other by gradual transition through the intervening regions. A fairly simple case of this nature is that of the common checkered skipper, Pyrgus tessellata. Skinner ${ }^{15}$ named the pale western form of this species occidentalis. Williams ${ }^{16}$ later discovered that the two differed in genitalic structure and called them good species. Barnes and Lindsey ${ }^{17}$ examined material from various localities scattered ${ }^{16}$ Ent. Nevos, Vol. XVII, p. 96, 1906.

${ }^{26}$ Ibid., Vol. XXX, p. 38, 1919.

17 Ibid., Vol. XXXII, p. 79, 1921. 
across the continent and found a gradual transition from one extreme to the other both in superficial characters and in genitalia. This is only one example among many, but it is an excellent illustration. The individuals of California are never directly associated with those of Iowa or New York. In any of the three states they are as independent as if they were actually distinct species, consequently they respond to the conditions of their own limited environments and hand down through heredity such peculiarities as their heritages display, maintaining distinctive characters of geographic races. It is possible to demonstrate their relationship by tracing the gradual modification of the species through the intervening regions, where even reproductive association maintains an indirect connection between the extremes.

MacDougal ${ }^{18}$ has produced a similar effect by raising Scrophularia leporella, which grows normally in the mountains of Arizona, at the Desert Laboratory near Tucson, and near the sea. The plant usually has a "strict, scarcely branching shoot with a few fleshy, succulent roots," but at the Desert Laboratory it branched more profusely and formed more roots, and in the maritime location it formed such extreme growth that some shoots died early for lack of nourishment, and the roots became a great mass.

${ }^{18}$ Am. Nat., Vol. XLV, pp. 5-40, 1911. 
The species must embrace all of these forms and the many others which appear as minor variations. It is characterized for our convenience by the limited assemblage of characters common to all individuals, but it consists in reality of every character produced by all individuals, wherever they may occur in its entire range.

Obviously the intricacy of this association of many individuals, widely scattered, with an extreme variety of environmental conditions, offers an opportunity for the development of almost infinite variety in the species. A high degree of constancy is not impossible; some species vary to a scarcely appreciable extent, no matter how wide their dispersal and the variability of the conditions to which they are exposed. But within our powers of observation a species may be very constant as a rule and still include many individual variations from time to time, apparently because the proper association of heritage and environment for their production is rarely attained. There is a possibility even that existing species may encounter conditions with which they have never before come into contact. Such things have happened. We are told by geologists that the evolution of the horse was accompanied by increasing dryness in North America and that the onset of the glacial periods changed the entire climate of this continent. Granting the ability of the organism to live in spite of the new 
conditions, such changes of environment could not fail to produce characters hitherto not realized by any of the individuals constituting the species.

In view of the facts which have been considered regarding the association of individuals and species, it is a necessary conclusion that whatever occurs in the individual is a part of the species. If the onset of a new condition brings about the development of new characters, they are as much a part of the species as of the individual, for the individual exists only as a component of the species. If they disappear when the associated environmental conditions disappear, they are none the less a part of the species, for environment is as much an essential in its existence as heritage.

The great problem of evolution has hitherto been treated as a question of the importance or insignificance of these various factors. If a character appears only in the individual in response to external conditions, can it be of importance in the evolution of the species, or are those things which come from within the only significant characters? This attitude seems a mistake. How can anything which appears in an organism, barring modifications due wholly to accident, such as mutilations, fail to be of potential, if not of immediate and obvious, evolutionary significance? Keeping in mind the facts laid down, that individuals exist only as components of species, that heritage and 
environment are both inevitable factors in what they are and in what they may become, is not it wiser, more scientific, to inquire into the nature of association of these items in the progress of evolution than to weigh them one against the other and ask which is useful and which impotent? 


\section{III}

\section{SOURCES OF CHANGE}

All of the material things in the world, as far as we know, are due to the action of certain forces upon certain materials. Even the rocks may be classified according to the substances of which they are formed and the means whereby they were shaped. They may be granitic or basaltic, limestones, sandstones, or shales; they may be igneous or sedimentary or metamorphic. Obviously a modification of the materials composing them or of the forces shaping them must have given rise to different products. So too in the case of man-made things. If we desire a given result we must adhere strictly to the materials and processes which give that result. If we are careless of our specifications we cannot expect a uniform product.

The organism is subject to these same conditions. It is a product of a certain complex type of matter responding to various conditions of environment. The living matter of which organisms are composed may be of many different kinds and the conditions to which it responds are no less varied, hence the great variety of living things which populate the earth. May we conclude also that a 
modification of either material or forces will produce a change in the organism? It seems wholly probable, but we encounter a specific problem here which is quite different from any associated with inanimate objects. The matter of which living organisms are composed possesses a power of self-determination through which it is protected from passive molding by environmental forces. In the course of evolution, as we have noted, organisms tend to secure more and more independence of environmental conditions through the autonomous activities of their own bodies. Outer forces cannot fail to bear upon living things, but internal forces also affect them. Our problem necessitates inquiry into the effectiveness of these various forces in the shaping of organisms.

In approaching such an inquiry it is pertinent to note that the discoveries of modern physics disclose the existence of internal forces in inanimate things which we cannot fail to consider. Chemical changes are brought about by the action of physical forces, such as X-rays, but modern physics has shown that change may take place as a result of internal forces. Atoms of some of the heavier elements, such as uranium, are constantly undergoing disintegrative radiation which transforms them ultimately into lead. The concept of independent internal activity in living matter is therefore not impossible. It leads to the admission 
that change may occur entirely from within in some cases. But, paradoxically, physics and chemistry provide us at the same time with an abundance of facts in the phenomena of the colloid state which seem to dispense with the necessity for such explanations of organic change. External conditions are commonly the cause of chemical and physical transformations, and the usual manifestations of life are inseparably linked with external conditions.

In seeking the cause of change, the variability of the environment is so conspicuous that it is everywhere to be seen. The variation of the heritage is no less obvious, since variation is a universal characteristic of living things, and the determinative powers exercised by the organism are apparently functions dependent upon the nature of its heritage.

Variability of the environment impinges upon organisms in a number of ways. In a given locality marked fluctuations may occur, and in any locality some fluctuation is inevitable, due to the topography of the land and the meteorological conditions prevailing. High altitudes, for example, are characterized by rarefied air. This factor not only conditions the respiration of animals, but also influences temperature. During the day when the sun shines it is a poor insulator, hence the body is exposed to intense heat. I have picked caterpillars 
from sage brush only a foot or two above the ground and seen them die when dropped onto a surface nearby which was without protection from the rays of the sun. At night the same limitation of the air permits rapid dissipation of heat, both from the earth and from the body, and contrastingly low temperatures result. Water supply fluctuates with rainfall, which is conditioned by many factors. In central California and similar regions the summer months find practically desert conditions while winter brings abundant rainfall. The organic environment is no less variable. The life cycles of plants and the migrations of animals bring about changes from season to season in food supply and other less direct contacts. And the internal environment varies constantly, but in a degree which is in inverse ratio to the degree of independence from the external.

The locomotion of animals and gradual dispersal of plants may also bring them into contact with different conditions of environment as they invade new regions. Other things being normal, animals probably seek congenial surroundings and plants develop better under favorable conditions, hence their contacts are not likely to differ from those established under fluctuating conditions in one environment while such conditions are available. It is more than likely, however, that dispersal is accompanied by gradual adjustment to 
new conditions as a species pushes out farther and farther from its original center.

Another source of environmental change whose value must be extreme is gradual modification over long periods of time as a result of geological transformations. Elevation of a land mass may substitute the extreme diurnal fluctuations of high altitude for the fairly even temperature of low areas, or depression may result in the intolerable climate of Death Valley. The thrusting up of a new mountain range may bring a new abundance of rainfall on one side and reduce the neighboring lands on the other to aridity. The geological history of North America shows the past occurrence of tropical and arctic conditions where it is now temperate. Moreover these are not fleeting changes. As construed by human concepts of time they take place slowly and endure long. Within human experience and no doubt for a vastly longer time our continent has been temperate; the whole world, in fact, has had a fairly constant distribution of climatic conditions during recorded history.

Fluctuations of the heritage are more elusive. The heritage, in the first place; is a variable concept. In the individual it is limited by the particular assortment of characters for which determiners were received from the parents; in the species it is the entire range of characters possible to all of the individuals that may be produced. 
According to the discoveries of genetics, the individual components of the heritage are remarkably constant, but we are indebted to the same science for the discovery that a reassortment of these units is possible up to the physical limitations of the reproductive mechanism. This reassortment is apparently due to chance. We can in no case say that a given condition will bring about a certain association of chromosomes during normal meiosis and thus give a particular distribution of potentialities in the resulting cells. Nor can we attribute a controlling power to the activities of the cells themselves. To this extent, then, the heritage possesses a definite capacity for variation among the individuals of a given species, and this variability is independent of environmental factors, whether or not its expression in differentiated characters of individuals may be equally independent.

The reassortment of individual determiners during sexual reproduction is, however, of a nature to guarantee the production of all possible combinations, hence it cannot be a determining factor in evolutionary change independently of other conditions. It is important in this respect, but only as one factor acting with others to attain a given result.

A more significant inquiry is whether or not the heritage of an individual, a fixed association of 
materials received from its parents, is susceptible to modification from within or from without, and if so, whether the modification is of any importance in the evolution of species. This matter is at the heart of the problem with which this work is concerned, and consequently involves more questions than the mere possibility of change in the individual. It will be considered later from several points of view.

Changes in organisms due to any of these factors constitute the individual differences in a species, as well as the variability of the individual through the successive periods of its life. They are the variations which are so universally evident among living things, and regardless of their immediate cause, must be looked upon as potentially of interest in any study of evolution.

The attitude of scientists to this problem has been an interesting evidence of the degree of explanation which may be satisfactory to scientific minds. Darwin ${ }^{1}$ recognized the occurrence of fortuitous variations without making any attempt to explain them on a basis of cause and effect; as some writers have expressed his attitude, he regarded them as axiomatic. Nevertheless he was not unaware of the effectiveness of Lamarckian principles in producing variations. He noted the

${ }^{1}$ (a) The Foundations of the Origin of Species, A Sketch Written in 1842, edited by Francis Darwin, Cambridge, 1909; (b) The Origin of Species, 1859;

(c) The Descent of Man, 1871. 
effects of use and disuse, and at one time expressed the belief that the incidence of new conditions over a succession of generations might result in greater variation. He did not, of course, have the knowledge necessary to an appreciation of the recombination of characters by sexual reproduction which is now known to be so important, but even so we find him writing: "A certain degree of variation seems inevitable effect of process of reproduction." $1^{a}$

Other writers have taken various attitudes toward the causes of variation. They could not fail to recognize the occurrence of variations, even as Darwin did, but recognition is not explanation and the trend of modern science is inquiry into causes to the utmost possible degree. In 1909 Bateson wrote: "In reply to the question so often asked, Has modern investigation given evidence as to the nature of these causes? the answer must still be, Almost nothing." 2 In 1913 he inquired at length into the causes of variation, ${ }^{3}$ but still found no satisfactory explanation. His difficulty in satisfying himself on the addition of characters to an organism is a very real one, and if we concern ourselves with specific causes we must admit that his recognition of scientific ignorance is valid. The

${ }^{1 a}$ See footnote 1, part $a$.

${ }^{2}$ Mendel's Principles of Heredity, p. 279, 1909.

${ }^{8}$ Problems of Genetics, 1913. 
problem seems, however, to be solved in a general way by Osborn's tetrakinetic theory.

Osborn recognized the failure of evolutionary theory to accord with the evident facts of evolutionary progress, and logically concluded that the explanation of evolution "must lie somewhere within the actions, reactions, and interactions of the four physico-chemical complexes, namely, the physical environment, the developing organism, the heredity-chromatin, the living environment, because these are the only reservoirs of matter and energy we know of in life history." 4 His last clause is worthy of note. These factors are the very foundation of life, so far as we can determine. How can they fail to be at the same time the source of organic change? Yet this does not meet the difficulty of specific points of relationship and he continues: "While it is possible that the relations of these four energy complexes will never be fathomed, it is certain that our search for causes must proceed along the line of determining which actions, reactions, and interactions invariably precede and which invariably follow those of the body cells (Lamarckian view) or those of the chromatin (Darwin-Weismann view)." 5

This is as far as we can carry an inquiry into the cause of variations at the present time. As long as we pursue our investigations on the mechanistic

4 Origin and Evolution of Life, p. 145, 1917.

${ }^{5} O$ p. cit., p. 145. 
basis the only admissible source of variations will be recognized as these four factors. Their interactions vary in results, but evidences of one or another kind are everywhere available. If fluctuations take place in the external environment, the responses of individuals are modified. Such physical stimuli as intense sunlight and activity produce demonstrable, usually useful, results which Conklin has classified as follows: ${ }^{6}$

Stimulus

Increased light

Increased friction

Increased use

Unusual foods

Unusual temperatures

Poisons or toxins

Injury
Beneficial Response

Increased pigmentation

Increased thickness of epidermis

Increased size or strength

Appropriate digestive fluids

Acclimatization

Toleration or antitoxins

Regulation or regeneration

Changes in the organic environment are more likely to lead to a modification of behavior than of visible organization, although they may act upon the organism in the form of a modification of food supply.

The organic results of such changes as these are visible to us only in the individual, and have logically been called modifications. The term acquired character is satisfactory but it has been so sadly abused that it is better avoided.

The possibility of changes occurring in the inter${ }^{6}$ Rice Institute Pamphlet, Vol. VIII, pp. 322-323, 1921. 
nal environment, i.e., in the body of the individual, without immediate cause in the other factors of life, must be admitted. The body is exceedingly complex and it is quite probable that reactions may occur in it which are not immediately dependent upon external conditions or upon the action of hereditary units. Changes due to increasing age are undoubtedly of this type in part. Since the body is an intermediary between heritage and environment, however, these changes seem less significant in evolution than those correlated with external stimuli. Whatever takes place in the body is possible by virtue of properties received from the heritage and developed in response to external conditions, hence purely somatic actions are more likely to be a result of, and in harmony with, normal activity than to be a source of novelty.

Fluctuations of the heritage occur, as we have seen, by chance recombination within the limits of the species, but they are of interest to us only in their relations with other factors.

Thus far the appearance of new unit characters in the constitution of a species is limited to one known process, mutation. It has been easy to look upon mutations as fortuitous occurrences. Indeed, they are a part of the heritage and have their basis in the chromosomes, but they cannot be referred to the action of the chromosomes alone for these bodies, like all living matter, exist only 
by virtue of environmental association established through the cytoplasm. Even mutations, therefore, must be a product of some phase of the environment acting directly or indirectly on the chromosomes. This becomes increasingly evident in the light of experiments with X-rays, notably the recent researches of Muller ${ }^{7}$ on Drosophila, and the discoveries of Babcock and Collins ${ }^{8}$ in California concerning the effects of terrestrial radiation on the same insects. The body is a complex phase of the environment, far more complex, indeed, than some of the external conditions which give pronounced results in the individual, and it is quite possible that it may undergo changes from time to time which produce mutations. To what extent such changes are associated with fluctuations of the external environment it is impossible to say, but it is at least probable, as we have noted, that independent changes are not likely to modify the heritage. The changes due to increasing age, for example, cannot be referred to external environmental stimuli, save only to the extent that everything in the body is a product partly of these stimuli, directly or indirectly. We have no reason to believe that such changes affect the offspring of an individual in fundamental ways.

The importance of these various changes to the

7 Science N. S., Vol. LXVII, p. 82, 1928.

${ }^{8}$ Science Supplement, p. x, Aug. 2, 1929. 
organism throws additional light on their significance in evolution. Since organisms exist as reaction products of heritage and environment, it is obvious that these factors must be in harmony if life is to continue. A given condition of the environment must be met by a particular power of the organism to respond, a function which is the expression of some structural component of the individual. Since, at the outset of their existence, individuals receive a certain equipment and are produced in a suitable environment, their development and the major steps of their independent life are fairly uniform throughout any species. Adaptation is an inherent necessity and a universal phenomenon.

Some of the adaptations which have been observed in the living world are wonderful, and have given rise to a probably unwarranted emphasis upon the adaptive value of organic structures. Attention has frequently been called to the fact that the mere existence of an organ does not signify adaptive value. The presence of eyes is a valuable adaptation for life in the open, but is of no use in dark retreats. Lack of eyes must be a limitation to an organism which lives in the presence of light, yet many such cases occur. So too, animals with eyes have been found in caves. It is necessary in evaluating characters to recognize adaptation as a twofold phenomenon of process and result. All 
characters are a result of the interacting factors, heritage and environment, and it is probable that all are potentially useful in relation to conceivable environmental conditions, save possibly during periods of development and atrophy. A structure may become an adaptation to conditions which have had no part in its production, and conditions may bring about the development of structures which do not adapt the individual to respond to them. But regardless of these facts, the things which enable the organism to meet conditions of environment are adaptations.

The changes which individuals undergo, on the other hand, are in part evidences of the process of adaptation. Each is provided at birth with a hereditary equipment of adaptations, but as it encounters fluctuating conditions of environment it must adjust itself by the modification of its previous condition. The deposition of pigment in the skin is an obvious adaptive response, since it provides protection against the ultra-violet rays which bring it about. That individual responses are not always adaptive is amply shown by Sumner's experiments with white mice (see Ch. VI). Increased size of appendages appears in no way to be of value in relation to the higher temperature which brought it about.

It is, of course, difficult to suggest the causes of existing organs without risk of serious error. The 
functional "lungs" of the lobe-finned ganoids were obviously not developed in response to the conditions of terrestrial life, although they were an important adjunct to the successful attainment of terrestrial habits. Lungs are associated with air and air is available to swimming animals as well as to terrestrial species, yet there appears to be no peculiar need for lungs among the fishes and the air has no peculiar power to cause the development of lungs. However, many such structures have developed in the past, and, once developed, have been available for use and consequently have become adaptive. It is possible to find other well developed characters which are apparently without adaptive value. Such are the brilliant colors of some butterflies. The transverse ridges on the shells of some lamellibranch molluscs and the sharp keels on others are apparently of no fundamental value to the individual. The fantastic projections on some of the tree hoppers are not known to be adaptive, nor are the spines on the legs of Hesperioidea, since they may be present or absent in closely related genera.

To the extent that all characters are a product of definite hereditary capacity responding to a definite environmental stimulus, there is a similarity in the origin of everything organic, but it is obvious that a character which bears to the stimulus producing it no relationship of importance to the organism is 
not just the same as a character which fits the individual to cope with the inciting stimulus. We must admit the truth of Cunningham's statement that adaptive and non-adaptive characters are distinctly different, if only in this matter of origin, whether or not we agree with his conclusion that "their origin and evolution are entirely distinct and different." " 9 It is exceedingly risky to generalize concerning origin on the basis of adaptive value.

It is significant that the individual receives a normal complement of adaptive structures as a part of its heritage, while its response to a fluctuating environment involves the adjustment of these structures through its power of individual adaptability. It may be called upon during its life to meet many fluctuations of environment; it does so, not by producing new organs, but by the modification of the things already present in its body. The tanning of our skin is not a deposition of pigment where none existed, but only an increase of the normal deposit.

Adaptation in the individual may be looked upon, therefore, as a process or a variety of processes giving rise to modifications of hereditary equipment in response to the fluctuations of environment. The nature of the process is obscure. It has been admirably discussed by Conklin, ${ }^{10}$ and for

${ }^{\circ}$ Hormones and Heredity, p. 21, 1921.

${ }^{10}$ Rice Institute Pamphlet, Vol. VIII, pp. 299-380, 1921. 
the present his conclusion is a wholly satisfactory expression of our knowledge: "Since it is present ... in living things generally, it may be considered to be one of the original properties of life, and our inability to explain its origin is not different from our inability to explain the origin of metabolism, reproduction, irritability, or of life itself."

The nature of its results and its immediate causes are varied, and as a result many errors have crept into the discussion of acquired characters. Mutilations, for example, have been the subject of many pages of wasted effort. They are accidents. No thinking scientist would give them serious attention in the critical study of evolutionary processes, yet they have had a prominent place in the older literature of evolution. I have previously discussed this point in greater detail, showing that other modifications, such as the flattening or constriction of the skull by artificial means in infancy are of similar nature. ${ }^{11}$ All of these changes are impressed upon the organism by the external environment. The organism is unfortunate enough to get in the way of a train or a sword or an amputating knife and thereby loses something which it cannot replace, or its parents bind its feet, and in spite of a noble struggle its body is prevented from gaining normal expres${ }^{11}$ Am. Nat., Vol. LXI, pp. 251-265, 1927. 
sion. In both cases inherent capacity for normal behavior is evident, either in the actual production of the part which is later lost or in the agony resulting from the interference with normal processes.

The more significant individual modifications have already been listed. They are due to the responses of the individual to external stimuli; regardless of the particular conditions involved, they always include these two factors, stimulus and response, and the result is a product not only of environment but also of heritage. If there is any doubt of this, we have only to consider such conditions as obtain in the albino. These individuals may encounter the same stimulus that produces heavy pigmentation in normal individuals but they lack the hereditary ability to respond.

There has been a tendency in the literature of evolution to handle these individual adaptations in separate groups. This treatment is not necessary. Whether they fall in one of the groups listed or in another they are all the result of increase or decrease of some functional activity which brings about a corresponding change of functional capacity to meet a need arising in the life of the individual.

Most of these responses appear to be adaptive. It is easy to look upon them also as positive and negative in that a lessened stimulus results in a lessened response and vice versa, but it seems more 
accurate to regard these degrees as positive responses to varying conditions. The organism adjusts itself to fluctuations of environment and any adjustment demands positive action.

Some apparently non-adaptive responses of individuals seem more truly negative. Deficiency diseases and less serious organic disturbances resulting from dietary deficiencies are of this nature. The lack of a vitamine or of iodine, or insufficiency of either, is obviously a fluctuation of environment, but the human body usually lacks hereditary power to effect an adjustment to it, and if it exists in spite of the unusual condition, it does so in a subnormal state. The thyroid disturbances arising from lack of iodine, for example, result in positive conditions in the body which constitute a clinical picture, but they are no more than the results of an abortive attempt at adaptation for they do not fit the individual to meet the conditions which cause them.

When we consider these cases thoroughly we find that they are not different, however, from adaptive responses, even though they are more obscure. Our reaction to fluctuations of iodine or vitamine intake are not considered until these substances fall below the necessary minimum and disease results. If tanned skin were not visible our response to sunlight would probably be just as much neglected, but let sunlight be reduced below the necessary 
minimum and disturbances result, such as rickets in the growing child. Here again the body is incapable of adapting itself; its capacity for adjustment is limited.

The greater size of mountain plants produced by MacDougal ${ }^{12}$ at the lower level of Tucson, the development of a wider head in Daphnia by Woltereck ${ }^{13}$ in response to overfeeding, and Sumner's experiments with mice ${ }^{14}$ in which animals raised at higher temperatures had larger feet, tails, and ears, are distinct evidence that characters produced in individuals need not be adaptive, even though associated directly with an environmental stimulus. There is no reason to suppose that large plants of a given species would succeed better as individuals in the conditions prevailing at low altitude than small ones; their increased size and branching in MacDougal's experiments were apparently an outcome of longer growing seasons and better nourishment. Nor can one see how larger feet and ears, and particularly longer tails, would benefit mice in warm regions. Such characters may be termed incidental individual responses in contrast with the adaptive responses previously considered, but they are no less definitely a result of hereditary capacity expressed according to prevailing environmental conditions.

${ }_{12}$ Am. Nat., Vol. XLV, pp. 5-40, 1911.

${ }^{13}$ Verh. d. Deutsch. Zool. Ges., pp. 110-172, 1909.

${ }^{14}$ Jn. Exp. Zool., Vol. VII, pp. 97-155, 1909. 
Since the species is the sum of its individuals, it is obvious that these individual responses, adaptive or otherwise, are as distinctly a part of the species as are those characters which invariably appear in the normal course of development. The two have been contrasted in all of the literature of evolution. Why? In order to answer it is necessary to consider the nature of the normal specific characters. Ordinarily we say that they are hereditary, but careful thought shows that the organism does not inherit characters, but only the ability to produce them during the course of development. ${ }^{15}$ Development takes place normally only in the proper external environment, but the immediate condition to which a given hereditary power responds is in many cases established by the body as development proceeds, so that the relationship with external conditions is indirect. All of us have eyes. The development of eyes cannot precede the differentiation of ectoderm and neural tube. All of us attain stature and mental development within normal limits, but thyroid deficiency or persistence of the thymus exerts a modifying effect. These things are quite in harmony with the principle already expressed, that the major tendency of evolution is toward greater independence of external environment. The things which characterize all individuals of a species are not inherited as ${ }^{15}$ Conklin, Sci. Monthly, Vol. VII, p. 499, 1919. 
such, but they are developed by each individual in response to conditions which its body is normally able to produce in spite of moderate fluctuations of the external environment. They are fundamentally in contrast with the modifications constituting purely individual responses not in heritability but in the source of the stimuli which bring them to expression.

The question of change in species is different from that of change in individuals and is closely linked with the selective processes whereby a degree of evolution is known to be accomplished. While the individual is a unit made up of inseparable components, all necessary to its existence, the species is made up of a large number of individuals, varying according to recombinations of hereditary units, and continues to exist even though a large part of these individuals are destroyed. Change of a species may result, therefore, from any factor which tends to preserve one aggregation within it or to destroy another.

The individuals of a species spread in the course of time over great areas. As they spread they encounter different conditions of environment, but even barring this condition it is improbable that they will remain exactly the same in two separate regions, because of the reassortment of hereditary units in sexual reproduction. Through chance or through some peculiar fitness of a given heredity 
the original inhabitants of a region may bring in certain hereditary characters which distinguish them from members of the same species in other regions. As they reproduce, their descendants express an aggregate of the predominant characters, and thus perpetuate the difference. Such differences may characterize geographic races or, by the vagaries of taxonomic procedure, subspecies or varieties. They need not be adaptive but may be purely incidental, and they are due solely to the isolation of a given hereditary combination.

The sharpness of boundaries in such cases must, of course, go far to establish the definiteness of the subspecific units. Oceanic islands like the Galápagos archipelago provide an absolute isolation of long duration and so, quite naturally, afford the best illustrations. The mocking birds of the Galápagos are of several closely related species, found on separate islands, their distinctive characters apparently without adaptive significance. ${ }^{16}$ The ground finches of the same islands show a remarkable series of species or forms based partly on the size of the beak, which varies from enormously large to rather small without correlation with food habits, but in this case the various species are not sharply isolated. Wheeler notes of two species of Galápagos ants that "each of them is represented

${ }^{16}$ Gifford, E. W., Proc. Cal. Acad. Sci. (4), II (2), p. 207, 1919; Beebe, William, Galápagos, World's End, 1924. 
by distinct varieties on each of several of the larger islands" and lists for Camponotus macilentus ten varieties, including the typical form, occurring on eleven islands. In this remarkable series only two varieties occur on two islands and only one island has two varieties. ${ }^{17}$ Conclusions regarding the origin of the archipelago and its fauna are by no means fixed, but it is at least probable that the islands were long ago isolated from the Americas as a single mass of land which later gave rise to the separate islands of the existing group, thus isolating portions of the parent species. Such a history would account nicely for the varieties inhabiting oceanic islands.

The types of selection emphasized by Darwin also tend to preserve a limited range of the hereditary characters of species by eliminating the individuals which do not possess them. We cannot doubt the reality of these processes, however much they may have been overemphasized in the past. Both natural selection and sexual selection are wholly logical in theory. Like many other problems of evolution, particular cases may be obscure in detail, but the principles involved are too well established to be discarded as ineffective. Usefulness is the keynote of adaptation. We cannot doubt that organs occur in various hereditary degrees of development, nor that the individuals

${ }^{17}$ Proc. Cal. Acad. Sci. (4), II (2), p. 263, 1919. 
with optimum development will be more likely to succeed than those less favored and more likely to perpetuate their characters in posterity. This constitutes an isolation through usefulness; the species consists more and more, as generations of pass, that group of individuals which possess the useful character. Instead of embracing the original wide range of variation it embraces a restricted portion of that range.

Sexual selection has rather less evident importance. It has not been demonstrated by human standards that any particular kind of excellence is chosen by females in their acceptance of mates, although the possibility seems admissible in the case of higher animals. Certainly the display made by birds during courtship implies that there may be a basis for choice. When males habitually fight for mates, it seems probable that the aggressiveness and fighting ability of the species must be improved, but since the male takes the active part in this process it is rather a "survival of the fittest" than a selection by the female.

In addition to these processes whereby certain parts of the original hereditary complex are preserved and certain others eliminated, or the species is split up into races by the simultaneous preservation of various characters in various regions, we must not overlook the effects of external environment in producing changes in entire species. In 
every case forces outside of the body are involved, but they act in different capacities.

We have recognized the ability of individuals to respond in various ways to environmental conditions, and have concluded that everything belonging to the individual belongs also to the species. In a different way entirely, individual responses may become characteristic of the species if a change in the environment is so extensive as to affect all individuals; the resulting development of individuals will then occur as uniformly as the normally inherited complex of characters. Environmental changes of this extent are likely to occur only as the results of extensive and important geological events, like the elevation of great land masses. Such events do not come and go rapidly. Once they occur, their effects are likely to be felt for a long time. Generation after generation the individuals constituting our hypothetical species may respond to the same conditions by producing the same expression of characters. The results will be as certain of appearance while the environmental conditions persist as will the characters which inevitably develop during ontogeny. If the climate of North America should suddenly become subtropical we might confidently expect the pawpaw butterfly, Papilio ajax, always to occur in its summer form, while now its spring brood is recognizably different. And if the rainfall of some trop- 
ical countries should be evenly distributed through the year, we might expect the wet- and dry-season forms of butterflies to give place to successive generations of similar individuals.

The difference would still exist among specific characters that some were due to response of heritage to factors of the external environment while for the others the internal environment would normally provide the proper stimulus. The same thing is true of characters which we now consider in the establishment of species and their subdivisions. Sumner's mice demonstrate this fact. The characters which they usually present in size of feet, ears, and tail, are as definitely a response to external conditions as are the changes produced experimentally.

It will be noted that all of these changes, be they of the "inherited" or of the "acquired" type, deal with degrees of development. Degrees are important. Most species differ in degree rather than in kind from the nearest related forms and such transitions are to be expected first if we ever succeed in producing new species in the laboratory. Nevertheless, change to the extent of complete loss of an existing structure has been noted in the classical example of the mutant, polled Hereford cattle, and almost complete loss in the wingless mutant of Drosophila. Such losses may well be due to accidents of meiosis, and so products of the 
heritage primarily, or to gene mutations, and subject to the attendant uncertainty of origin, or they may be due to external stimuli reaching the chromosomes directly.

It is difficult to imagine the addition of a new character by accident to the chromosomes, but there seems to be no obstacle whatever to modification of characters either in this way or by action of external stimuli on the germ cells. In the former category we may place the results of polyploidy and heteroploidy. ${ }^{18}$ Some condition, no doubt, in the organism or in the external environment, is responsible for the appearance of these chromosomal abnormalities, so that we cannot leave environment entirely out of consideration. De Mol's studies of polyploidy in tulips give striking evidence of this association of factors. ${ }^{19}$ In the latter category mutations produced in Drosophila by the action of X-rays afford abundant examples. These mutations, like the similar but less frequent changes in untreated cultures, are in the nature of modification or loss rather than the addition of new structures.

Change in organisms is by no means difficult to note. It emanates from all phases of the environment and from the heritage, but whatever its source, we find that significant changes invariably

${ }^{18}$ Morgan, T. H., Theory of the Gene, Ch. XI, XII, 1926.

${ }^{19}$ Genetica, Vol. XI, pp. 119-212, 1928. 
concern both heritage and environment. There is some difference in the various types of change. Species will always continue to display a capacity for individual adjustment to fluctuating environment and there is no reason to suppose that the resulting conditions in individuals must become fixed characters of the species nor that they may never become so fixed. These changes must take their place with the purely hereditary characters as possible materials of evolution and from the entire assemblage our conclusions regarding the origin of species must be drawn.

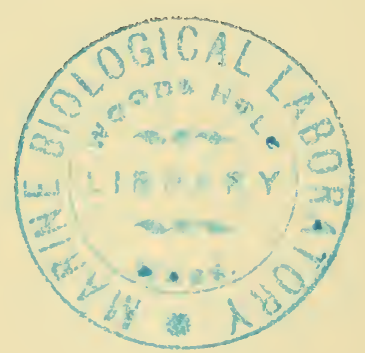




\section{IV}

\section{GENETICS}

During the twentieth century the science of genetics has given us a valuable account of the transmission of hereditary characters, and associated cytological studies have disclosed many details of the material basis for these phenomena. The association of genetics with the problems of evolution is not wholly a happy one, for it has set up in the minds of some scientists a new bias, no less enthusiastically received and supported than those of the past. Therefore, while genetics is one of the most promising fields for the investigation of evolution, it is like other fields in presenting material which must be very carefully estimated.

The fundamentals of Mendelian heredity are, presumably, known to every serious student of the problems of evolution. The basic concepts of genetics are very different. We may regard the existence of genes as definitely established. Certainly there are few if any competent judges who now deny that the chromosomes are responsible for the transmission of hereditary characters, whether or not they accept the modern idea of genes as subordinate units within the chromosomes. Grant- 
ing this much, there are still important matters to be dealt with in the association of these units with the process of evolution.

Genes have never been seen, but since their existence is established beyond reasonable doubt, we may judge them by the things which we know of the chromosomes containing them. Their functions in heredity are recognized; they have even been regarded as independent of external conditions in their hereditary capacities. Nevertheless the succession of generations is always accomplished by complete cells, not by nuclear units or nuclei alone; chromosomes have never yet been shown capable of action independent of the surrounding nuclear and cytoplasmic materials. For this reason the part played by the cytoplasm, as well as the known functions of the chromosomes, is a matter for serious consideration. Opinions of its importance vary widely. Some scientists have concluded that it is responsible for a transmission of characters no less definite and orderly than that carried on by the chromosomes, and have sought in cytoplasmic inclusions the material basis for this transmission. Others have denied that any orderly inheritance proceeds through the cytoplasm. From the point of view of this study it is necessary to seek the relationship existing between it and the nucleus, rather than to defend any existing view. 
The relationship may differ somewhat in the germ cells and in the specialized cells of the body. Years ago, before cytological studies disclosed the true facts, it was supposed that the hereditary units of the germ cells were distributed differentially to the developing cells of the body, so that a specialized cell not only had characteristic differentiations of cytoplasm but also a corresponding nuclear condition. Boveri ${ }^{1}$ showed in his studies of Ascaris that the chromatin is diminished in quantity in the cells of the body and that the remainder is broken up into small particles, but even in this case the differentiation is not comparable to that of the cytoplasm. In by far the greater number of known cases the full chromosome complex of the species seems to persist in all cells of the body which retain nuclei capable of mitotic division. Even the marked contrast between the germinal cytoplasm and that of the most highly specialized cells is not accompanied by comparable nuclear differentiation. The differentiation of the cytoplasm thus becomes one of the great problems of development, and the relations of nucleus and cytoplasm in reproductive cells are part of the general problem of interaction of cellular constituents.

The nucleus is commonly accepted as a control-

${ }^{1}$ Die Entwicklung von Ascaris megalocephala, etc., Festschr. f. C. von Kupffer, 1899. 
ling center of the cell, and since everything contained in it but the chromosomes is repeatedly discharged into the cytoplasm and reformed in daughter nuclei during cell division we may apply the same interpretation to the chromosomes. The additional fact that these bodies alone are universally maintained and perpetuated in a characteristic state throughout the vicissitudes of normal development and reproduction is further evidence of their importance, and the many discoveries of genetics which correlate the development of characters with chromosome behavior are perhaps the most convincing tribute of all to the type of control which they exercise.

Nevertheless even chromosomes are dependent. The nucleus lies within a cytoplasmic envelope which is necessary to its existence. It may be removed by micro-dissection but cannot live independently so far as is known. Conklin ${ }^{2}$ has succeeded by centrifuging eggs in producing daughter cells of which one had a small nucleus, abundant yolk, and a minute amount of cytoplasm. The cytoplasm later increased in quantity; if none had been present, it would be evident that the nucleus alone might produce it, but this condition has not yet been attained. Moreover cytoplasmic materials may pass into nuclei, so that the formation of cytoplasm by a nucleus would not be evidence 2 Jn. Exp. Zool., Vol. XII, No. 1, 1912. 
that the chromosomes actually produce the substance. A few cells, notably the spermatozoa, have the cytoplasm greatly reduced, but in every case, natural or experimental, that has been noted, the nucleus is associated with at least a small amount of cytoplasm.

Neither does the cytoplasm have the power to exist independently for more than a short time. The red blood corpuscles of mammals lose their nuclei in the course of development, but they are short-lived and are constantly being destroyed and replaced. Protozoa may be deprived of their nuclei artificially and may continue to live for a time as masses of cytoplasm, but they are incapable of normal anabolism. Their activity seems to be due to the residuum of potential energy persisting from their nucleate stage.

It is evident that the present state of our knowledge permits only the conclusion that nucleus and cytoplasm are coexistent. We do not know the nature of their interaction, but a significant fund of information enables us to establish satisfactory working hypotheses concerning the essential details.

In the latest summary of this question known to me, Conklin mentions the uncertainty which prevails, but in quoting Morgan's statement: "While, then, we may not be warranted in speaking of the genes as enzymes, the genes may be protein bodies, 
one of whose activities is to produce enzymes which, being set free, act in each cell, and take part in catalytic reaction in the cytoplasm," ${ }^{3}$ he further states: "This conclusion seems to coincide in broad outlines, though not in all details, with the views that have been generally held since the hypothesis of De Vries." 4 Indeed, the far-reaching importance of enzymes in the living body makes it very easy to accept such a view, even though details are lacking. The contributions of Troland, ${ }^{5}$ and lately of Alexander and Bridges ${ }^{6}$ carry out some interesting considerations of these matters, and Goldschmidt's work, ${ }^{7}$ also mentioned at some length in Conklin's paper cited above, is perhaps the most detailed of all published theories. These several works are interesting and suggestive; even though they attempt such detailed treatment that they are unavoidably speculative, the reiteration of interpretations based upon enzymatic action is an indication of its fundamental importance.

The perpetuation of the gene is highly suggestive of autocatalysis; the control exercised by the nucleus over cytoplasmic action is equally suggestive of heterocatalytic powers. Whether Goldschmidt's statement: ". . . die Natur des Gens die eines

${ }^{3}$ Am. Nat., Vol. LX, p. 510, 1926.

${ }^{4}$ Ibid., Vol. LXIII, p. 10, 1929.

${ }^{5}$ Ibid., Vol. XLI, p. 326, 1917.

${ }^{6}$ Colloid Chemistry, pp. 9-58, 1928.

${ }^{7}$ Physiologische Theorie der Vererbung, Berlin, 1927. 
Autokatalysators sein muss, also eines Katalysators, ... ." 8 is justified, remains for the future to prove, but we may be certain that the nucleus does discharge substances into the cytoplasm, that it does receive substances from the cytoplasm, and that it does play the controlling part in the synthesis of all living structures. Conklin ${ }^{9}$ emphasizes the discharge of materials into the cytoplasm during cell division. This period certainly affords an opportunity for the complete dissemination of accumulated nuclear contents, but the normal activity of established cells shows that an interchange must also take place without disruption of the nuclear membrane, even though it may be limited to a dialyzable portion of the available substances. The ability of the nucleus to prepare itself for repeated divisions is, in itself, proof that it receives material from the cytoplasm, for the process cannot be repeated indefinitely without intervening periods of growth, but in addition actual growth of nuclei without cell division is a matter of record.

As in the case of heritage and environment in the existence of the organism, here is an association of essentials. Cytoplasm is as necessary for the expression of the genes as the nucleus is for the differentiation of the cytoplasm; neither can act without the other, and we must bear in mind, as in the

${ }^{8}$ Op. cit., p. 91.

${ }^{9}$ Am. Nat., Vol. LXIII, p. 11, 1929. 
former case, that essentials must be equally important, although they may differ in the nature of their importance. The determinative powers of the genes have concentrated attention upon the chromosomes, but we have no evidence that they can exist independent of the cytoplasm. What then, may be the capacity of the cytoplasm for a distinctive rôle in the determination of the organism?

Numerous attempts have been made to establish the theory that some of the cytoplasmic inclusions, such as mitochondria, have functions in heredity comparable to those of the chromosomes, but without success. That such inclusions not only occur, but in some cases divide and are handed down to daughter cells, is well known, particularly in plant cells where the chloroplastids are perpetuated in this way. Morgan says of such bodies that "they are inherited but not with the precision of the genes. There has never been any serious attempt to ignore this kind of heredity, though it has seemed to me desirable to keep it in a chapter by itself. . . . except for the rare cases of plastid inheritance, the inheritance of all known characters can be sufficiently accounted for by the presence of genes in the chromosomes. In a word the cytoplasm may be ignored genetically." 10 He calls attention also to the evidence furnished by reciprocal crosses. The hybrids so produced should differ ${ }^{10}$ Am. Nat., Vol. LX, p. 491, 1926. 
if cytoplasm has specific value in heredity, since it comes chiefly or entirely from the mother, but they are usually the same. The exceptions, such as the mule and hinny, are an interesting problem, but they are sufficiently rare to present no general contradiction of his statements. One other opinion of interest here is Lillie and Just's conclusion: "The materials of the cytoplasm are . . . being constantly consumed in the metabolism, and the process of renewal and increase of such materials involves interaction of nucleus and cytoplasm." 11 Whatever the cytoplasm brings to the cell, then, falls immediately under the control of the nucleus with which it is associated and soon becomes an expression of the powers of that nucleus.

But until it is definitely established that the sovereignty of the genes is complete, that they are not merely a controlling center but also a producing center, some function in heredity must be recognized in the cytoplasm. It is a reaction product; the quality of the ancestral cytoplasm has a part in its origin. Granting even that it will be maintained in a constant state in spite of enormous fluctuations in the conditions governing its production, it is still impossible to avoid the chance that it may vary even in the same type of cell, governed by the same complex of chromosomes. Nor can we believe that the same determiners ${ }^{11}$ Cowdry's General Cytology, p. 471. 
acting on different materials can produce uniform results, and since self-maintenance and propagation are among the results of gene action, the genes themselves may well undergo change in the normal course of life. As this matter is presented here, it seems highly speculative, but it is in no way out of harmony with the known facts concerning mutation.

The field of embryology also provides us with abundant material. Many eggs show a definite distribution of cytoplasmic materials which is correlated with the distribution of organ-forming substances during cleavage, others show a slight differentiation involving at least a localization of yolk, and even those in which the cytoplasm is apparently homogeneous display evidence of its differentiation in their polarity and symmetry. The bearing of these matters on development is considered by Conklin in the paper cited above, where our limited understanding of them is indicated in the following statement: "It would be interesting to know to what extent this promorphology of the egg is the result of the activity of genes within the egg-cell and how much is due to the immediate environment, for, of course, both intrinsic and extrinsic factors are involved in the development of a spermatozoön or ovum as well as in that of all later stages." ${ }^{12}$ But regardless of the

${ }^{12}$ Am. Nat., Vol. LXIII, p. 15, 1929. 
source of the influence, chromosomes of one or the other generation have much to do with the promorphology of the egg, for its immediate environment is the maternal body.

Promorphology goes far to establish the importance of the cytoplasm in the cells of the body. Since the cytoplasmic materials are variously distributed, they are apparently distinctive in the various types of cells, at least in potentiality. Associated with the complete chromosome complex of the nucleus it is quite logical to expect different results from the different cytoplasmic materials. Were there no essential difference in the cytoplasm of specialized cells, we might expect them to undergo complete dedifferentiation when removed from their normal environments; that this is not the case is shown by tissue cultures, where distinctive functional characteristics, at least, are retained by the specialized cells and their descendants. Even though the chromosome complex is apparently complete in the various kinds and the environment is uniform, the cells do not assume a uniform character; this failure can only be associated with their cytoplasmic differences.

It is a strangely baffling situation, out of which we can safely draw only meager conclusions, viz., (1) that the chromatin of the cell is preëminently a center of control which is dependent upon the cytoplasm for its continued existence, but which 
is largely responsible for the development attained by the cytoplasm; (2) that the cytoplasm is primarily a plastic material of construction which must, like the chromatin, be handed down from a previous generation; (3) that inheritance through the cytoplasm is primarily inheritance of materials, while inheritance through the chromosomes, which must also involve special materials, is primarily inheritance of potentialities for shaping these materials and for their elaboration and diversification; and (4) that these facts are harmonious with the constant association of heritage with environment, both external and internal, in the production of living things. It is doubtful whether, under these conditions, the statement that the cytoplasm may be "ignored genetically" is justified. It seems rather to be a factor which is normally constant in the various cells of a given species.

The relations of nucleus, or chromosomes, and cytoplasm are somewhat similar to the relations of germ plasm and soma, to which Weismann's work gave a prominent place in biology. Indeed, the germ plasm has been called identical with chromosomes and the soma with cytoplasm. In sexual organisms the individual usually springs from a fertilized ovum which is regarded as germ plasm, as also are those cells which lead from it to the germ cells developed in the new body, while all 
cells differentiated to carry on the necessary functions of the individual constitute the soma. According to the Weismannian interpretation the germ plasm thus has power to perpetuate itself while developing in successive generations the somatic tissues through which it is associated with the environment. The somatoplasm is therefore discontinuous while the germ plasm is continuous. In contrast to this condition, the association between cytoplasm and nucleus is never interrupted; the continuity is twofold. A true parallel would exist if the chromosomes alone carried on the reproduction of cells and if daughter groups of chromosomes gave rise to the cytoplasm of the new cells, but this is not known to occur in any case and as a rule is obviously not the method of cell division. As cell division actually proceeds it is parallel only with fission and to some extent with budding but not with sexual reproduction. Another point of view admits the parallel unconditionally and permits the recognition of the germinal cytoplasm as a connecting link between the somatoplasm of successive generations; it would be difficult to defend this interpretation. Nevertheless there is a parallel in the fact that neither chromosomes nor germ cells, in themselves, express their own potentiality; they must accomplish this end through interaction with the cytoplasm on the one hand and the somatic cells on the 
other. The comparison is valuable but it must obviously be used with care lest it lead to implications which cannot be supported.

Since it is impossible, in view of the uninterrupted continuity of the cytoplasm, to ascribe to the chromosomes unlimited ability to synthesize their own materials of construction, the suggested origin of these fundamental parts of the cell as differentiations of an originally more homogeneous unit is not difficult to accept, and their rôles as complementary parts are significant. We have already noted the tendency in evolution toward greater independence of environment; here is an initial step whereby the vital controlling factors are removed from direct association with external forces. Granting the presence of a favorable environment, the resulting cytoplasm is able to take in everything necessary to the life of the entire cell and, under the control exerted by the nucleus, to play its part in the normal processes of life. Modifying conditions impinge upon the cytoplasm. Unless they are extreme, its intake of materials may still be sufficient for the cell to maintain a normal composition through selective synthesis, so that the normal functions of the nucleus are not prevented. Temperature changes may, of course, reach all parts of the cell, but within normal latitude they merely retard or hasten its processes. Various rays may penetrate the entire substance of 
the cell and these, as we now know, may bring about profound modification of the chromosomes themselves. But in a normal environment the organization of the cell is apparently a guaranty of constant normal activity, due to the removal of the controlling center in a large degree from the fluctuations of external environment.

There is every reason to conclude that the soma bears a similar relation to its various parts and to the germ cells within it. The fundamental reason for specialization is the more efficient performance of necessary duties, and in a highly developed organism the total performance of many organs is such as to provide an internal environment in which the fluctuation of conditions is at a minimum. ${ }^{13}$ Those parts which establish contact with the outer world-sense organs, alimentary tract, integument-must encounter the uncontrollable fluctuations of nature or evade them, but while the fluctuations are not injurious they stimulate the organism to responses which tend to maintain its normal condition. Parts which are shut away from direct external contacts-kidneys, endocrine glands,-are thus responsive to a more constant environment to whose constancy they contribute in turn, and the germ plasm, which apparently has no part to play in the life of the individual, may

${ }^{13}$ Pike, F. H., and Scott, E. L., Am. Nat., Vol. XLIX, pp. 321-359, 1915, present an excellent discussion of this matter. 
be provided a practically uniform environment within the body. This condition is all the more striking when we consider that reproduction in the natural state occurs when conditions are optimum for the individual, when the external environment affords the best opportunity for the internal environment to maintain a normal state.

But this is a matter of degree. It does not mean that germ cells, chromosomes, or genes are wholly independent of external environmental conditions or that they encounter uninterrupted constancy of conditions in the body. Every organic structure acts toward this end but organisms are imperfect and no part of them can be wholly independent of any phase of the environment. Germinal cells may be affected by moderate changes of temperature to such a degree that even the normal body temperature of homoiothermal animals may be inimical to their production. It has been shown that the descent of the testes into a scrotal pouch in mammals, either periodically or permanently, provides a lower temperature than that of the body for the normal production of spermatozoa, and that forced retention of a testis in the abdominal cavity results in the prompt breaking down of the germinal epithelium and the resorption of the fully developed spermatozoa. ${ }^{14}$ The

${ }^{14}$ Lawrence, Walter, Biol. Bull., Vol. LI, pp. 129-152, 1926. See also comment in Cunningham, J. T., Modern Biology, p. 162, 1928. 
results of X-ray treatment of Drosophila also bear witness to the possibility of external environment reaching the chromosomes, whether somatic or germinal. Nevertheless the great bulk of genetic evidence demonstrates that the chromosomes are usually able to maintain themselves within remarkably narrow limits of variation, not to say in an invariable state. This seems the goal of organic activity. Change is a normal occurrence under existing conditions, but wherever an approximately constant environment prevails we see the tendency of the organism to be constant, and everywhere in the organic world there is evidence of the tendency toward preservation of that which exists. Constancy in spite of conditions is a goal but constant adjustment to conditions is a universal necessity.

It is apparent at once that this is the major problem of evolution, and that chromosomal functions are a vital part of it. If we could know exactly how their relations with the cytoplasm are consummated, the problem would be simplified, but that is obviously impossible at present. We must be satisfied with the conclusions already recorded as we proceed to the consideration of less fundamental aspects of the relationship.

Weismann's interpretation of the continuity of the germ plasm implied isolation from the influences of the body. This idea has colored biological 
thought to a surprising degree, and makes it necessary to consider the possibility of a reciprocal effect of the body upon the germ cells in connection with any analysis of evolutionary processes. Here the parallel with cytoplasm and nucleus is of interest, for effects of cytoplasm on chromosomes must be similar to that of body on germ cells, or rather germinal tissue. In both cases a modification of fundamental hereditary units is brought into question, and in both the internal environment is the source of stimulus. There is still a difference to be considered, for a somatic condition reacts directly only on the cytoplasm of the germ cells; another barrier intervenes before the closely safeguarded chromosomes are reached.

Evidence on this problem is, unfortunately, of a highly unsatisfactory kind. We know that chromosomes-genes-change. The abundant occurrence of mutations in organisms used for experiment is evidence of that. We know too that the change may be associated with conditions of external environment now that mutations are so readily produced by various kinds of irradiation. But when we consider the expression of characters in the organism in response to varying conditions of environment we encounter conflicting opinions which interfere seriously with our conclusions.

Morgan ${ }^{15}$ has studied such a character in ${ }^{15}$ Am. Nat., Vol. XLIX, pp. 285-429, 1915. 
Drosophila which, while evidently a mutation and a Mendelian character, was governed in its appearance by the amount of moisture contained in the food of the insects bearing the mutant gene. The character, abnormal abdomen, was dominant over normal and was sex linked. Heterozygous females were produced at will by mating abnormal males with wild females, and the offspring reared in moist bottles disclosed the Mendelian behavior of the character. If reared in dry bottles, even the individuals bearing the mutation were normal, although they could produce offspring showing the abnormal character. In drawing conclusions from his experiments, Morgan writes: "The evidence shows in the clearest manner that the condition of the parent, whether normal or abnormal in type, has no effect on the character of the offspring," a statement whose truth must be freely admitted.

While this case stands out as a striking example among the experimental records of genetics, it is by no means unique. Compare it with any of the individual responses previously considered and a marked similarity is evident. The human body inherits the ability to deposit pigment, otherwise we would be albinos, but indoor workers of the white race remain pale while individuals constantly exposed to sunlight become deeply tanned. The Mendelian basis for pigmentation is not fully understood, but it is obviously an inherited character, 
and just as obviously the degree of pigmentation which it brings about is conditioned among whites by the environment. Butterflies of the wet- and dry- season forms inherit the capacity to develop into either, but actually develop according to the conditioning environment. ${ }^{16}$ There are many cases of this kind; in fact, all individual responses are included. They have not been shown to affect the chromosomes, for they are not transmitted in the usual sense.

A peculiar attitude has grown out of this situation. The gene, according to experimental evidence, shows an astonishing degree of stability. When it changes, it does so without evident external influence except in the irradiation experiments referred to, and these influences appear merely to hasten the occurrence of that which would have occurred in due course of time. All experiments in which apparent modification of genes has occurred in connection with ordinary individual responses to environment unfortunately lend themselves to more or less destructive interpretation, and in the most favorable cases the possibility exists of the influences involved actually reaching the chromosomes of the germ cells and acting upon them directly. But a constant material and constant conditions cannot give different re-

${ }^{16}$ Dixey, F. A., Proc. S. Lond. Ent. \& Nat. Hist. Soc., 1916-191\%, p. 11, 1916, cites experiments performed by Marshall. 
sults. When change occurs in the genes in a single generation, since the new genes spring from a common source, it must be due to some modifying condition, perhaps not in the external environment, but certainly in the body. The view that all evolutionary change has proceeded from recombination and selection of existing characters is neither adequate to explain the origin of species nor compatible with the commonly accepted monophyletic origin of living things. In spite of its obvious value it must be associated with the possibility of actual genetic change.

Absolute scientific evidence of the modification of the genes through normal reaction to environmental conditions is not available. The idea that all such changes in organisms have come about in response to cosmic radiations is scarcely acceptable, in view of the fact that they constitute such a minute part of the total environment. Nevertheless the proved modification of genes as a result of such influences lends color to the possibility that they may be amenable to other conditions as well, and the possibility of modification of genes through changes in the environment generally must be accepted as a working hypothesis until it is either proved or disproved. Our failure to produce them more freely is not surprising, for changes in the environment are compensated by the body, changes in the body are still further compensated by the 
cytoplasm of individual cells, and so the genes of the germinal chromosomes are held inviolate to a remarkable degree.

Since the probable modification of genes through the indirect action of environmental factors must rest upon this type of evidence for the present, it is significant to note the expressed conclusions of various writers on the subject: These are only a few of many statements, but they are representative. Troland regards enzyme action as a general solution of many biological phenomena, including variation. ${ }^{17}$ Conklin says: "Various changes in the chemical and physical environment produce abnormalities in the number, distribution and constitution of chromosomes, as was pointed out on a previous page, and it is not antecedently improbable that such environmental changes may produce similar modifications in genes themselves." 18 Cunningham is a little more positive in his statement: "Whenever a changed environment acts upon the organism, therefore, it to some extent affects the normal excretions and secretions of some or all of the various tissues, and these react not only on the tissues themselves, but also to a less degree upon the determinants representing them in the germ-plasm." 19 Alexander concludes that "the specificity of the germ plasm is evidently ${ }^{17}$ Am. Nat., Vol. LI, p. 327, 1917.

${ }^{18}$ Sci. Monthly, Vol. X, p. 511, 1919.

${ }^{19}$ Hormones and Heredity, Ch. XIV, 1921. 
guarded by many factors, among which seem to be selective absorption and differential diffusion of dissolved substances through its protecting walls or membranes. Nevertheless unusual influences must occasionally change it materially without destroying it, and along this line experiment may be directed. It may be that the germ plasm can be affected through the somatoplasm, as well as by direct means." ${ }_{20}$ Even Muller, one of the ablest geneticists of the time, makes a concession to the possibilities of the internal environment by saying that mutations may be due to "accidents' occurring on a molecular scale. When the molecular or atomic motions chance to take a particular form, to which the gene is vulnerable, then the mutation occurs." ${ }_{21}$ And Petrunkevitch is certain that "the mutations themselves must be the result of some physico-chemical change and this in the end-analysis is due to environmental factors." 22

When we consider the implications of this point of view in connection with the normal variation of hereditary characters in response to fluctuating environmental conditions, the question inevitably arises, are the genes involved in these variable responses? We speak of them as somatic characters, acquired characters, or individual responses. We look upon them as cytoplasmic. Are we to under-

${ }^{20}$ Science N. S., Vol. LVI, p. 325, 1922.

${ }^{21}$ Am. Nat., Vol. LVI, p. 43, 1922.

${ }^{22}$ Organic Adaptation, p. 109, 1924. 
stand by this that the cytoplasm alone is responsible? Is it possible that the genes, once having done their part in bringing the character to expression, have ceased to act? That they have provided the cytoplasm with a degree and kind of development which enables it to act alone during the remainder of its life? The evidence is distinctly against such an interpretation. Cells may lose their nuclei and thereafter exist as cytoplasmic units, but they are relatively short-lived and their activities are little more than chemical reactions of their specific contents. The one common example of this phenomenon, the erythrocytes of mammalian blood, is a convincing demonstration of this fact. Experiments with artificial enucleation also indicate a lack of anabolic power in cytoplasm isolated from its nucleus. Since individual adaptive responses are often anabolic, we may conclude without hesitation that the nucleus remains active throughout the life of the cell, and consequently that its essential elements, the chromosomes and genes, are also active.

It is true, of course, that the literature of genetics deals merely with the production of characters, not with their behavior during the life of the individual. Genes are handed down from generation to generation, and a character is heritable if its genes normally result in its appearance during embryonic or postembryonic life. We cannot say 
that the developmental powers of the gene are always active; they are normally active only during the period when a given character is formed. This does not mean, however, that genes cease to exist with the fulfillment of their destiny to this extent, but only that the conditions demanding the activity of their formative powers occupy a limited part of the life cycle of the individual. In some cells even developmental capacities may be proved latent, for osteoblasts, usually bone formers only during development, become active again in the adult under the unusual stimulus arising from bone injuries. The activity, even the formative activity, of genes is not limited to embryonic life nor to the period of growth, and the degrees of development occurring in completed individuals must be interpreted as expressions of gene activity. Everything which appears in an organism during its life must have some foundation in the genes.

Still another question presents itself in connection with this point, viz., the sphere of influence of the gene. In 1927 I suggested a possible interpretation. ${ }^{23}$ Recognizing the occurrence of a uniform chromosome complex even in the somatic cells of the body, it is obvious that every cell contains many genes which it cannot express in its differentiated cytoplasm. This means that if the action of the gene is limited to the cell containing

${ }^{23}$ Science N. S., Vol. LXVI, p. 328, 1927. 
it, a vast majority of the genes occurring in the body are inactive. Such a condition appealed to me as entirely out of harmony with the known facts of organic activity. Wherever we find organic units of higher degree associated, each retains the structures which are actively or potentially of use to it; other parts may persist for a long time but they tend to disappear. This led me to propose the hypothesis that genes may act upon cells other than those containing them, so that a given character may be the expression of many similar genes throughout the body, rather than of those in the cells expressing the character alone. If the nucleus acts by the production of enzymes their transportation to other cells is not impossible, but it is not known to occur.

At the time of formulating this conclusion I recognized the apparently contradictory nature of gynandromorphs. Recently Gowen has added a discussion of mutations induced in somatic cells of Drosophila by the use of X-rays, which he regards as absolute proof that the activities of genes are limited to the cells containing them. ${ }^{24}$ Patterson ${ }^{25}$ recorded the occurrence of similar localized mutations in Drosophila. Eye mutations even occur in such limited areas as a few ommatidia, so that a red eye may show a small white patch or isolated

${ }^{25}$ Ibid., Vol. LXVIII, pp. 41-43, 1928. 
white facets. At first thought this evidence seems conclusive, but more careful consideration shakes one's confidence. We know of localization factors in the inheritance of colors in mammals. May they not also occur in arthropods? Spencer ${ }^{26}$ has recorded such a possibility in connection with this very condition of spotted eyes in a sequence of generations of Drosophila. Obviously there is more to be said on the subject for which we have no sound evidence at present.

One condition would decide this matter finally. If the cells in a developing body which express a given hereditary character could be deprived of the genes for that character, then we might see whether the similar genes in other cells could bring it to expression. It seems impossible to obtain such a condition. The whole matter is closely linked with cytoplasmic differentiation during embryonic development, which presents such a marked contrast to the uniform distribution of the chromosomes. We know relatively little about the relationship existing here.

If we approach the problem from the point of view that the cell is the unit of living matter, then its actual development would seem to be determined from within. Its susceptibility to influences outside of itself would seem to be entirely in the nature of a response to environmental con-

${ }^{25}$ Am. Nat., Vol. LX, pp. 282-285, 1926. 
ditions, in the body or in its own cytoplasm, and the limitation of gene action to the including cell would seem to be inevitable. The results of gene action might contribute to the environment of other cells, but this effect could hardly be associated with the formative influence exerted by a gene within the cell.

Wherever we drop the problem it leaves a feeling of tantalizing uncertainty and in my own thoughts the persistence of a horde of unused, inactive genes in every cell of the body is the most serious difficulty. There is no evidence that any part of the chromosome complex in any cell loses its potentiality. Weismann's idea of differential distribution of the nuclear elements has not only been overthrown by cytological evidence, but also replaced with opposite evidence that there is no such differentiation. There are some cases of cell modification which bear out this view thoroughly, the most important being the origin of germ cells from somatic tissues. The chromosomes of the germ cells alone must be complete. There is not the slightest possibility that a cell without a complete assortment of genes may develop into a complete individual. Yet specialized tissues in plants may give rise to germ cells, and a few cases among animals indicate the same transformation. Fell ${ }^{27}$ has shown that in cases of sex-reversal in ${ }^{27}$ Brit. Journ. Exp. Biol., Vol. I, p. 97, 1923. 
the domestic fowl the male germ cells arising after the destruction of the ovary are formed from the peritoneal epithelium, both of the degenerating ovary and of the vestigial right ovary. More convincing evidence that the genes in somatic cells may retain their full powers could not be asked.

Nevertheless, the genes can be maintained only through the activity of the cytoplasm; they are dependent upon it for everything necessary to their existence. In some cells the cytoplasm becomes extremely specialized. Its differentiation may be associated with relatively few genes, yet it continues to provide the proper environment for the full complex of genes belonging to the species. Elsewhere in the body other highly specialized cells of an entirely different nature, dependent for their differentiation upon an entirely different set of genes, may be doing the same thing in addition to their special functions. This condition makes it impossible to avoid the conviction that even though control over development is exercised by a gene only within the including cell, the body must provide a universal basis for the maintenance of the genetic complex, in which every cell takes part and upon which its special characteristics, be they a matter of normal differentiation or of mutation, are superimposed. Continuity in descent cannot be denied, even though it may be freed from Weismann's interpretation. If a change in a chro- 
mosome occurs, then its descendants cannot be expected to produce the same results, even though they act upon the same cytoplasm as that of the parent cell, nor should a constant cytoplasm necessarily restore them to the previous condition. But in the individual organism it is more than probable that the body as a whole maintains its chromosome complex; only this view is in harmony with the common persistence of the entire complex in somatic cells.

There is every reason to expect such a condition. Each individual maintains a reproductive mechanism which is of no fundamental value to it as an individual. The claims of the species are great enough to attain this end and we cannot logically avoid the probability of a correlation between the total activities of the individual and the link which connects it with the species, viz., the reproductive cells. The individual is, after all, the only manifestation of the species as a complex of differentiated characters; to argue that its self-maintenance exerts no influence on the characters of the species is to argue that it is a dissociated byproduct.

One other matter of gene behavior is of great importance in this study. This I have taken up previously as an application of the principle of use and disuse which is well established in the case of macroscopic living units. ${ }^{28}$ The theory may be ${ }^{28}$ Am. Nat., Vol. LXI, pp. 251-265, 1927. 
stated briefly as follows: Use and disuse are to be regarded as the degree of exercise of functional powers. It has been established in many cases such as muscular activity, bone development, and immunization against poisons, that conditions of environment which demand a given response result, if long continued, in the modification of the functional capacity of the part activated. Use brings about increase of functional capacity and disuse, decrease even to degeneration. There seem to be limits of stimulation beyond which harm may result, rather than adaptation. Since chromosomes and their contained genes are living units, albeit immune from the methods of observation and experiment which may be brought to bear upon macroscopic parts, and since they are active in controlling the activities of the cell throughout its life, there is every reason to conclude that they share in this capacity for increase or decrease of their functional powers as a result of the degree of activity demanded of them. I am unable to find any material, logical or otherwise, in refutation of this view. Its value, of course, rests upon the uniform maintenance of the chromosome complex throughout the body, including the germinal epithelium.

With this discussion of some of the significant facts and problems of heredity, it is apparent that the nature of the interaction of heritage and en- 
vironment is by no means simple, and that the reduction of the theoretical approach to the problems of evolution to a basis of scientific fact is in most points difficult and in some impossible at present. It is safe to say that we shall not know exactly how evolution works in terms of absolute observation of details until the nature of the gene and of its action are definitely determined. While at first this suggests the futility of existing methods of approaching evolutionary problems, we may still expect valuable progress from intelligent use of these methods. The organism has not yet been reduced wholly to terms of physics and chemistry. Its reactions in such terms are of the utmost interest and importance, but the great range of organic responses which are known only in terms of biology may still give us the key to evolutionary processes long before their ultimate basis becomes known. 


\section{V \\ THEORIES OF EVOLUTION}

It would be gratifying if all studies of evolution and all controversies on the subject could begin with the same well-established foundation of facts, but this is, unfortunately, impossible. The vitalists still hold sway with the mechanists, the selectionists and mutationists have very nearly monopolized the field, and the Lamarckians have trailed along with dogged persistency in spite of the unfeeling reception of their views by a large part of the biological world. There is often misunderstanding between the various schools of thought. The facts of nature do not vary, but our knowledge of them is such an exceedingly uncertain thing that in expressed views on evolution we must be critical of everything involved. Theories may be attractive and yet be unsoundly based; even apparently logical conclusions drawn from carefully safeguarded experiments may be proved unsound by the use of additional facts, sometimes of the most obvious nature. And when we add to these difficulties the utter impossibility of securing agreement even among scientists on the significance of established 
facts in evolution, the situation becomes one of scant hope.

It is necessary at the outset for every evolutionist to establish his articles of faith if he would be understood, for this, in the end, is the basis for our investigations until our knowledge can be brought to greater exactness. It must be admitted that no one view has been established to the exclusion of all others by scientific proof, hence these articles of faith should be at once a basis for study and a confession of the tentative nature of all evolutionary theories. The attitude of every individual must be based in some degree on what he finds it possible to believe, and belief is not final proof. With such an attitude toward his subject, the evolutionist may examine the work of his fellows fairly, and without bias accept such modifying factors as may be brought to bear upon his own views. If anything is necessary to progress in our knowledge of the processes of evolution it is this very recognition of limitations: limitations of knowledge and of the interpretation of facts, limitations of the other fellow's work and of one's own.

The spirit of fairness demands that we consider the beliefs of the vitalists as well as those of the mechanists, if only to make clear our reasons for abandoning the vitalistic approach. We have no more evidence for the non-existence of a vitalistic principle than for its existence. Nevertheless a 
large part of the literature of this distinctly philosophic mode of thought is biologically unsatisfying. The manipulation of words which have special significance to the manipulator is never wholly satisfactory in science, for the goal of science is to reduce knowledge to the most accurate possible terms of human sense perceptions. The best that we can do to adhere to this worthy purpose is none too good; it should be an ample warning against unnecessary flights of fancy. But a recognition of the serious difficulties of this field of thought demands that we respect the sincerity with which our more philosophic fellows pursue their investigations, and that we acknowledge in many of their utterances the fairness, the unbiased desire for truth, which we should all strive for. Johnstone's consideration of the matter is an excellent illustration. He concludes with these words: "If life is not only energy but also the direction and coördination of energies; if it is a tendency of the same order, but of a different direction, from the tendency of inorganic processes, all that biology can usefully do is to inquire into the manner in which this tendency is manifested in material things and energytransformations. But the tendency itself is something elemental." 1 Wagner formulates a hypothesis of neovitalism, an association of a vitalistic principle with a physico-chemical foundation, and

1 The Philosophy of Biology, p. 340, 1914. 
regards it as the only philosophy which can do justice to all of the facts. ${ }^{2}$ Unfortunately we cannot all agree that the tendency of life processes "is something elemental," or even that a vitalistic concept is necessary, but it is obvious that we may concur with the vitalists in the opinion that biology can only inquire into the manifestations of life as they stand before us, on a physico-chemical basis, whatever may be their ultimate cause.

With this precept as an initial article of faith we may eliminate from consideration all of the vitalistic theories of life and evolution. Whether an unknown principle is at the foundation of vital processes or whether these processes are not, rather, merely the results of incomprehensible intricacy of organization, we cannot say, but we may be increasingly certain as biology progresses that every vital process is the immediate outcome of characteristic physico-chemical phenomena and that it is governed by physico-chemical laws. To Johnstone this attitude on the part of biologists means that the "mechanistic conception of life is only the result of the extension to biology of methods of investigation, and not a legitimate conclusion from their results." " To the biologist it means that only one course is plain, viz., the extension of these methods to the greatest possible degree until one of two ends shall be reached. They may trip him

${ }^{2}$ Geschichte des Lamarckismus, p. 18, 1909.

${ }^{3}$ Op. cit., p. 121. 
up as a mechanist, to be sure, but to the extent that he is a true scientist it will make no difference to him whether they prove the mechanistic or the vitalistic concept, provided only that they ultimately result in proof.

The foundations of mechanistic theories of evolution are in one way only a step removed from the vitalistic. They have the marked advantage of limiting themselves to primary concepts which are at least susceptible to scientific proof, while the ideas of vitalism are beyond the reach of existing scientific methods, but their susceptibility has not yet come to fruition. The obstacles to scientific treatment of the materials of evolution are so great that our understanding and acceptance of them still rest on logical appeal rather than on scientific values, hence the basis of faith with which they are inevitably associated. It is often difficult in this field to say with certainty when an observation is factual and when it is limited by incompleteness of data and by the personal equation. But we are human, and the best that we can do is to admit the probable accuracy of observations checked and rechecked, and agreed upon by many scientists rather than by one or two individuals. Pioneer efforts cannot partake of this support, but they should at least be amenable to it.

Accepting only the well-established theories of evolutionary method our remaining articles of 
faith are the apparently sound principles which they supply. Our point of departure is narrowed down at once to the two great schools of thought, the Darwinian and the Lamarckian. Whether we adhere to the original views of the two men or to the modifications introduced by their followers the separation is not particularly well taken, but in the main the Darwinian idea emphasizes the organism as the source of change while the Lamarckian idea emphasizes the part played by the environment in the adaptation of the individual.

Since Darwin made no attempt to explain the origin of variations, but merely accepted them as a potential source of evolution through selection, it is only natural that his views should have been supplemented by many others. He emphasized the usefulness of variations as a potent factor in evolution, and we have come to realize that much evolution has been accomplished among characters for which we can discover no use. Even in the expression of his great theory of natural selection are possibilities which it has remained for his followers to bring out.

Briefly, Darwin's theory of evolution, or natural selection, rests on the several postulates of overproduction, the resulting struggle for existence, the survival value of variations, and the cumulative modification of the characters involved through succeeding generations. That there are serious ob- 
jections to the theory has been pointed out enough times in detail to free us from the necessity for additional critical comment. Most of the objections are readily met with no greater strain on our credulity than the theory itself involves, but still we have no explanation for the cumulative modification of characters nor for the origin of variations in the beginning. The result is that the theory becomes an explanation of the adaptation of species through the selective action of the environment on the characters already present, and not an unlimited explanation of evolution. As a theory of species-adaptation, and to that extent of evolution, few scientists will deny that it is logical and therefore worthy of a place in our explanation of organic evolution.

The idea of natural selection has been responsible for several other expressed selection theories. Darwin himself recognized the futility of ascribing definite usefulness to all organic characters, or even of classifying all characters as either useful or harmful. In partial explanation of development beyond the reach of natural selection he advanced the theory of sexual selection, in which the deliberate choice of mates was regarded as the active force in determining what degree of development of a variable character should survive. Granting that a choice occurs and that it is based upon a fairly uniform standard of excellence, such a proc- 
ess may well be active in limiting a species to a certain portion of its possible range of development.

Some other writers have out-Darwined Darwin in their insistence upon the unlimited potency of natural selection, not contenting themselves as he did with the recognition of its validity as one possible process. Fortunately these over-zealous selectionists have not dominated the field, for there have been equally ardent supporters of Darwin who recognized with him that his work was not perfect. Among them Weismann occupies a commanding place. Certainly his work has done as much to turn thought into the channels of Darwinism as that of any other man, although his own selection theories have gained little acceptance. He recognized the failure of natural selection to explain the degeneration of organs or their development beyond the point of usefulness, and just as clearly saw the uselessness of his own early theory of panmixia. His germinal selection was an ingenious but unwarranted extension of the principle of struggle for existence to the minute and then hypothetical determinants within the germ cells. The most potent objection to it is that the idea of formative influence of nourishment gives a decidedly Lamarckian character to his argument. Elsewhere I have also advanced the criticism that there is no basis for the belief that parts of the 
individual body compete with each other for nourishment. ${ }^{4}$ When insufficient food is available such differential distribution as may occur is rather a result of coördinated processes of the organism as a unit than of struggle among its several parts as competing units.

Roux's intraselection likewise assumes that the relationship existing between the parts of an organism exerts a determinative influence upon their evolution. Certainly the interaction of coördinated parts must have an influence upon their development in the individual, but from the point of view of this work each is a part of the environment of the others, and any influence which it may exert is environmental in nature.

Coincident selection, too, which is the organic selection of Baldwin and Osborn, has had its vogue among those who were reluctant to consider the environment in evolution, but it is little more than an evasion. It is based upon the concept of individual adaptations which preserve the species until similar hereditary characters appear through other - unfortunately obscure-means. As Herbert has logically shown, this hypothesis defeats its own purpose in failing, by the assumption of effective individual adaptations, to provide any basis for the elimination of the individuals which fail to produce hereditary modifications.

${ }^{4}$ Textbook of Evolution and Genetics, p. 407, 1929. 
If we consider all of these selection theories carefully we find that such as are valid, in that they deny any developmental rôle of the environment, are almost equally well described as isolation theories. The remainder are either insecure or distinctly Lamarckian. To the extent that choice is involved, as in artificial and sexual selection, a process may be truly selective, but an active selective factor is usually lacking in natural selection. In every case some condition tends to preserve a limited extent of the normal range of variation of a species in the offspring of a limited number of individuals, and in the original statement of the theory this factor is the survival of the favored individuals and the death of the remainder.

It is evident that the individuals which survive in any generation must perpetuate a great many characters which have no decisive part in their survival. Out of the assemblage of inherited characters found in a species, relatively few can be regarded as useful in the Darwinian sense, to the extent of preserving those individuals in which they are slightly more effective in relation to a given condition. Most characters must be regarded as indifferent in relation to any particular factor in the environment as long as they serve the individual normally, yet they vary like all characters and since many individuals perish some of the indifferent variations must inevitably be 
preserved while others are lost. Even though useful characters may determine survival, an evolution of indifferent characters will follow as a corollary.

The results of selection may therefore be summed up as threefold. First, useful characters are preserved; second, harmful characters are destroyed; third, indifferent characters are modified through their association with the other two.

We are justified in questioning whether this is the only possible end of natural selection. Granting that overproduction and consequent crowding, or interspecific competition, make necessary some adjustment of the organisms involved, are survival or death the only alternatives? Obviously, as has been contended, if some individuals are better fitted to secure the necessities of life they will survive at the expense of the others, but need the others die? In a few cases of dearth of food which have come to my attention the result was an extensive migration in search of food, and it seems likely that lack of any necessity from any cause might first of all impel the organism to seek actively for that necessity. Moreover if a species has a variety of food habits of which certain ones are preferred, the effect of overcrowding might well be the adoption of the less favored habits by the individuals which are less fitted to secure the preferred foods. 
The results of anything but differential death among these alternatives savor much more strongly of isolation than of selection. Wagner, ${ }^{5}$ in his elaborate presentation of the isolation theory, emphasized geographical isolation as a factor in the evolution of species, but it is evident that other things than space may isolate organisms. I have cited elsewhere the case of Plebeius melissa, one of the small Lycaenid butterflies. The males appeared in Dickinson County, Iowa, during the period of my observations, six weeks earlier than the females. Males were abundant in July and were present during the last two weeks of June. Females appeared in small numbers toward the end of July and were abundant in August. This case involves a seasonal isolation which would tend to eliminate any characters possessed by the earlier males exclusively. The insects are so delicate that they must be destroyed accidentally in large numbers, and it is doubtful that even a moderate percentage of the very early males have an opportunity to mate.

Great variation in size also has an isolating effect, since extremely large and extremely small individuals of opposite sex may be unable to mate. This is obviously true in the case of some insects in which the abundance of food is reflected in the size of the adults, and is conspicuously so in such

${ }^{5}$ Entstehung der Arten durch räumliche Sonderung, 1889. 
variable species as the domestic dog, as has been pointed out by Devaux. ${ }^{6}$

Organic isolation, however, demands a considerable degree of established difference within the species. It may further evolution but cannot be expected to initiate it. Geographical isolation, on the contrary, may split a species into groups without the slightest activity on the part of the individuals involved. Rivers like the Missouri not infrequently establish new channels by cutting across narrow necks of land left by their meandering curves. The resulting ox-bow lakes left in the old curved channels contain remnants of the river population, now destined to live in still water and away from the flora and fauna of the parent stream. The ancient seas which cut across North America from north to south must have divided species into eastern and western groups in many cases. And the separation of islands in oceanic archipelagos, or the peopling of newly-formed islands by immigration from other land masses, must in every case result in spatial isolation of related individuals.

It is very probable that individuals isolated in a restricted area by such processes will possess a limited range of the variations characteristic of the species to which they belong. Their descendants can only display the characters or express the potentialities of the isolated stock, for without

${ }^{6}$ Rev. gen. sci. pures et appl., Vol. XXXIX (10), pp. 299-306, 1928. 
association of individuals of all degrees of variation there can be no maintenance of the original characteristics of the species. This is equally true of all characters, useful, harmful, or indifferent, so far as the direct results of isolation are concerned.

The question arises, are such geological phenomena as those mentioned necessary to the complete isolation of conspecific groups? Obviously not, but in contrast to spatial isolation of other degrees they accomplish such clean-cut separation that they are striking examples. Every species, be it plant or animal, tends to be dispersed from its center of distribution. Animals, through their powers of locomotion, may spread more rapidly than plants, but no more surely. The individual animal may migrate long distances, while the individual plant must usually stay in one place, but the seeds of the plant are scattered through many effective adaptations, sometimes over incredible distances. The animal may direct its own dispersal into favorable regions, while the scattering of seeds is random, but the seeds may germinate and grow only in favorable places so the result is, in the end, the same. Ultimately both plants and animals extend their distribution over great areas. If they push down along the sides of a great river or a mountain range over which they cannot pass, they are as effectively divided in one direction as if the geographical feature had sprung up in the 
midst of their area. If they extend ultimately beyond the range of individual migration, their extremes are as surely isolated as if an insurmountable barrier existed between them.

There is a difference between these types of spatial isolation, however. While organisms living in Colorado cannot possibly mate with organisms living in Maine, there is a gradual chain of association connecting the two extremes. The individuals of a species are linked together throughout a continuous area of distribution by indirect and potential reproductive association, even though not by unlimited possibility of direct contact. On a group of islands like the Galápagos they may be absolutely isolated in separate groups. In either case certain characteristics within the range of heritable variations of the species may originally have determined the distribution of individuals, but at the same time many incidental characters, bearing no determinative relationship to the location, may characterize the development of the isolated or partly isolated groups. And even though a tenuous indirect association may persist throughout the range of a species, there is little actual chance that the characteristics of the Colorado individuals will affect the development of the species in Maine to a noteworthy degree.

An example of these types of isolation has recently demanded my attention, namely, the cir- 
cumpolar skipper, Pyrgus centaureae. ${ }^{7}$ This insect is found in northern Europe and North America, and extends in the mountains as far south as Colorado. It has been taken in New Jersey at Great Notch, and is fairly common in Labrador. In these and the intervening eastern areas it occurs, necessarily, at fairly low altitudes, but in Colorado it is found on high mountains. I have had it from an altitude of 13,000 feet. Labrador specimens are not unlike Colorado specimens. The New Jersey specimens that $I$ have seen are rather dissimilar in appearance. Specimens from Lapland are much like those from Labrador, Colorado, and various parts of Canada. There is no available evidence for regarding this assemblage of insects as more than one species; certainly, according to the accepted views of all entomologists, one species extends over the entire area even though it may be associated with another. Yet there is a rigid isolation of some individuals on the Colorado mountains and on the two continents and an actual isolation with indirect association between the individuals occurring in the east and at higher latitudes. The future development of the species in Colorado must obviously be based on the characteristics of the original stock of that region, while its development in New Jersey may be based on an originally different heritage.

${ }^{7}$ Ent. News, Vol. XXXIX, pp. 239-241, 1928. 
The operation of the forces of selection and isolation in nature, therefore, is due to a complex association of organic functions and environmental conditions which tend to accomplish one of two ends: the splitting up of species into groups of individuals which may differ in heritage within the original limitations of the species, or the preservation of individuals falling within a certain range of variation and the concomitant destruction of the remainder. It seems wholly logical that some degree of evolutionary transformation may be accomplished in nature in this way. Certainly the changes wrought in domestic animals through selective breeding show that possibility, even though they do not demonstrate survival values with respect to natural environmental relationships.

Another problem arising from these factors is the incidence of new conditions upon the organism and the reactions which they arouse. Whatever may cause the isolation of a group of individuals, they can scarcely meet just the same conditions that have previously constituted the environment of their kind. The possibilities are several. Dispersal may, as has been noted, be a result of the natural tendency of a successful species to spread, or it may be due to the overcrowding due to overproduction which Darwin regarded as so important. In the former case the organism is likely to seek 
new fields as nearly as possible like its old environment, but it is inconceivable that it could always find exactly the same surroundings. In the latter, if its powers of migration are great, the same result may follow but otherwise it may be forced to avail itself of other habitats in the same region. The result is a variation of environmental stimuli which must have an effect in the life of the organism. Characters which previously served it in one way, or failed to serve it to a considerable degree, may take on a new importance in response to the new conditions. These are the preadaptations of Cuénot. What is their potency? May the new stimuli provide for the appearance of new powers of response and new development of the organs which they call into use, or are they only a factor in natural selection?

There are valuable ideas in this material, in spite of the fact that Darwinism has never been free from attack. Weismann, himself an ardent selectionist, admitted that the usefulness of early stages in the development of organic structures must be taken on faith. The weakness of the selection theories in the explanation of degeneration and overdevelopment of parts has already been mentioned in connection with the theory of germinal selection. More recently Cuénot ${ }^{8}$ has proposed several criticisms which seriously impugn

${ }^{8}$ Archives de philosophie, Vol. VI, pp. 80-91, 1928. 
the value of natural selection itself. He shows that the destruction of most animals after birth occurs during early stages of development or vulnerable stages of metamorphosis and is accidental, giving no opportunity for the operation of slight advantages accruing to the individual through the variation of specific structures. He bases another criticism on the fact that organisms meet the exigencies of environmental contact through physiological rather than morphological variations, but this is a less valuable point, since processes are always the expression of structures. The total value of his criticism is tempered by the pronounced teleology of the statement: "Tout se passe comme si la Nature, voulant la perpétuation et l'extension de la Vie, donnait avant tout une prime à la fécondité et suscitait à l'intérieur de l'espèce des préadaptations en divers sens qui, aux moments de crise, sauvent l'espèce ou étendent son aire." 9

Regardless of the possible weakness of some of the points in selection and isolation, we must admit their probable potency, but even then we find that they have failed to establish an evolutionary process capable of transcending the original limitations of species. They may break a species up or they may gradually lessen the extent of its variations, but they may not change it otherwise. The progress of evolution demands inevitably the ${ }^{\circ} \mathrm{Op}$. cit., p. 90. 
modification of existing things beyond existing limits, the establishment of new trends in development. Variation may be taken for granted, but this acceptance does not explain the origin of variations, which is the critical point of evolution. It has been shown that selection may be carried to a certain point and that beyond that point it does not result in change. Johanssen's work on beans, which established the principle of pure lines, is the classical example of this limitation.

Only two of the older theories have soundly attacked the problem of the origin of variations, namely, the Lamarckian theory and the mutation theory. The former must be considered more fully in later pages; the latter is of interest here because it has so often been advanced as an explanation of the origin of variations within the organism.

The reality of mutations cannot logically be doubted. De Vries' work, which bears the same relation to the mutation theory that Darwin's bears to evolution generally, was based on the sudden appearance among evening primroses of individual plants with heritages demonstrably different from the parent heritage. These plants bred true, save that they might, in turn, produce mutations in a small percentage of their progeny. Mutations now play a prominent part in genetics and have been recorded in domestic animals and plants and in various organisms picked at random in nature. The 
two treasures of the geneticists, Oenothera and Drosophila, are the outstanding examples.

The objection has frequently been advanced that the species which give rise so freely to mutations are merely natural complex hybrids from which homozygous combinations occasionally segregate. Such a condition is conceivable, but if all mutants were homozygous recessives, then reverse mutations could not occur. Reverse mutations actually do occur, however, both in Oenothera and in Drosophila. Moreover some mutant characters are dominant over the natural characters which preceded them; if they were merely segregated in homozygous dominants any visible difference must have been evident in previous generations. And lastly some mutations are characters which did not appear at all in previous generations; they are apparently new characters arising from some chromosomal modification. In short, the evidence is wholly against the view that species which produce mutations are hybrids in the natural state; such conditions may occur, but mutations undoubtedly occur also as actual departures from the previous condition of the heritage.

Granting the occurrence of mutations as definite modifications of an existing heritage, two possible evaluations are open to us. De Vries himself provided the interpretation that they are the direct source of new species, and named his Oenothera 
mutants as new species. Others have suggested the availability of mutations of large or small degree as materials for selection, leading ultimately to the production of new species. Here we must be sure of our definition of species, but on the basis of definite departure from the condition of a previous heritage we may recognize both possibilities. Observed mutations have failed to provide us with new species, but it may be that our knowledge of their origin influences unfavorably our judgment of their rank.

Lotsy ${ }^{10}$ has attempted an explanation of the origin of species on the basis of hybridization. His theory has been given very full expression and we must admit that hybridization provides a means of securing reassortments of characters beyond the results of selection and that it is effective in connection with mutations. Lotsy's species, however, is the pure line of other scientists, and when we extend his idea to include the type of change which evolutionists usually seek to explain we encounter the intricacies of hybridization among natural species-the linneons of Lotsy-which show at once that the process is too limited to be an explanation in itself of species formation in the ordinary sense. The idea also encounters difficulty when we inquire into the source of the parent stocks, for unless we base it upon a polyphyletic scheme

${ }^{10}$ Evolution by Means of Hybridization, 1916. 
we must still explain the origin of variations from less varied ancestral stocks. The value of the theory seems distinctly limited.

Returning to mutations as one explanation of variation, we find in the writings of Cuénot a suggestion of three degrees of importance of mutations. ${ }^{11}$ If inferior to the parental form in their capacity to survive, they must gradually disappear; if superior, they tend to replace the parent form; if on an equal footing, they introduce variability. The supplanting of a parent species by mutations of sufficient degree would satisfy all of the requirements for the origin of species.

The problem of the relation of mutations to selection demands the consideration of still another point. Granting that a mutation of slight degree appears in a certain character, and that it aids the individuals possessing it to meet existing conditions of environment more effectively than the ancestral form, we have the necessary conditions for the action of natural selection in the preservation of the mutation and the possible elimination of the individuals which are without it. The fact that the mutation is a permanent departure from the previous range of variation of the character in question is not, however, a guaranty of further change in the same direction. Nothing assures us that the character will undergo cumulative muta11 Op. cit., p. 87. 
tion in successive generations. That this possibility exists cannot be denied, but it is no more than a possibility under the usual uncritical acceptance of mutations as spontaneous changes. Hence natural selection plus mutation is of little more value in evolutionary theory than either process alone. It is more than probable that both are effective processes in the modification of organisms, but scarcely possible that they are an adequate explanation of organic evolution generally.

In order to meet these conditions the idea of a tendency to produce mutations progressively in a given direction has been advanced, which is closely akin to the theory of orthogenesis, an uncertain quantity in the field of evolution. Orthogenesis has been a distinctly vitalistic theory, as in the hands of Nägeli, depending upon an internal directing force which was supposed to cause development in a given direction. It has also been a distinctly Lamarckian theory involving the progressive response of a succession of generations to the same environmental conditions. To these views may be added the idea of progressive mutations. The word applies very well to any of the phylogenetic series which palaeontology has given us, but it is descriptive rather than explanatory. As Newman has stated, "orthogenesis is not a causomechanical theory of evolution at all." 12

12 Evolution, Genetics and Eugenics, Revised Edition, p. 36, 1925. 
However we may qualify and modify the idea of mutation, we are still not free from the necessity of explaining these interesting changes. Some views have regarded the process as a spontaneous occurrence in the organism, which might occur periodically during the existence of a species or at a given point in its development which has been likened to the maturity of the individual. De Vries stated the possible interpretations very fairly as follows: "If mutability is a permanent condition, it has of course no beginning, and moreover is not due to the agency of external circumstances." 13 "If, on the other hand, mutability is not a permanent feature, it must once have had a beginning, and this beginning itself must have had an external cause." 14 Thanks to modern experimental work in genetics we may now conclude that external factors may cause mutations, but the sharp distinction between environment and the genes is scarcely justified, for a stimulus which causes mutation in one species may, even when intensified, fail to produce it in another. The inherited character of the chromosomes undoubtedly plays a part. In some species the genes are evidently unstable; they change, sometimes in response to conditions in the organism and sometimes in response to conditions of the environment, such

${ }^{13}$ Species and Varieties, Their Origin by Mutation, p. 690, 1905.

${ }^{14}$ Op. cit., p. 691. 
as the various rays which have been used experimentally in their production. But we have no reason to conclude that even an unstable unit will change spontaneously. In some phase of the environment, internal or external, we must assume that fluctuating conditions provide the stimulus for the modification of the gene. Mutations, like other organic phenomena, must involve a reaction of the heritage to the environment. But in arriving at this conclusion we have approached the other school of evolutionary thought, the Lamarckian idea of the potency of environmental factors in the evolution of living things.

Cuénot has taken up the matter of organic adjustment to new environments very logically in his theory of preadaptation. ${ }^{15}$ He points out that a character present in an organism living under certain conditions may, in a different environment, serve their possessor in a different capacity. As the organism moves from one region to another, or as changed surroundings are forced upon it, new demands are made upon its body which must be met in the best possible way. Obviously a need cannot immediately produce new structures in an organism; it must be met at once if the organism is to survive, but it can be met only by the use of parts already functional in the individual. In illustration of preadaptation many existing possibilities

${ }^{15} \mathrm{La}$ genèse des espèces animales, 1917. 
may be cited. The curved claws of the ant-eater are used primarily to tear open the nests of termites, but in case of need they are effective weapons of defense. Hairy vestiture in plants protects them against undue loss of moisture and characterizes many xerophytes, but it serves also as a protection against cold. And in the past evolution of animals such structures as the fins of the Crossopterygii were evidently developed in one environment for one purpose, only to become exceedingly important in another environment for another purpose. Preadaptation adds another concept for the explanation of the adjustment of organisms to the environment without explaining the origin of the characters involved.

The attitude which forces itself inevitably upon the student of evolutionary processes is that the theories which are based upon the belief that the organism alone is the source of change are limited in possibility. Certainly an organism may accomplish nothing for which it lacks hereditary capacity, but all of the selection theories, all ideas of isolation, all of our knowledge of mutations, serve only to show that the characters which make up a species may be reassorted, redistributed, preserved in part and destroyed in part, or modified in some degree. Only when we have recourse to a vitalistic principle or to an environmental control do these factors align themselves with the evolution which has 
been recognized in the world of nature. That which exists in a species is not enough to explain the intricate ramifications of many species and their close correlations with the infinite possibilities of the environment. We must turn to the Lamarckian view and see what it contributes to the sum of evolutionary thought.

It is probable that no part of evolutionary theory has been more maligned or more subject to mistaken discussion than this. If there were no demonstrable organic power of adjustment to environmental conditions, if individuals must meet their surroundings with only their hereditary structures and without the capacity for regulating these structures in the slightest degree to meet the peculiar conditions surrounding their own lives, then there would be no reason whatever to investigate the possibility of adaptation in the species beyond the selective processes already discussed. But we do witness adaptive processes in the individual which result in direct adjustment to environmental conditions and the possible extension of these processes to the production of specific adaptive characters will not down. It seems incredible that the processes of individual life should be wholly unconnected with the adaptations present in species as hereditary characters.

The possibility has been overworked in the past, but we may say the same of selection theories. 
Nothing in this field could be more strained than the attempts of some Darwinian evolutionists to find usefulness in characters whose indifference is almost axiomatic. But the subject is a difficult one; Guyer's expressed attitude commends itself to all evolutionists: "Distrust of the earlier naïve belief in the wholesale inheritance of any or all modifications which might be acquired by the body was the necessary prelude to the later doctrine of germinal continuity which has proved to be such a remarkable incitant to research in the fields of embryology, cytology, and genetics. As an outcome of this research one important discovery has followed another until today we have before us in these several realms an imposing body of interrelated facts. But in our effort to root out the cruder Lamarckian heresies, is it not possible that we have been more zealous than our actual knowledge warrants?" 16 It is this very attitude of intelligent appreciation of difficulties and possibilities which is so greatly needed.

Certainly the original ideas of Lamarck were in part naïve, and just as certainly some of them are still without any evident basis in fact, but he worked half of a century before Darwin and was a pioneer in biological science, so we can hardly expect in his results the accuracy which we seek in modern biology. His idea of the inheritance of

${ }^{16}$ Proc. Am. Philos. Soc., Vol. LXII, p. 274, 1923. 
acquired characters has not been established by subsequent discoveries, and his assumption that necessity gives rise to suitable organs is logically untenable unless carefully interpreted. In order to exist, organisms must have everything necessary for existence. A new need may give rise to a new use for some organ already in existence, and so provide a stimulus for additional modification, but if it is need in the absolute sense it must be met at once and not by the development of a new organ.

Lamarck's first law, that use of an organ strengthens and develops it and that disuse weakens and diminishes it, is sufficiently established to be accepted without question. Darwin, no less than his illustrious predecessor, regarded use and disuse as a valid principle in evolution, as well as in the development of individuals, and repeatedly asserted it as a part of his evolutionary theory.

It is difficult to judge Lamarck's own expression of his theories fairly. There is more than a suggestion of truth in them, but the literal meaning of his statements is not one to inspire confidence. When the acceptable features are reduced to the simplest possible form we find in them the idea of use and disuse and the influence of environmental stimuli as the modifying factors in individuals and species. This view necessitates belief in some degree of inheritance of the effects produced in individual organisms. No one now credits the 
view that the full degree of an acquired character is inherited, but many scientists admit the possibility that the heritage may be somewhat modified through the influence of individual development. To this extent we may recognize in Lamarck's work a keen appreciation of natural processes, in spite of an admixture of wholly unscientific assumptions, and it is noteworthy that it is more effective than Darwin's work in accounting for the origin of changes in the organism. Lamarck's theory accounts for the origin of variations to the extent of referring them to a universal property of living matter, but fails to account for their perpetuation in the species; Darwinism accounts for the behavior of existing variations but fails completely to account for their origin. Thus the essential difficulty of evolutionary theory in general remains the association of individual development with the evolution of the species. The inheritance of acquired characters is, as I have said before, an objectionable term, but it indicates in familiar words the major problem of evolution.

The supporters of Lamarck's views have, in their theoretical work, devoted themselves to the formulation of hypotheses to meet this problem. Some have to do with particular phases of environmental influence, others are merely general hypotheses.

Cope's theory of kinetogenesis has long held a place in the literature of evolution. It assumes, in 
brief, that mechanical stresses exert a stimulating influence on the development of the skeletal parts involved. The repeated impact of the feet of cursorial animals on the ground, for example, is supposed to have led to the lengthening of the bones of the limbs. Bones have been shown to increase in size in response to such influences, but in other cases pressure has resulted in the local limitation of bone development, hence the theory seems to be a valid explanation of change in the skeleton as a result of mechanical stresses. It is, of course, subject to the same fundamental limitation as other Lamarckian theories in that it does not explain the cumulative action of the process through successive generations.

The more prominent hypotheses for the association of bodily responses with the hereditary mechanism are Darwin's pangenesis, ${ }^{17}$ Semon's mneme theory, ${ }^{18}$ and Rignano's centro-epigenesis. ${ }^{19}$ There is little use in a detailed criticism of these views. Their chief and common limitation is their use of elaborate and purely hypothetical mechanisms. Pangenesis is of only historical interest; the other two hypotheses are logical, but like all expressed views of this subject, they yield readily to the ${ }^{17}$ Animals and Plants under Domestication, Second Edition, Vol. II, Ch. XXVII, 1887.

${ }_{18}$ Die Mneme als erhaltendes Prinzip im Wechsel des Organischen Geschehens, 1904.

${ }^{19}$ Über die Vererbung erworbener Eigenschaften, Hypothese einer Zentroepigenese, 1907. 
recognized possibility of a chemical association between the body and the germinal tissues, which may impress individual responses on the heritage in some degree.

One of the most unfortunate of all tendencies growing out of opposition to the Lamarckian view of evolution is the evasive theory of parallel induction, the idea that an environmental stimulus may bring about a certain response in the body of an organism and at the same time act directly upon its germ plasm to produce a determiner for the hereditary transmission of the character. If such a peculiar association of factors were necessary, it would be as satisfactory a solution of the difficulty as any, for the desired end is not the establishment of any one theory but only the discovery of the facts. It can make no difference in results if the adjustment of species to the environment is effected by direct action of the environment on the germ plasm or by indirect action through the body. But germ cells and somatic cells are not the same. It is difficult to see how the same environmental influence, acting on somatic cells in one case and on germ cells in the other, could in one produce a given adaptation and in the other a determiner which would later produce the same adaptation without the intervention of the environmental stimulus. Such a situation would be much more difficult to understand than the simple 
reaction of the adaptation upon the germ cells produced in the same body.

Many experiments bearing on Lamarckian problems have been made and some of their results are interesting and suggestive, but they make possible only one conclusion: that further investigation is greatly to be desired. An excellent summary and discussion of many of these experiments has been published by Cunningham. ${ }^{20}$ With laudable care he notes the apparently positive results of these experiments and their serious weaknesses, and limits himself, an avowed Lamarckian, to the position that the Lamarckian view best explains evolution on a hypothetical basis. This is as much as can be said. Proof is lacking, but experiments have given results which point clearly to the need for more searching and more conclusive experiments in the future.

Out of the contributions of the past we derive little absolute knowledge of evolutionary processes. The various theories have served a valuable purpose in directing and stimulating scientific inquiry, but they provide only a partial explanation of evolution, and that on a theoretical basis at the best. Together they have led to the accumulation of a wealth of experimental evidence and observations bearing on this theoretical framework, from the sum of which we may draw useful conclusions

${ }^{20}$ Modern Biology, 1928. 
and map a sound course for future procedure, but the results establish no method of evolution to the exclusion of all others. We can scarcely doubt that the way of nature embraces many factors which are embodied in the various theories, hence we may add our remaining articles of faith: Given variation, it is probable that selective and isolating factors contribute to the breaking up of species and the formation of geographic races which are potential species. Hybridization may play a part in this reassortment of existing characters also. But when we attempt to account for the origin of variations we can only look to mutations or individual response to environment; here the dividing line is by no means clear. We need more knowledge, and we must turn to experiment for it. 


\section{VI \\ EVOLUTION IN NATURE}

Some biologists still find the idea of mutations, even with no attempt to explain the underlying cause, an adequate explanation of evolution. The occurrence of mutations and of the selective processes which may act upon them is too well established to cause any deep concern; even though the idea of evolution by such means demands a tremendous range of mutations and an almost equally great destruction involving the mutant individuals which fail to encounter a satisfactory environment or to receive an adequate heritage, we must admit the remote possibility that it points the way to some evolutionary change of positive adaptive value. So far as I am aware it would be difficult to predict adaptive value in the mutations which have been observed, but Muller points out in a recent article that the abundance of mutations in Drosophila meets one of these conditions, and further that most of these mutations are of a sort which would lead to destruction rather than to survival in the natural state. ${ }^{1}$ This obliging little fly gives abundant evidence of mutation and de-

${ }^{1}$ Scientific Monthly, Vol. XL (6), pp. 481-505, 1929. 
struction, but not yet of the appearance of useful changes.

Nevertheless we must grant the possibility that mutations of slight degree, even like those observed in Drosophila, may occasionally be of use under peculiar environmental conditions. The fact that survival value has not yet been associated with observed mutations is not in itself conclusive and our admission of possibility is no more unsound than the admission in the case of natural selection that slight variations may sometimes be of use to the individual. Indeed, since natural selection explains evolution beyond the existing characters of a species only when taken in conjunction with mutation, the two are essentially the same thing. When we arrive at this point in our analysis, only one thing remains to be done; we must explain the occurrence of mutations.

We now have absolute evidence on this point. $\mathrm{X}$-rays are capable of effecting a change in the arrangement of inorganic compounds, as in the photographic plate, and the success of geneticists in producing mutations by the same agency is apparently due to the same type of action. Why should not the chemical organization of the gene, relatively stable though it is, be altered by forces capable of penetrating all of the defenses which shield it from the outer world?

The favorable acceptance of mutations produced 
by $\mathrm{X}$-rays and other forms of radiation has been based hitherto on the satisfaction arising from the experimental production of heritable characters. Unfortunately another point of view is possible which is much less favorable to the current evaluation of these changes. We have considered among the results of environmental factors acting on the organism two classes of effects, viz., mechanical modifications such as mutilations and the shaping of the skull by restriction during infancy, and modifications due to a functional response of the organism to the conditions surrounding it. X-rays are a distinctly environmental factor; to which class of characters do their effects belong? It is possible, of course, to regard a chemical reorganization as response, but the nature of $\mathrm{X}$-ray actions in general suggests very strongly that here is a modification of the other type, a condition forced upon the organism regardless of its functional powers. Certainly some genes may be less susceptible than others to the rays, but this variation is not necessarily a matter of function in the biological sense. The attitude that $\mathrm{X}$-ray mutations are actually a result of damage to the genes has much to recommend it. Since these rays penetrate all defenses of the chromosomes and act upon them directly, they cannot fail to leave their impress upon the heritage if they cause any change at all, and their action may be so delicate that the gene is not destroyed, 
but only modified beyond its former limits of activity. The demonstrated effects of alcoholism in a parental generation upon the heredity of the descendants has been flouted on the ground that alcohol may actually reach and injure the germinal tissues. Is the difference between these two cases as great as the present attitude of geneticists would have us believe? If the action of $\mathrm{X}$-rays on genes is similar to their demonstrated action on inorganic substances, then certainly it is on a par with other modifications forced upon the organism by the environment, even though it occurs on such a small scale that the result may be only a slight modification of the previous expression of the gene.

Returning to the paper cited above, we are told that a comprehensive series of breeding experiments to determine the effects of other external factors on the fruit fly has failed to demonstrate a significant response in the production of mutations. Two alternatives present themselves: We may conclude either that mutations do occur in response to fluctuations occurring in some phase of the normal environment and that we have merely failed to accomplish this result experimentally, or that mutations are always the result of penetrating rays which reach the chromosomes and act upon them directly. The latter view puts a terrible burden on rays and a greater one on our credulity. Considering the fact that the existence of the 
organism is so closely linked with a great array of environmental conditions, any attempt to explain its evolution as the result, primarily, of a single one, partakes too strongly of the limitations which have hitherto characterized evolutionary theories.

It is doubtful that any thoughtful biologist would choose to defend a narrow view, but the implications which this situation suggests to me have been quite generally neglected. Indeed, I know of less than a dozen writers who have ably and persistently maintained a broad attitude toward the problem of evolutionary change. Unless all permanent modification of the heritage is due to radiation it must be associated with other environmental factors, in the sense that the chromosomes change in response to conditions surrounding them in the body which are directly or indirectly associated, in turn, with conditions in the external environment. This conclusion follows logically from our knowledge of natural phenomena. Given identical heritages, or identical genes if you prefer, and identical environments for them, and we can expect only identical results. The environment fluctuates, not spontaneously but as a result of the complex interaction of natural forces, hence the expression of the heritage must always differ as it responds to various conditions of the environment. Therefore a change in a gene must follow from some change in the complex 
environment which either stimulates it to a new response or forces upon it a change of structure. In addition the change must fall in one of two classes, it must be either adaptive or incidental, related in the future activity of the individual to the stimulus producing it or merely a product of that stimulus acting with the previously existing heritage. Unless we consider these possibilities we have failed to recognize all of the factors in the problem of evolution.

Again, granting that change may be brought about in genes as a response to environmental conditions, are the characters so produced to be regarded as mutations? The concept of mutation, or saltation, was originally that of a sudden change of considerable degree. Gradually it has been revised to include slighter and slighter degrees of modification until Sumner, in a very able discussion of the problem, is able to write as follows: "Mutation, according to current usage, is nothing more than hereditary variation regardless of magnitude. It may be defined as hereditary (transmissible) modification of the germinal substance; conversely, any modification of the germinal substance, however produced, would by definition be a mutation." 2

We have already considered a mutation in Drosophila whose appearance was governed by

${ }^{2}$ Scientific Monthly, Vol. XL (1), 1929. 
environmental conditions, and according to our expressed interpretation of the organism the appearance of all characters must, in some degree, be governed by the environment. The mere fact that conditions which permit the existence of the organism normally permit the development of all hereditary characters does not contradict this point, hence we are brought very close to a union of the idea of environmental modification of living things and the idea of mutation. ${ }^{3}$

Several years ago I analyzed the "acquired characters" of the literature and pointed out that all significant cases involved the response of a hereditary factor as well as the occurrence of an environmental stimulus. ${ }^{4}$ The distinction between slight variations in the expression of a character as a given heritage responds to fluctuations of environment and the appearance of a mutation, or its failure to appear, according to environmental conditions, seems very tenuous. It is evident that many discussions of this point in evolution fail to strike at the heart of the problem.

With these matters in mind it is profitable to consider the ways in which evolution, as we see its results in the natural world, may have taken place. Thus we may apply the facts drawn from experi-

${ }^{3}$ Cunningham, J. T., Modern Biology, Ch. V, 1928, criticizes this interpretation of the environmental factors in normal development as expressed by Goodrich.

${ }^{4}$ Am. Nat., Vol. LXI, pp. 251-265, 1927. 
ment and observation more accurately to the conditions prevailing in nature.

Evolution is a process of change, therefore we must start with a homogeneous stock if we are to explain it satisfactorily. We may not even admit the normal hereditary complex of a single species like those of the present as a point of departure if we are to consider the full meaning of evolution, for the diversity of characters within the species is as much a product of evolutionary processes as the variety of species now inhabiting the world. A few factors only must provide our materials. As a natural property of living things, our hypothetical organisms will reproduce, even to such an extent that their initial home will be overcrowded. They will migrate, or be gradually dispersed by other means. Finally the conditions under which they live will fluctuate through forces over which living things have no control and of whose ultimate causes man himself knows nothing as yet. All of the fluctuations of environment which we have considered may impinge upon our homogeneous stock as a result of these fundamental causes. They may be subjected to variations of temperature, of moisture, of food, of light, of cosmic rays, of mechanical contacts, of acidity, and of many other things.

At the outset natural rays acting on the similar materials of many individuals may bring about 
heritable diversity of the originally uniform heritage and may pave the way for the establishment of various pure lines and for the operation of the principles of hybridization and selection. We have granted the possibility that some of these mutations may be of use to the individual, while noting that experimental evidence fails to support this possibility. Certainly while the environment remains fairly constant the modification of species by selection among these mutations must be at a minimum.

It is inconceivable, however, that the environment would remain even approximately constant for all individuals. Even though it may be so within the area occupied by the original stock, future generations must be forced out of this area through the natural expansion of the group or the natural means of dispersal. In various regions they must encounter changed conditions. These conditions must be met by some reorganization of their vital processes. They are able to respond to the conditions governing their existence in various degrees, and so the individuals which encounter more and brighter sunlight at lower latitudes, or low pressure at high altitudes, or a different food supply in a new region, will develop and behave differently from their ancestors. It probably makes little difference to a coyote whether it eats rabbit or gopher, but the technique of hunting the two ani- 
mals must be very different; in one case speed is valuable but in the other the ability to stalk cleverly and to spring quickly must be much more useful. Prey which depends on speed for safety cannot readily be stalked, and prey which is never far from an open burrow can scarcely be lured into a race for its life.

Obviously, if new conditions descend upon the home of a species as a result of physical conditions, or if some individuals migrate permanently to a region where a different environment prevails, any adjustment which the individual may make to the environment will be made by all individuals, generation after generation, and will appear as surely as any character in the hereditary complex. As long as the condition prevails, the adjustment is present and the visible results are characteristic of the species. To what extent are the minor taxonomic units of the present due to such responses? It has been suggested that geographic races develop in this way, ${ }^{5}$ and it is certain that many of them may do so. Jordan's observations on the Loch Leven trout support this conclusion perfectly. ${ }^{6}$ Loch Leven trout were planted in the waters of Alder Creek in Yosemite National Park in 1896. In 1905 Captain Benson, superintendent of the park, took "some fifty-four fishes" from this

${ }^{5}$ Rensch, B., Das Prinzip geographischer Rassenkreise und das Problem der Artbildung, Berlin, 1929.

6 Science N. S., Vol. XXII, pp. 714-715, 1905. 
creek, "but to his surprise and dismay he found them corresponding exactly to the markings of the English brook trout." Jordan cites further instances as follows: "Dr. Day speaks of the Loch Leven trout as changing into ordinary brook trout, when planted in streams of Gloucester or Guildford, the colors of the Loch Leven trout being seen on exceptionally well fed individuals only. In Australia, according to Day, fine examples of the Great Lake trout, Salmo ferox, weighing twenty pounds, have been reared from eggs of Salmo fario [English brook trout], taken in Hampshire and Buckingham." Here we see that actual species of the accepted classification, not mere geographic races, owe their differences to the conditions under which they live.

In contrast with the case of the trout, Sumner has found that the subspecies of California deermice (Peromyscus maniculatus), are germinally fixed, regardless of the conditions under which they are reared. ${ }^{7}$ Mice of the subspecies rubidus, sonoriensis, and gambeli, from Eureka, the Mohave Desert, and Berkeley and La Jolla, respectively, were studied for correlation of their characters with the conditions of their environments, and later specimens of sonoriensis were reared at Berkeley. "Neither the originally introduced animals nor their offspring, nor their grandchildren, have thus far ${ }^{7}$ Am. Nat., Vol. XLIX, pp. 688-701, 1915. 
shown any perceptible approach to the local type. They are still obviously of the sonoriensis race." 8 Sumner's results in this and in other papers ${ }^{9}$ on the same subject show great care in the evaluation of results and a clear appreciation of their true significance. His published results may be taken as fairly sound evidence that geographic races, or subspecies, may be germinally stable. The only doubtful factor is time; it is conceivable that a long succession might show responses which are not attained in a few generations. But this, after all, is only a possibility which must be taken into account for the sake of accuracy. The experiments cited covered a period of eight years.

What do these differences indicate? First they show that characters may exist in nature generation after generation without being permanent to the same degree as strictly heritable characters. They illustrate very clearly the point that characters may be definitely a product of a particular environment without fitting the individual to meet the conditions which produce them, since in the species mentioned, the distinctive characters are superficial. They suggest two possibilities as to the origin of permanent characters, one that they are based on mutations as ordinarily interpreted and the other that they are the ontogenetic characters, or individual responses, developed

${ }^{8}$ Op. cit., p. 697.

${ }^{9}$ Am. Nat., Vol. LVIII, pp. 481-505, 1924. 
gradually to a condition of independence from the fluctuations of the environment. And as an important point, they show that the species and subspecific units of our present classification are not always based on characters which are hereditary in the usual sense, but may sometimes be produced in part by specific conditions of the external environment.

When we seek evidence concerning the possible inheritance of some effect of individual response to environment we find that it is meager, although many experiments have been conducted and a few have given positive results of some degree. The experiments of Guyer and Smith on cytolysins in the production of eye defects in rabbits are too well known to need detailed mention. They are interesting, and in spite of the skepticism of some writers it seems to me that they have an important significance, but they appeal to me much less than experiments which have to do with responses to conditions which might very well occur in a natural environment. Among the latter a number deserve consideration.

Woltereck subjected lots of Daphnia to overfeeding, and noted as a result the development of higher heads. ${ }^{10}$ When the animals were returned to normal surroundings after the first appearance of the modification their offspring were normal.

${ }^{10}$ Verh. d. Deutsch. Zool. Gesell., 1909, pp. 110-172.. 
When overfeeding was continued for several months, individuals returned to a normal environment produced offspring in which the character was evident, although it disappeared in the course of a few generations. When the treatment was continued for two years, the enlargement of the helmet failed to disappear within the duration of the experiment even though the animals were kept under natural conditions. Woltereck shows that other factors than food, including temperature, bear upon the same type of modification through their effect on the rate of metabolism and the consequent degree of nourishment attained by individuals in a given environment. His work was so carefully safeguarded with respect to the uniformity of the heritage in his experimental stock and the possible interpretation of his results that it furnishes one of the finest, if not the finest, available study of this nature.

Sumner found that white mice reared at temperatures from $20^{\circ}$ to $30^{\circ} \mathrm{C}$. developed longer bodies, tails, ears, and hind feet than individuals reared at normal temperatures. ${ }^{11}$ When the modified mice were removed to cooler rooms and bred under normal conditions their offspring still showed the departure from normal, although in a lessened degree. ${ }^{12}$ The percentages were recorded as fol-

${ }^{11}$ Jn. Exp. Zool., Vol. VII, pp. 97-155, 1909.

${ }_{12}$ Arch. für Ent.-Mech. der Org., pp. 317-348, 1910. 
lows: The difference in length of tail between normal stock and young reared at normal temperatures from treated stock was thirteen per cent of the difference between the treated parents and the normal stock; in foot length the difference was twenty-six per cent; in ear, sixty-three per cent. Simultaneously with the publication of these figures Sumner suggested: "It might be argued that the very plasticity of a part, which makes it so responsive to outside influences, might render it correspondingly ill adapted to retaining such impressions permanently. Such speculations are decidedly premature, however." 13 Regardless of its standing as a conclusion from experimental evidence, such an interpretation is logical; the results are of the kind which might well be predicted of the responses of plastic structures to environmental influences. A valuable feature of these experiments is the fact that the mouse, a mammal, maintains a constant temperature, hence any suggestion of parallel induction must be abandoned.

Agar worked with Simocephalus vetulus, a phyllopod crustacean, recording the ratio of total length of newborn individuals to the width between the ventral edges of the valves of the carapace. ${ }^{14}$ When fed certain foods, the valves rolled back,

${ }^{13}$ Am. Nat., Vol. XLIV, pp. 5-18, 1910.

${ }^{14}$ Proc. Roy. Soc. Lond., Vol. 86B, pp. 115-116, 1913. 
increasing the width as thus measured. He also found that increase of temperature caused a lessening of length. When the animals were fed the experimental food for a single generation and then returned to a normal medium their young showed the acquired character strongly marked but in later generations it returned rapidly to normal. These results were based on about three thousand parthenogenetic descendants of one female, hence there can be no suggestion of Mendelian inheritance in them.

Finally, in plants, Bolley, working with wilt resistance in flax, stated the following conclusions: "Our results indicate no other conclusion than that wilt resistance may be accumulated rather rapidly by a non-resistant strain or variety and that, when it is thus accumulated, it is transmitted from generation to generation through seed; and, further, that when once obtained to a certain degree, it can be fixed through artificial crossing." 15

These experiments are not accepted generally as proof of the inheritance of acquired characters. The characters with which they deal were not established permanently so that they would appear through an indefinite succession of generations without the influence of the initial stimulus. Nevertheless they have this significance, that the individuals of our hypothetical homogeneous stock ${ }^{15}$ Science N. S., Vol. LXVI, pp. 301-302, 1927. 
which encounter a permanent change of environment may very well develop new characters which will appear generation after generation in spite of fluctuations in, or the occasional failure of, the inciting stimulus.

The possibility of these characters becoming so definitely established that they must appear in every generation involves the question of the initial external environmental stimulus being supplanted by an internal condition which would normally produce the character independently of external conditions. Can such a change occur? So far it has not been proved possible. Logically the possibility exists, but the lack of significant evidence makes it desirable to consider the matter elsewhere.

Once the heritage of the hypothetical stock has acquired diversity, whatever the cause, all of the processes of selection may be operative in some degree to break it up into different groups, but as we have already noted, these processes account only for the manipulation of existing things and not for the origin of new characters.

Preadaptation no doubt plays a considerable part in the adjustment of organisms to new conditions, either in their original area or in newly invaded territory. Many structures are capable of serving an organism in several ways and it is inconceivable that they should fail to serve it in any 
way favored by the environment. The preserving and destroying activities of natural selection and other selective processes are important in accomplishing slight degrees of differentiation within the species; they are, in fact, adaptive processes in their relation to species, whereby the adaptive processes of individual life are supplemented for the provision of the best available equipment at birth to the offspring of each surviving individual. But they do not provide for absolute departure from the existing state of development. Neither does preadaptation, to be sure, but it has an advantage in that it brings new stimuli to bear on old structures.

Assuming that our hypothetical species spreads in all directions, we may trace its development according to the several possibilities. To the north it may encounter low temperatures and as a result may develop smaller appendages, like Sumner's mice. To the west it may be forced to diverge in order to find favorable surroundings on opposite sides of a high mountain range. Here isolation may play a part in establishing northern and southern races if the divergent lines receive initially different heritages, without any other factor intervening to change the species. And to the south the species might well work its way gradually into warmer and warmer regions. The abundance of competing forms might cause it to seek an easier 
mode of life. Sharp claws which had served it for climbing might be turned to account for aggression or for burrowing, and it might well take on special food habits without passing the limits of the wider range of diet of the stock from which it sprang.

Are there such cases in nature? Ruthven regards the scutellation of the garter snakes as an indication of probable association with varying environmental stimuli as these reptiles spread from their center of origin in Mexico. ${ }^{16}$ Certainly his description of the group indicates a close parallel between transition of structure and transition of environment, even though the direct relationship of the two is not brought out. Borodin speaks of the "slow modification in the structure of the organisms under the influence of changed life conditions" in discussing the herrings (Clupea) of the Black and Caspian seas and Tscharchal Lake. ${ }^{17}$ According to his conclusions the Tscharchal Lake form cannot have been more than 20,000 years in developing. Again he fails to establish the association of environmental conditions directly with the characters of the fishes; he applies Osborn's idea of speciation to the problem, with naturally vague results. Moore shows that the fauna of Lake Tanganyika has distinct affinities with the marine fauna and that the lake was once connected with

${ }^{16}$ Bull. 61, U. S. N. M., 1908.

${ }^{17}$ Am. Nat., Vol. LXI, pp. 266-271, 1927. 
the ocean. ${ }^{18}$ His evidence is a masterly illustration of the isolation principle, even though it goes no further. And finally Schwarz's study of the Mona monkeys is one of the finest expositions of the diversification of animal species that I have read. He shows the occurrence of subspecies separated by natural barriers, the existence of varying degrees of diversity among the several divisions recognized, and in some cases even the overlapping of subspecies which have become too different to interbreed, although they now occupy the same areas. ${ }^{19}$ Rensch's work on geographic variation is an extensive treatment of the subject which describes numerous examples of a similar kind. ${ }^{20}$

Unfortunately mere observation of natural conditions does not show how the conditions arose. Organs may be associated with environmental conditions to which they are not due. Whether mutation, natural selection, isolation, preadaptation, or individual adaptation, has been the cause of a given condition we must often be unable to determine, although the few experiments cited and the many observations on record suggest the cooperation of all of these factors in bringing the population of the world to its present state. Even the close coincidence of graded series of variations

${ }^{18}$ The Tanganyika Problem, 1903.

${ }^{19}$ Schwarz, Zeitschr. f. indukt. Abst. u. Vererbungsl., 1928, Suppl. Bd. II, 1299-1399.

${ }^{20} \mathrm{Op}$. cit. 
with graded environmental conditions is not necessarily an indication of cause and effect; as Cockerell has pointed out, such a condition might very well arise from the separate formation and later overlapping of interbreeding forms. ${ }^{21}$ We may turn to nature only for materials and suggestions. If we would associate phenomena accurately with their causes we must see them as they occur, and for this we must turn to experimentation.

Since the theories of evolutionary method and their association with observations of living organisms are an incomplete picture of evolution, it is necessary for us to pick out their most useful disclosures, the most significant probabilities of evolution which they make evident, and to associate these things with such evolutionary series as we know in order to determine the most probable general conditions of the process.

As to source of variations, we admit mutations, but the modern use of the term has brought it to a point where any change affecting the germinal chromosomes must be regarded as a mutation. We have associated mutations with factors of the external environment, both in the direct action of rays on the chromosomes and in the development of known mutant characters in response to environmental conditions. A number of scientists have demonstrated beyond reasonable doubt the ${ }^{21}$ Science N. S., Vol. XXIII, pp. 145-146, 1906. 
possibility of so-called acquired characters being transmitted in some degree from generation to generation. This remains the most conspicuous controversial point, but it is certainly amenable to laboratory investigation.

Out of all of these facts we find that the mutation theory has failed to establish one of its early postulates, that new species arise suddenly by saltation, just as the Lamarckian theory has failed to establish the original laws of Lamarck. Indeed, the available evidence is definitely contradictory in both cases. Both views support the idea of gradual change. Both recognize the close association of environment and heritage in the establishment of species. The difference between them practically disappears save that they cling to the ideas, respectively, of random variation acted upon by selective forces and of a definite and direct adjastment of the species through the lives of its component individuals to the conditions of environment.

The nearest that we can come to the actual process of past evolution in nature is in the field of palaeontology. The evidence is fragmentary. Only here and there are series complete enough to yield satisfying tales of long-continued change. But the length of time covered by scientific observation of living creatures is so short in proportion to the periods obviously necessary for the consummation 
of reasonably great degrees of evolution that we must turn to these faulty records for illustrations of the evolution of species. In spite of their incompleteness, the materials of palaeontology afford a number of significant facts concerning evolutionary processes. In such phylogenetic series as the oft-cited horses, elephants, and camels, the cephalopods, and the series of greater taxonomic scope and consequent poverty of detail, two facts stand out with striking clarity. First, evolution has taken place in connection with gradually changing environments, and second, it has been accomplished by gradual change of the organisms involved. These facts are quite in harmony with the conclusions already cited from theoretical interpretation of conditions among existing organisms. Together they furnish justification little short of actual proof for this interpretation of evolutionary processes, and a majority of biologists will be found to concur in this interpretation.

Another consideration which arises from the entire field of evidence is the relationship of new characters to the preëxisting organic complex. We speak of them commonly as if they appeared suddenly in a fully developed state, or as an absolute departure from preëxisting conditions, during the course of phylogeny. This is only a matter of expression; we must deal with the origin of characters as we deal with the origin of species, even while 
recognizing that they are not sharply limited in time if our concepts of evolution are sound. Every character must have a beginning, but it must have its beginning in preëxisting structures. Novelty in organisms can only be a modification of familiar things.

We trace the one-toed foot of the horse back to a four-toed condition in ancestral species. It still carries the vestigial metacarpals of two other digits and the series of fossil remains connects these vestiges with functional toes of various degrees of development in a gradually receding series of extinct forms. And in the most remote known ancestor the fifth toe is present in a vestigial state. Given the pentadactyl appendage as a primitive character of the terrestrial vertebrates, we find its predecessors in the paired fins of the Crossopterygii. The fins seem to establish an abrupt departure, but there is rather good evidence for their association with the fin folds of the Cephalochordata, and when we have arrived at this simple beginning we are very near to the unmodified body wall. Skeletal structures present a like sequence in the vertebrates; bone, bone and cartilage, and cartilage alone, establish a transition in the phylogeny of the skull, and all of these stages depend ultimately upon the plastic mesenchyme. Such sequences are also established in ontogeny, and without regard to an individual's attitude to the 
recapitulation theory, he cannot fail to admit that a sequence which actually occurs in ontogeny must at least be possible in phylogeny.

One thing disturbs the perfection of this gradual series. However clear the succession of major structures may be, the microscopic cells producing them present a discontinuity. Bone cells have peculiar properties of their own, as also do cartilage cells and those of the various other types of connective tissues. A sharp division of the cells of the neural tube into nerve cells and neuroglia occurs during embryonic life. But these diverse elements may be traced to common predecessors also. The apparent abruptness of their separation is probably due to incomplete understanding of the minute details of structure and functions, and on the purely logical grounds of our interpretation of the organism they cannot fail to express potentialities of preëxisting units. They do not present a linear series such as may be traced in the phylogenetic history of a single structure, but rather correspond with the divergent products of a single ancestral form. They are not comparable with the foot of the horse and its predecessors, but with all vertebrate appendages, derived from the primitive pentadactyl source.

The development of discrete structures is somewhat closer to the appearance of new characters, but even these are merely the product of preëxisting 
materials and potentialities. Bones are distinct entities, intricately associated with the surrounding tissues, but they occasionally develop in situations where their appearance is not usual and so demonstrate the truth of this assertion. Sesamoid bones are a fairly common case in point. Less normal are cases of reversion, such as the development of one of the normally absent toes of the horse, ${ }^{22}$ and abnormal development of joints as a result of fracture, in place of normal healing. Everything in the organism, in short, is a resultant of something which has preceded it, both ontogenetically and phylogenetically, whether or not its history in the two fields corresponds in detail.

The whole idea is nothing more than the very logical deduction from past knowledge of evolution which has gained eager attention within the past decade under the title of emergent evolution. This doctrine, advanced as new in recent years but in reality only a clear expression of old truths, is based on the conclusion that the attainment of one step in evolution makes possible entirely new steps. To the extent that emergent evolution confines itself to this assertion it is not only sound but simple. When we add the statement that later developments are not an expression merely of the properties of their components in a simpler dis-

${ }^{22}$ Boas, J. E. V., Zool. Jahrb. Alt. f. Anat. u. Ont. der Tiere, Vol. XL, pp. 49-104, 1917; Vol. LI (2), pp. 313-322, 1929. 
sociated state, the idea requires interpretation. Is it permissible to say that water has properties which are not an expression of the properties of oxygen and hydrogen as elements? Obviously, for the one is a liquid while the others are gases at normal temperatures. The compound has altogether different physical properties in other ways as well. But we cannot say that water is not an expression of the potentialities of the two elements. We have merely introduced relationship between the two and association with environmental conditions as an additional source of stimulus to bring about the expression of otherwise latent possibilities, a situation wholly similar to that which obtains in the organism. Hydrogen may not express its share of water-forming power save in the presence of oxygen, and vice versa. Even though mixed the two do not become water unless the proper external conditions prevail. Yet if the power to produce the properties of water is not inherent in hydrogen and oxygen, then certainly the union represented by $\mathrm{H}_{2} \mathrm{O}$ may sometimes give different results-an obvious absurdity. It is impossible even with the aid of emergent evolution to discard the fact that the characteristics of an organism are resultants of its components and the conditions under which it exists.

Morgan's distinction between emergents and resultants is philosophically a nice bit of reasoning, 
but biologically it has less value. The idea that a thing may be new in the sense that it has never before occurred or existed is thoroughly valid, and such a thing may be soundly termed emergent. But as Turner has pointed out, things may be resultant and emergent simultaneously. ${ }^{23}$ If a phenomenon has occurred before it lacks novelty and hence is merely resultant, but in the field of biology an emergent must certainly be looked upon as a resultant, and for our present purposes the latter consideration is the more important.

If, then, absolute novelty does not appear in existing organisms save as the realization of hitherto latent possibilities, what are the relative merits of individual response to environment and mutation plus selection as judged by their harmony with the known facts? Does the one rest on sound and complete foundations while the other is fundamentally lacking? Has the one been proved a source of new species while the efficacy of the other in this respect is disproved? An unbiased answer to these questions shows very clearly how uncertain our knowledge of evolutionary method is, even yet.

Mutations in laboratory organisms are of several kinds. The actual loss of a portion of a chromosome may occur, bringing about the loss of some character in the organism. Translocations may ${ }^{23}$ Nature, Vol. 120, pp. 261-262, 1927. 
result in a multiplication of portions of chromosomes, or chromosome numbers may be multiplied, or individual genes may undergo change. All of these things result in mutations, or in characters which are different from the preëxisting state, but they are no more than a modification or a loss. The idea has been seriously advanced that evolution is due to mutant losses, but it has received little support and is apparently worthy of no more. Losses have played their part, but like all other limited factors, they cannot be extended to explain the whole process of evolution.

One possibility suggests itself as an explanation of mutation by the addition of new things, viz., that the variation of association in the individual between heritage and environment may sometimes bring about conditions which enable the genes themselves to change. Guyer has cited a very interesting chemical action which illustrates this possibility. ". . . when hydrochloric acid is passed into an alcoholic solution of hydrocyanic acid, provided there are sufficient quantities of these three ingredients, five definite crystalline endproducts of their interaction result. First the hydrochloric and hydrocyanic acids combine to form amidoformyl-chloride, which then adds another molecule of hydrocyanic acid. This product next reacts with one molecule of alcohol which to this point has been inactive. The result is what 
we may call end-product one. Then end-products two, three, and four, respectively, are formed by the successive additions of a single molecule of alcohol to separate molecules of a part of the immediately preceding end-products. The fifth endproduct is not so directly related to the others. It is elaborated chiefly through the interaction of hydrocyanic acid and water, but this interaction cannot take place until water is released through dehydration of some of the other compounds. There is little doubt that such sequential reactions as these may be taken as simple models of what goes on on a tremendous scale in the developing germ cell." ${ }_{24}$ I include Guyer's conclusion in order that his use of the illustration may not be misunderstood. The same sequence is an equally valuable illustration of contingent reaction as it may occur during the formation of the gametes in the parental body. Even recognizing the many safeguards which tend to maintain the genes unmodified from generation to generation, a chemical basis for their qualities must exist, and any such basis must be susceptible to change if the proper conditions reach it.

But this brings us again very close to the possible action of individual responses. If a given condition of environment should prevail for a long period of time, admittedly all individuals of a

${ }^{24}$ Am. Nat., Vol. XLV, p. 285, 1911. 
given heritage would show any characters which this environment could bring out. The modification of the body would certainly subject the germinal tissues to a change of environment through this continued individual response of successive generations. We may say that any resulting change in the heritage is a mutation because it is directly due to conditions limited to the body, but we gain little by doing so, for again we are concerned with the response of living substance to the conditions surrounding it, and the chain of environmental relationships always involves both external and internal factors.

The possibility also exists that the effect of individual responses in the body is only quantitative. If so, have we any reason to expect qualitative changes to result? Unfortunately no definite conclusion is indicated here, but quantity is difference of a kind and may provide for unexpected contingent actions. Le Dantec regards the variations due to individual response in this light, and traces quantitative change to a point where the complete elimination of one or another component may bring about a definitely qualitative result. ${ }^{25}$ And the formation of $\mathrm{CO}$ and $\mathrm{CO}_{2}$ may depend entirely on the amount of oxygen available. Indeed, the two gases are quantitatively different in a sense, but they are also qualitatively different in many ordi${ }^{25}$ Évolution individuelle et hérédité, 1898. 
nary relationships. It is no less probable that quantitative changes in an organism may lead ultimately to conditions in the organism which enable it to take advantage of additional possibilities of the environment, and thus to truly qualitative change.

We are also forced to consider whether changes of any type can be indefinitely cumulative. The best answer from the point of view of evolution is that cumulative change is very common in the long phylogenetic series of fossil remains and that it is evident in individual responses.

There is a degree of speculation in all of these points, but they serve the valuable purpose of indicating how gradual is the transition between apparently different concepts. When we consider them, it is less easy to trust the common idea of mutations. Even new characters take on a meaning entirely different from the direct implication of the word new, and the imperceptible gradation which must be a prominent feature of evolutionary processes stands out in its true perspective.

Through this as through other approaches we arrive ultimately at the same point. No existing interpretation of evolutionary processes is an adequate explanation. Some are wholly satisfactory as partial interpretations of things which have been observed in nature and in the laboratory, but even the association of these valid partial explanations does not provide a sound and satisfying 
explanation of all evolution. Mutation as a result of the action of rays on the genes, followed by natural selection of an inconceivable extent, provides an explanation which is logically tenable if one's mental processes are sufficiently elastic to encompass it without serious distortion. To my mind, and I advance this entirely as a personal view, the idea demands too much credulity. The close parallel between the adaptive processes in individuals and the adaptations evident in species suggests too strongly that adaptation of species is not wholly haphazard at the outset, that it does not depend wholly upon random mutations, but that it is a part of the astonishing plasticity of the living substance which, in spite of its tendency to retain its fixed characteristics, has displayed such versatility in meeting the conditions available over the world.

One cannot accept this view without admitting the possible truth of Devaux's conclusion that evolution is now at a low ebb and that, at one time, living matter was in such a plastic state that many species were formed as the many available habitats on the sparsely populated earth were invaded. ${ }^{26}$ This possibility, however, only complicates our problem. If evolution is now at a low ebb, it will be more difficult to demonstrate the method of its progress. We need not expect that method to be ${ }^{26}$ Rev. gen. sci. pures et appl., 39 (10), pp. 299-306, 1928. 
different from the method of past evolution, but we cannot expect to find it easily nor to disclose it as a simple process.

After admitting the efficacy of selection, of preadaptation, and of isolation in the development of taxonomic units of specific degree or less through the differential assortment of existing characters, and the possible occurrence of new species through mutations of large degree, the remainder of the problem narrows down again to the association of individual adaptations with the species. Of the details of the association I can say no more than I have already written. In the end it is still a matter of speculation, of probabilities, and the most valuable step now to be taken is the search for an effective method of investigation in the light of the successes and failures of the past. 


\section{VII}

\section{THE ORGANIC TENDENCY}

According to the available facts of biology there are no organic characters of evolutionary significance which may be called the product of heritage or of environment exclusively. The vast majority of characters may be interpreted as the result of distinctive hereditary substance responding to distinctive environmental conditions. The idea that the individual inherits an adequate environment as well as the organic foundations for its development is partly true; the activities of its parents certainly tend to produce it under favorable conditions in every group of organisms, and among the animals which exercise some degree of parental care this guaranty is extended more or less into the otherwise independent life of the young. It is difficult to determine the extent to which we are justified in considering these facts, or obliged to consider them, as factors in evolution. We cannot avoid the conviction that in our own lives parental care and the favorable environment provided by our social organization are potent forces in the future of mankind. They must, therefore, be considered in the broader aspects of evolution, although 
they are not necessarily a source of deep concern in the problem before us.

At the outset of its individual existence the body of the organism takes over the control of its environment in some degree. It has been guaranteed the attainment of autonomy, barring accidents, by the actions of its parents; it may be guaranteed a certain amount of protection and training during the more vulnerable period of its infancy; but its own body thereafter provides properly for the gradual consummation of the remaining steps in its development and adult life. It is still subject to external and internal influences which lead to modification, but it is self-determinative within certain limits. In this condition all of the factors in organic existence are realized. Heritage, internal environment, and the physical and organic factors of external environment, are all operative in shaping the course and development of the individual. Nothing which appears in it during its normal life can be separated from the heritage; none of its characters can fail to involve factors in the internal environment; and none can be without a fundamental association, direct or indirect, with the conditions which the organism encounters in the world about it.

The concept of the origin of life which follows inevitably from the physico-chemical interpretation of the organism and from modern evolution is 
the most striking point of emphasis upon the environment as a factor in evolution, for it leaves us no alternative to the acceptance of the environment as the primary reality and the primordial living substance as the result of a favorable juxtaposition of materials under a peculiar complex of conditions. In the recognition of a certain degree of self-determination as essential to the preservation of living things from the destructive forces of a fluctuating environment we have the beginning of heritage. To say that heritage has been responsible for all evolution is a denial of its probable origin. To say that it is now the source of all evolutionary change in living things is a recognition of the control which it has wrested from the environment, the degree of self-adjustment which it has attained, but at the same time this attitude is a failure to give due recognition to the part which the environment continues to play. While there is the slightest residuum of dependence upon the environment, and this must always be, environment is a factor which must be considered in all organic phenomena.

The past evolution of living things presents a series of phenomena which are strongly suggestive of pure opportunism. In the origin of life, at the outset, our hypotheses leave us only the one logical explanation which has just been mentioned. As we ascend the scale of known phylogenetic series a 
similar opportunism is manifest. The ancient Crossopterygii could live out of the water, and outside of the shrinking streams they found less severe competition with other creatures. Moreover the shrinkage of the hydrosphere left greater opportunity for life in the transitional zone and so placed a premium on their utilization of their capacity for semiterrestrial life. The arboreal ancestors of man could live on the ground and so were not forced to retreat with the tropical forests in order to maintain themselves. In every known case of evolution, the capacity for life under new conditions has been present and the new conditions have become available. The one factor is as necessary as the other, and their coincidence establishes an opportunity which has, apparently, seldom been refused.

Non-adaptive characters are no less a result of opportunity in the sense that inherent possibilities and favorable circumstances are necessary to the production of any organic entity. The colors of butterflies' wings are due to hereditary factors, including the ability of the body to form the necessary pigments in the case of pigmental colors, but in the wet- and dry-season forms previously mentioned we see that the external environment may also play a direct part in the production of a given color or pattern. The factors of heritage and internal environment have certain potentialities; 
their expression depends on the opportunity extended by the external environment.

So it is with the other fluctuating characters. An organism, according to the theory of natural selection, may be adapted to a given mode of life but competition forces it to use other inherent possibilities and to change its habits, or to perish. Even the normally inherited characters develop according to the opportunity given to the normal heritage by the developing body. A normal mental heritage in man finds expression in the internal environment provided partly by a normal thyroid gland, but the thyroid cannot function normally if the external environment does not provide enough iodine.

The astonishing uniformity of a species through many generations is a tribute to the fact that the environment has provided it with adequate opportunity. The living substance has been able gradually to appropriate new things from its environment, to build from them a heritage of ever-increasing complexity, and at every step to make the consummation of its normal life a little more certain and a little more independent of fluctuating external conditions. With each step new possibilities have been realized, as the doctrine of emergent evolution states, and so still further steps have been made possible. As Child has expressed it: "Actually, however, it becomes more and more evident that life is largely, if not 
wholly made up of accidents. The constancy and uniformity of normal development in nature, results, as already noted, from the fact that a certain degree of standardization has occurred in the course of evolution as regards the range of such accidents to which the developing individual is likely to be exposed. This has been accomplished in various ways, e.g., through position of the gonads, through conditions under which fertilization occurs, through the formation of enveloping membranes, jelly, or capsules about the developing eggs, through the selection of certain localities for egg deposition, through care of the young, viviparity, etc. But these various provisions do not eliminate external factors; they merely tend to limit the variation in range, in other words, to standardize their action." 1

What is at the root of this self-determination? Here again we come near to the fundamental interpretations of life, but within the limits of sound biology the complexity of the problem is not overwhelming. In spite of our ignorance of methods of evolution we can only accept the view that the intricacies of life are merely resultants of the intricacies of heritage and environment interacting. Existing life must owe its intricacy to gradual evolution from a simpler primordium responding to the vast and complex world environment

${ }^{1}$ Child, C. M., Physiological Foundations of Behavior, p. 222, 1924. 
through long periods of time. Only nervous processes continue to present a somewhat mystical aspect. Mental activity is only beginning to yield up its simpler secrets. Until these things are on at least as firm a scientific basis as other aspects of physiology it is not strange that nervous phenomena seem less amenable to a physico-chemical explanation than the better known physiological processes, but scientifically such an explanation seems inevitable, if remote.

"This means, of course, that thinking is mechanistically determined, the same as flying and walking; and also that thinking is a true cause of subsequent events-not an epiphenomenon. We do not know how the brain thinks, nor as much as we would like about how a muscle contracts; but this does not forbid accepting the evidence that these organs do perform these functions." 2

Nevertheless mind, especially as it is developed in the human species, is sufficiently unique to command our attention as a possibly novel factor in evolution. To what extent may it have influenced the development of animals as it has gradually advanced in importance to the individual? To what organic property does it owe its origin? Is it universal in all organisms in one or another stage of development? And is it effective even in its

${ }^{2}$ Herrick, C. J., Brains of Rats and Men, p. 17, 1926. Reprinted by permission of the University of Chicago Press. 
primitive form? It would be difficult to pick a more uncertain field of inquiry or one more likely to be complicated by differences of opinion, but even here we have a gratifying morsel of logical probability, if not absolute truth, on which to base tentative conclusions.

The one fundamental quality of protoplasm on which the development of mind may rest is irritability. The living substance is always sensitive to some conditions of its environment, and is activated by the stimuli which it is thus able to receive. This property is more highly developed in animals than in plants and culminates in the former in the complex nervous development of man, but it is nowhere wholly lacking in the organic world. The development of various organisms results in many degrees of complexity and in corresponding degrees of exactness in the responses of the organism, but difference of kind has not been demonstrated. According to Herrick: "The functions of the human brain, so far as exact physiological knowledge of these processes has gone, can all be reduced to phenomena of excitation and conduction not radically different in fundamental character from those of a protozoan or a polyp." 3

The primitive responses of simple organisms to environmental stimuli, commonly called tropisms or taxes, result in favorable orientation of the

${ }^{3}$ Herrick, C. J., Neurological Foundations of Animal Behavior, p. 297, 1924. 
individual with respect to environmental conditions. If a protozoan encounters sunlight and sunlight is harmful to it, it turns away toward a darker part of its habitat. If it encounters an unfavorable chemical stimulus it turns toward a more favorable region. If it encounters food it moves toward it and eats until satisfied. The exact underlying action in these cases is elusive. It is probable that the chemical state of the organism has certain potentialities, and that the exercise of these potentialities results in a state of well-being which is favorable, while anything which interferes with them results in a contrary state which causes the withdrawal of the organism from the adverse condition. This is not explanation, to be sure, but only a suggestion of what may occur during response to a stimulus.

Kepner enlarges upon the prescience of organisms of all kinds in their preparation for future needs through normal development and behavior, and on the ability of animals generally to accept and reject alternatives in securing for themselves the best available environment. ${ }^{4}$ While his book is an interesting and stimulating inquiry into this phase of organic activity it leaves us still without a fundamental explanation. We know only that living matter even in the more primitive organisms reacts to environmental stimuli in such a way as

${ }^{4}$ Kepner, W. A., Animals Looking into the Future, 1925. 
to avoid the unfavorable and to attain favorable surroundings.

In the higher animals with well developed nervous systems the same result is equally evident. The organism recognizes unfavorable circumstances and turns away from them if possible, or moves toward a favorable condition, or selects the best of an average assortment of alternatives. The activity of the nervous system reaches a higher plane with the elaboration of memory and association. Animals profit by past experience, so that an unfavorable stimulus leaves an impress on the organism which leads to its avoidance in the future. The conditioned reflex appears. An animal may taste unpalatable food and later recognize it by sight or smell and avoid it without tasting again. And the squirrel, without any immediate need for nuts, stores them up for the coming winter.

What is memory? What is foresight? What are the instincts which lead so surely to a given action without any previous experience to guide the individual? Without being able to answer these questions simply and directly we find many significant facts in the manifestation of various degrees of mental development in the animal world.

The insects are primarily governed by instincts; indeed, instincts so largely explain their behavior and irregularities are so rare that it is difficult to 
concede them any but the most rudimentary freedom of mental activity. I place a new hive at the end of a row, and many of the bees returning from the field to the neighboring colony are lost. They have been returning to the hive at the end of the row; they continue to do so, but it is no longer home and the reorientation is a difficult task. Some bumble-bees nested under a pile of scrap lumber beneath my porch, entering always at one corner of the pile. I removed a few tools which were leaning against the lumber and for hours bewildered bumble-bees searched for the entrance to their nest, which was actually clearer than before. But in the end the repeated trials of these wonderful little creatures resulted in the recognition of new landmarks and the changed conditions became familiar.

Major Hingston has recently given us an unsurpassed collection of data bearing on the mental processes of insects. ${ }^{5}$ He relates many fascinating instances of instinctive action more fixed than that of the bees, of instincts which operate so rigidly that the slightest depàrture from natural conditions, a departure demanding no more than a trifling modification of the accustomed behavior or even the repetition of a familiar act out of its usual order, may result fatally for the animal or its young. In other cases he records a marked

${ }^{5}$ Hingston, R. W. G., Instinct and Intelligence, 1929. 
irregularity of instinctive action. Individuals vary within a species, and the individual itself may sometimes do one thing and sometimes another under similar conditions. Finally he records among these highly instinctive little animals cases which can be understood only by granting that insects have the rudiments of intelligence. When accidental occurrences, depending upon peculiar and seldom-repeated circumstances, are met by actions which are distinctly suited to the unusual conditions, we cannot fall back on unmodified instinct as an explanation.

From a slight degree of adjustment of behavior to conditions, to the complex intelligence of man is only a matter of increasing complexity. The difference is great, to be sure, but the transition is not difficult to grasp.

What of the importance of these things in evolution? Does the behavior of an animal lead to change? Is it, in itself, a force which may lead to new development in the organism? Or is it simply and solely a coördinating factor? And if it is merely coördinative, has it any important relation to the question of evolutionary change?

If we refer to the simplest manifestation mentioned, the tropism of the simple animals, we note that the result of a stimulus is always the most effective orientation possible for the maintenance of the animal in its normal state. Change is not 
suggested. The tendency of the living substance is apparently self-maintenance.

Animals with the more intricate nervous processes made possible by synaptic organization of the nervous system still exhibit simple responses in some of their behavior, and the result of these simple responses is still self-maintenance, favorable orientation. In the action of instincts we find an important point in answer to our questions, for here are responses no less fixed than tropisms but often much less favorable in their results. The fixed instinct preserves the species admirably under fixed conditions, but is not always governed by the associated conditions of environment, hence it may be fatal to the species if conditions change. In intelligent behavior we find again responses which are directly and often intricately coördinated with environmental conditions, and because of this coördination their results are, again, a marked tendency to self-preservation, not to self-modification. The instinct seems to be comparable to the blind alleys of evolution which can lead only to ultimate extinction, while intelligent behavior permits adjustment to changing conditions.

The origin of instincts is obscure, but it presents a few striking features. Although they may be so rigidly fixed, they must obviously have sprung from variable sources for related species, as the wasps, often have very different instinctive be- 
havior patterns. Since related species trace ultimately to common ancestors, these ancestors must have had more generalized nervous processes than their existing descendants; they must have varied to a degree which permitted them to give rise to a wide range of more or less fixed instincts. But why should an organism with even the rudiments of intelligence give rise to a form whose limitations of instinctive behavior might be its doom? The situation is a peculiar one which admits of only one construction. Fixed instincts are valuable in a fixed environment. Since insects much like those of the present have existed through long periods of geological time, it is probable that some of the existing species have developed their fixed instincts through long association with a remarkably constant environment. In drawing this conclusion we must remember that the insect is a small creature, capable of occupying a spatially limited environment, and that the possibility of his finding an approximately constant environment of long duration is great; the more complex an environment, the greater is the chance of variation in it.

These considerations point clearly toward selfmaintenance as the goal of the adaptive mechanism of the individual, and intelligence need not be excepted. The simpler forms of intelligence enable their possessors to adjust themselves to a greater range of conditions, but the adjustment 
is very likely to be an effort to find normal surroundings, the type of environment to which the organism is accustomed. Only in man are mental powers so highly developed that intricate associations may be worked out for the realization of the greatest possible good, but even in man the end seems to be largely the same as in the lower animals. Man has developed the ability to see how his fundamental activities may be modified for his future good. He has guaranteed himself a constant food supply over much of the earth. He has overcome the physical environment to such an extent that he can live at least temporarily on any part of the earth. He is learning even that his own kind may be improved by judicious control of his own reproduction. But in spite of his progress, he has done relatively little to change the face of the earth and less to change himself; his activities have resulted chiefly in his securing a more nearly constant favorable environment. Human progress, beyond the degree to which it has been forced upon us by the persisting exigencies of environment, is an outcome of the opportunity to work more or less constantly under optimum conditions.

When we consider the possible bearing of these things on evolution one point stands out above all others: Evolution is change, and the organism is reluctant to change. Change is universal; nothing remains static. As a result evolution has been 
regarded as the natural tendency of the living substance by some writers. Natural tendency it is, but in the complex of heritage and environment, as indicated in Osborn's discussions of speciation, and not of heritage itself. It seems that organic evolution is universal because it is unavoidable, not because it is an inherent tendency, and that the natural tendency of the organism is to maintain its normal state. Examine a culture of Paramecium in which bacteria are thickly clustered. It is unnecessary to pursue the animals under these conditions. They may be found nosing up against the masses of food, almost motionless, as they eat; even locomotion is at a minimum when it is not necessary to supply the ordinary needs of the animal, and in the intestinal parasites a similar coordination of surroundings with locomotion is even more extremely developed. So it is with all organisms in the presence of favorable conditions; they do not seek a change when they have found the optimum. Even intelligent man is less likely to attempt new ventures when he has found his desire than to settle down to enjoy his contentment. Most human activity is the result of need, not necessarily for the biological fundamentals but at least for the gratification of some higher desire. The most intellectual and altruistic workers would probably not carry on their activities but for the fact that they gain personal satisfaction in doing 
so; this may be admitted without discounting in the least the high valuation which we place upon unselfish work.

Certainly the exercise of intelligence with respect to biological necessities leads to the preservation of that which exists in the species and not, in itself, to change. But fortunately for evolution, the environment is an inevitable and perpetual source of change; the organism cannot secure exactly the same materials at all times nor is it always subject to the same stimuli. Successive generations cannot always live under the same conditions. Individuals in nature must take what they can get, as a result of availability in the environment and ability on the part of the organism. Opportunism is a fact in nature. Nothing goes to waste, for as surely as a bit of food is found in a vacant space, some organism will find in it an opportunity for the release of some pressure in its existing mode of life, and a new step in evolution is accomplished.

The effects of environmental conditions are various. An organism may have to migrate if crowded in one region, or it may have to climb or burrow or run because of the activities of its associates. It may go south because the climate has grown colder, or raise a thicker coat of fur for the same reason. Always it does what is most certain to provide for its needs, within its inherently possible responses, or perishes, and since its own activities 
are not the initial stimulus for change, the environment comes to the fore as the initiating cause of evolution.

Nothing is so strongly indicative of this fact as the abundant evidence of organic constancy furnished by modern genetics. The organisms with which we must now work have heritages so stable that their absolute permanence has been seriously proclaimed, and yet the most serious supporters of this view have been, at the same time, the most vigorous proponents of the idea that change must emanate from the heritage. This anomalous situation has nothing to support it. The heritage tends to maintain itself and does so to a remarkable degree. As it now exists it is an extremely variable factor which may give rise through recombination of its many components to new or previously unknown conditions in individuals, but the explanation of its variability is one of the tasks of biology. Its failure to be completely invariable must have adequate cause, and with a complex and variable environment inevitably associated with it, it seems utterly useless to seek change in the one factor which tends to be constant.

Anent this matter, Osborn has recently written as follows: "Finally, and perhaps from glandular impulses (Keith), phylogeny proves that independent of selection, of environment, of habit, certain phyla exhibit rapid or accelerated physical and 
mental adaptation, while others are held back. The creative brain, the tool-making hand, the fleet hind limb of man apparently combine in accelerated adaptation, while forest-loving primates advance much more slowly." " But can this be true? If a certain part undergoes great development in one line of descent it must be due to causes in heritage or environment. If glands are involved, they cannot progress without adequate heritage and favorable environmental conditions, and if they result in true evolution their effect on the heritage must certainly be as an internal environmental influence. Moreover no character can long remain "independent of selection, of environment, of habit," certainly not long enough to be involved in phylogeny, for it must soon influence the opportunities of the individuals possessing it, either as a hindrance to normal activity, as an aid under normal conditions of life, or as a factor in bringing about a change in the internal environmental conditions. Some of these relations must develop unless the character is to remain indifferent in individual existence and in evolution alike.

The fact remains that organisms of the present have gone far along the path of self-determination. As we have already noted, the complex body reduces the effect of environmental fluctuations to a minimum through the ability of each associated ${ }^{6}$ Osborn, H. F., Science N. S., Vol. LXXI, p. 7, 1930. 
part to do its work at a fairly even rate in spite of the uncertainty of its surroundings. The total activity of the organism may therefore be much more constant than the conditions of environment, and many processes of the individual body may seem wholly independent of external conditions because of their remarkable constancy in a variable environment. But the fluctuations must be met. There are always changes to which the individual must adjust itself in order that its vital processes may go on within normal limits, and there are often conditions of less importance to which it must respond by the production of non-adaptive characters, merely because the potentialities of its heritage and the existing stimuli lead to such an end. And if the changed environment be permanent, then all individuals of the species must be adjusted to it. Whether the adjustment be directly adaptive, potentially adaptive, or purely incidental, it provides a new factor in the vital complex and a potential basis for other changes in the course of evolution.

From the lowest type of organic response to the highest there is little fundamental difference with respect to adjustment to environment save in complexity. The simple tropisms of primitive organisms result in effective adjustment of the individual within its limits of possibility. The highest type of intelligence likewise operates for the mainte- 
nance of effective environmental contacts. Because the latter is much more elaborate it is able to effect much finer details of adjustment, even involving modification of the environment itself, but again, it does so within its inherent latitude of possibility. Even intelligence is not omnipotent. It has enabled man to accomplish an unsurpassed invasion of the earth, but it is not able to decree that he shall enter a difficult environment and become acclimated to it; he enters it through his ability to produce artificially the conditions necessary for his existence. He may be forced even under these tolerable conditions to live abnormally in some respects. The functions of his body may shift within their inherent limits to meet conditions beyond his control, and in shifting they must inevitably provide a changed internal environment which may play a part in the future development of his body and its derivatives. But intelligence can accomplish no more in evolution than this deliberate exposure to conditions which may result in evolution.

Because adjustment is the price of existence, it is impossible to imagine an environmental condition so extreme as to demand an absolute change of vital functions and yet within the range of tolerance of the organism. A certain latitude must characterize all vital processes; they can scarcely be rigidly uniform. Obviously conditions of life 
must be met within this latitude of response if the individual is to persist, and the most extreme change that can be expected is an adjustment of the function in the direction of the environmental demand, not a sudden complete shift to an entirely new response. An opportunity may be extended of which, if it has the power, the organism may take advantage. The results in evolution must necessarily be slow, perhaps too slow to become evident as a true evolutionary change within a reasonable span of experimental study, but this is clearly the direction which our investigations must take.

If this procedure should ultimately demonstrate that organisms still have some capacity for evolution, that they may still meet new environmental conditions and become adjusted to them as species by an actual change in the heritage, then all of the significant facts and observations relating to evolution would be harmonized. The process would not be Lamarckian, for the environment would not have impressed itself upon the organism and organic responses would not be wholly adaptive. It would not be Darwinian, for the organism would actually be undergoing change in direct response to the environment, and it would not be mutational, for it would involve a gradual building up of a character in the heritage under the proper environmental stimulus. Yet it would be all of 
these together, for Lamarck recognized the activity of the organism in evolution, Darwin believed in the potency of use and disuse as sources of change, and any change in the heritage fits the modern definition of mutations. Under these conditions the biological world would be forced to recognize the necessity which Whitman pointed out thirty-five years ago and which I have sought to emphasize in these pages, that it is not a question of finding the potent factor in evolution, but of learning how the obvious factors interact. ${ }^{7}$

But, as in so many biological problems, experiment is necessary before this discussion can be extended beyond a summary of the pertinent facts and the apparent possibilities of evolution. We know little or nothing of several of the most significant questions involved, including the nature of individual response, its possible effect on the heritage, and its importance in connection with such other evolutionary processes as preadaptation and selection. It is completely illogical to abandon this field of investigation without adequate reason, or to deny its importance in the study of evolution. It is the one field in which our knowledge is at such an unsatisfactory point that we can say neither "true" nor "untrue." We may call it the inheritance of acquired characters and arbitrarily discard it through the prejudices of the

${ }^{7}$ Whitman, C. O., Woods Hole Biol. Lect., 1894, 1895. 
past, or we may call it the rôle of individual response to environment and open a promising field of investigation. But since the tendency of the heritage seems distinctly not toward change, the latter course urges itself upon us. 


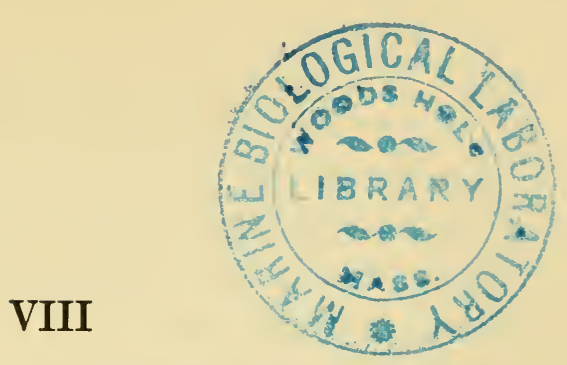

\section{OUR FUTURE COURSE}

The views expressed in the preceding pages appeal to me as nothing more than a sound interpretation and application of the principles of good biology and common sense to the problems of evolution. It sometimes seems that no position is more difficult to establish, for the careful application of facts demands the discard of all dogma and controversy of the past in its attempt to reduce all factors dispassionately to their proper places in the greater whole. We have had little but controversy in evolution for many decades, yet it has not been especially productive; the same controversial treatment is still possible. Controversy is much too likely to breed opinion instead of progress, and progress, at present, is greatly to be desired.

The outstanding feature of this interpretation of evolutionary processes is the fact that it is neither Darwinian nor Lamarckian nor mutational. I have attempted to show in my first few chapters how utterly impossible it is to separate the factors of environment and heritage in living things, and how illogical it is to debate the relative importance 
of essentials. Nothing of significance in the organism can fail to have its foundations in the heritage; no character or function can fail to be related to the other parts and functions of the body; and nothing in the individual can be without an association, direct or indirect but vital none the less, with the factors of external environment. The organism, whether we speak of individuals or of species, is a resultant coördinative mechanism which arises through the harmonious interaction of a self-perpetuating physico-chemical complex, its heritage, and the intricate complex of conditions under which it develops. This essentially epigenetic view is not uncommon; it is ably developed by Child ${ }^{1}$ and is accepted by most modern biologists.

It is true that the recognition of these facts justifies the opinion held by many evolutionists that the environment is merely directive, but the emphasis that has been given to their point of view seems wholly unwarranted. Even though an acquired character is the product of a basic heritage and of many factors in the body, brought to expression by an external stimulus, the fact remains that the external environmental factor is essential to its production, and that the hereditary basis is due in part to other environmental conditions of past life. These contributions from the

${ }^{1}$ Child, C. M., Physiological Foundations of Behavior, Ch. III, 1924. 
environment include both substances and stimuli. A true appreciation of these facts demands the complete discard of the older views. We must forget that we have had three-quarters of a century of bickering over the environment and the heritage as alternative causes of evolution and begin anew with a recognition of their essential and coördinated functions, for in no single case have we observed a significant organic change which could be ascribed to either alone.

The modification of the heritage, while it may be brought about through the action of penetrating irresistible forces of chemical or physical nature on the germinal chromosomes, as by alcohol or $\mathrm{X}$-rays, may also be sought in the variable environmental conditions which give it the opportunity for variable expression of its inherent properties. It is generally recognized that the inherent powers of the specialized tissues which make up the body are governed by the genes which associate these tissues with the preceding generation. If the individual receives one type of genes it may deposit pigment normally, if another it may freckle, and if a third it may be an albino, but whichever may be its heritage, it was represented in the chromosomes of the germ cells with which development started.

Some of the inherent powers of the chromosomes are realized, as development proceeds, in spite of 
any slight fluctuations of the environment. Others are expressed only under special conditions. The latter result in the acquired characters which have evolutionary significance. They include the striking responses to mechanical stimuli, light rays, unusual foods, and the various other conditions which have been previously listed, and they may be either adaptive or non-adaptive, according to the part which they play in the life of the individual. According to one possible interpretation of these characters, a given hereditary power is either used or not used during individual life; according to another, a given gene responds positively in various ways to various stimuli. It is satisfactory to use the expression use and disuse in this connection. This interpretation of gene action may be applied equally well to the variable development of heritable characters in connection with fluctuating conditions in the internal environment.

Elsewhere I have considered in detail the several kinds of acquired characters and have shown that all of them may be explained in this one way. ${ }^{2}$ Whether the condition is an acquired immunity, a degree of muscular development, or pigmentation of the skin, it is the result of use or disuse of some inherent functional capacity. This is the basis for acquired characters generally as far as they concern us.

${ }^{2}$ Am. Nat., Vol. LXI, p. 251, 1927. 
If the human epidermis is subjected to the rays of the sun it becomes pigmented. If the stimulus is continued the pigment increases, and finally the maximum power of the body to form pigment is expressed or an effective protection against the inciting stimulus is attained. The action is probably cumulative. In the case of tolerance for narcotics the cumulative nature of the action is even more evident, for tolerance may be built up by gradually increasing the dosage, to a point which is not found in untreated individuals, and a return to normal must be accomplished in the same way, by gradually decreasing the dosage. According to Wells ${ }^{3}$ tolerance for morphine and alcohol must be, in part at least, due to "a certain refractoriness or cellular immunity," in addition to any possible power to destroy the toxic substance. Whatever may be the mechanism of this tolerance, which is not definitely understood, it indicates a cumulative acquisition of a quality present to a much smaller degree in the initial state of the individual.

That the response of the heritage is invariably cumulative in individual response to environment cannot be said with certainty. Information on this subject is inadequate. Nevertheless the available facts point to this probability. While with-holding dogmatic assertion on the question, we may work with confidence on the tentative conclusion that

${ }^{3}$ The Chemical Aspects of Immunity, Ch. XII, 1925. 
the living substance in any form is able to respond to conditions demanding the exercise of a given function by the gradual increase of its capacity for that function, and if the type of activity excited by the environmental stimulus results in a visible development, that too may be expected to increase. Conversely, no part of the organism and none of its functions may be expected to develop beyond the degree favored by the conditions of its existence. The possible limits of the cumulative process can only be estimated. When an organ is absolutely unused its reduction may proceed in the individual to a state of atrophy, but the body maintains it in some degree of development. When excessive activity is demanded of an organ, the individual suffers; its capacity for response is apparently not unlimited, but it may be extended to an unsuspected degree by the cumulative effects of response to a long-continued or gradually increasing stimulus. Exact information on this problem is greatly to be desired. At present we can only rest on this significant but incomplete evidence.

Granting that cumulative change is possible, even in the individual, we have found a possible source of chromosomal change. Acquired characters are cytoplasmic in their expression, but so also are inherited characters. Cytoplasm is the material of construction in which all characters are wrought. But we have seen that cytoplasm 
alone is incapable of continued constructive action; everything that it accomplishes is ultimately referable to the controlling action of the chromosomes. Two interpretations of the activity of the chromosomes in the development of acquired characters are possible: We may conclude that they always exert the same influence and that the cytoplasmic result is cumulative, or that the chromosomes also undergo a cumulative change which is responsible for the condition of the cytoplasm, that the ultimate expression of the acquired character is the result of an actual increase, through use, of the functional capacity of the genes involved in its production. It must be admitted that these interpretations are speculative, but the probability of the latter is attractive. There is nothing to show that increased muscular power is purely a result of quantitative modification of cytoplasm or that tolerance for morphine is due to the accumulation in the cells of the body of some product which aids in protecting it against the drug. Again exact information is to be desired, and in its absence we must fall back on a logical interpretation of the available facts. It is commonly known that the material of which the body is composed undergoes frequent renewal under the control of nuclear activity. 4 This fact seems much more compatible with the idea of gradual modification of the func-

${ }^{4}$ McClung, C. E., Cowdry's General Cytology, pp. 665-667, 1924. 
tional capacity of the chromosomes than with the idea that fixed chromosomal functions may produce a cumulative effect in the cytoplasm. If increased pigmentation is due to cumulative deposit of pigment, the constant renewal of epidermal cells would seem inimical to the process; if it is due to an increased capacity for the formation of melanin by the melanoblasts, the newly formed epidermal cells would find an increasing supply of melanin as the organism responds to light. The latter alternative is in harmony with the known facts and indicates an increase in the functional capacity of the melanoblasts, which would involve the nucleus as well as the cytoplasm.

This idea is the theory of use and disuse in the chromosomes which I have previously expressed. In brief it is no more than the extension of the principle of use and disuse, which has been an accepted source of modification of living substance in macroscopic units, to the minute bodies which have been found so important in heredity. Its value is limited, like the value of all other theories of evolutionary method, but it has the unique possibility of explaining a chromosomal modification as a result of organic activity on the basis of a recognized peculiarity of living substance. It suggests a means whereby the existing latitude of organic response may shift in harmony with the demands made upon the organism by environ- 
mental conditions, whether or not the results are adaptive.

The chief limitation of this theory is the old difficulty of associating the responses of somatic structures with the germ cells. Since the structures involved in the development of acquired characters are somatic, the chromosomes directly associated with the response are necessarily somatic. The possibility of a change in the functional capacity of the chromosomes as an organism responds to environmental stimuli is a distinctly valuable factor in evolutionary theory, but it does not solve the problem of associating these changes with the chromosomes which are handed down to succeeding generations.

Weismann's interpretation of the continuity of the germ plasm has had a most unfortunate influence on scientific consideration of this problem. The continuity which he emphasized exists; indeed, it is so logical and in some cases has been so clearly demonstrated that it stands out as one of the salient facts of heredity. But the fact of germinal continuity is a wholly different thing from the isolation and insulation of germ plasm which Weismann proposed. We may even admit the validity for certain purposes of his distinction between germ plasm and somatoplasm without attaining the position which he defended. Although we are still ignorant of any mechanism whereby the influences 
of the soma are impressed upon the germinal tissues, the converse is equally true and the known interaction of organic structures through the medium of hormones is significantly indicative of possible relationships here. I have previously pointed out that continuity is incidental to the reproductive function and that the continuity of the germ plasm is conspicuous only because this is the normal reproductive substance. Continuity of somatic tissues is well known in plants and lower animals, and discontinuity of germ plasm is on record in a sufficient number of cases to destroy effectively the Weismannian hypothesis.

The most significant facts available in the present unsatisfactory state of scientific knowledge of evolutionary processes are those brought out in the preceding chapters. The organism exists by virtue of an association between heritage and environment. The cytoplasm exists because of the action of a characteristic chromosome complex upon cytoplasm derived from the preceding generation under conditions determined by all phases of the complex environment. The germinal tissues, even though they are safeguarded to the ultimate ability of the individual organism from external influences, are, nevertheless, produced by the chromosome complex descended from the original reproductive unit under conditions which are dependent upon the life of the individual. And since the 
chromosomes must grow and reproduce like all living things, we cannot avoid the possibility that, in spite of their remoteness, a residuum of influence may reach them from the surrounding body. Successive generations of them are, in their turn, products of their predecessors' reaction to their environment.

The nature of this influence may be obscure, but it presents one logical possibility. We know that organic activity or inactivity results in a corresponding increase or decrease of functional capacity and, without doubt, in a corresponding physicochemical development. If we extend this principle to the chromosomes or to the genes, as may logically be done, the exercise of a given function establishes a condition in the body which favors a coördinated development of the genes involved. There is no known reason why this condition should be limited to the cells involved in the expression of the character, for the individual maintains its entire chromosome complex normally in all cells of the body, without regard to their specialization and their individual cytoplasmic functions. A chromosome exists in a given state partly because a given condition in the body makes possible the development and perpetuation of chromosomes in that particular state. Since the same kind of chromosome appears in many cells, irrespective of their relation to the character whose somatic 
expression it governs, it is obvious that the condition governing its development and maintenance is available throughout the body. The significant aspect of this hypothesis is that the result is definitely associated with some condition of individual life. Whatever change may occur is only a reduction or enhancement of something already present, but it takes place according to the demands of the environment. In this the hypothesis is more satisfying and more in harmony with the known facts of evolution than the equally hypothetical idea that evolution has proceeded entirely from the random influences of rays upon the structure of genes. It offers equal possibility that a degree of development, once attained, may find a new importance to the individual under new environmental contacts without depending entirely upon this preadaptive value for its efficacy. Neither idea is, at present, susceptible to proof.

This idea of the development of the chromosomes harmonizes with the known facts of embryology and with the emergent interpretation of evolution. We cannot avoid the conviction that the chromosomes are always the controlling center of the cell, yet the same chromosome complex accomplishes a succession of varying results during the course of ontogeny. Each generation of chromosomes arises from a previous generation which is apparently similar, yet each brings about new stages of growth 
and differentiation. The potentialities of the whole organism must be present in the fertilized ovum, yet they are realized only through gradual development, with a gradual change of internal environmental relations. Given a normal opportunity, they express their inherent qualities normally in the adult, but the very nature of their attainment of this degree of expression suggests the possibility of some fluctuation in their later functional capacities, of later emergents.

If change through use and disuse may thus affect the chromosomes of the germ cells, the conclusion does not follow that the next generation will show the same character as its parents. It must still encounter the stimulus which brought out that character previously. If the stimulus is present, or better still, if it is intensified, there is a possibility that the condition of the genes may reach another degree of development, and so, generation after generation, lead to a state which was beyond the immediate possibilities of their progenitors. But if the stimulus is lacking, the possibility still exists that the heritage may respond as in previous generations.

During the entire period of development of a character in this manner it must maintain a place in the organism as a whole. If the organism exists in a given condition, then the maintenance of each part must conform to that condition, and if one 
part undergoes change, adjustments must be made elsewhere in the body. It is conceivable that through gradual development a character might ultimately attain a condition of sufficient importance, or a condition sufficiently different from that in which it existed at an earlier stage, that the body, in spite of the cessation of the original stimulus, could not return the character suddenly to its original condition, but must gradually work out an adjustment according to the importance of the internal relationships involved.

It is not necessary to limit our analysis of acquired characters to this one possible method of perpetuation. While it is conceivable that an organ may attain a degree of importance which would guarantee its persistence beyond its period of active usefulness and make its loss impossible save through the gradual reduction which we ascribe to our own vestigial structures, its development may also give rise to new environmental associations. Any association with an additional environmental condition would bring new stimuli to bear on its further development, and would also open the possibility of perpetuation of the character through selection. The latter point is the essential feature of Cuénot's idea of preadaptation, although he does not extend his theory to the origin of the character in the beginning. Any such shift in environmental relations must certainly add 
to the possibility of continued evolution of a character and to the complexity of interactions involved in its production and maintenance, and the more complex these interactions, the less chance there is that the loss of any single factor may completely eliminate the character.

This idea may seem to involve a contradiction in that I have spoken of the character as the result of a certain heritage responding to a certain environmental stimulus. It may be quite true that the character would never have been expressed without the intervention of the external stimulus, but in this as in the development of every organic structure, relationships in the internal environment are involved. No character is a simple result of one or a few genes responding to an environmental stimulus of slight complexity; instead the somatic expression of any heritage involves many factors, activated sometimes by external stimuli but always including complex interactions among themselves as components of the internal environment.

The importance of new conditions and changing relations in the body can scarcely be overestimated as an evolutionary force, and examples of their action are common among living things. For instance, the fishes have pharyngeal pouches which are of the utmost importance in the development of their respiratory system, and man retains these 
pouches as a feature of his embryological development, although he has no such need for them. During the ages of his past evolution each step was accomplished in association with these pouches and their derivatives, hence they persist in the development of structures which are now essential. It is unnecessary to write at length of the importance of the endocrine glands developed in this part of the body. They may originally have been incidental, but they existed and they are now indispensable, along with the pharyngeal pouches from which they develop.

These points are strictly in harmony with the facts of evolution as disclosed by palaeontology in long phylogenetic series, and with the limited experiments which have demonstrated an apparent inheritance of acquired characters. In the former case we find gradual change under a gradually changing environment to be a common condition. In the latter we find the gradual development of a character and its gradual disappearance in succeeding generations convincingly demonstrated, especially in Woltereck's daphnids.

Gradual appearance and gradual disappearance, however, introduce the problem of reversibility. If the changes under discussion are evolutionary, one may well ask how they harmonize with the generally accepted principle of irreversibility. It seems, first of all, that this principle is based upon 
a consideration of major steps in evolution, upon finished characters, rather than upon the process by which they are formed. In other words, we judge the results of evolution as they stand before us, and not the possible steps which preceded their consummation. It is obvious that a hand may not again become a fin, and that a flipper may not become a foot, but quite true that an organism which has legs may be the descendant of legless ancestors and the progenitor of legless descendants. Each structure is a positive phenomenon, the product of a given heritage, and because of its positive characteristics it is obviously impossible for it to present the conditions of heritage necessary for the production of a preëxisting stage of its development. As a result it cannot be the cause of its own cause nor of something exactly like it, but within its own latitude of development there is no fundamental obstacle to its fluctuation.

As an example the probable history of the pentadactyl appendage is excellent. According to the accepted view of the evolution of the terrestrial vertebrates, the initial steps in the development of these appendages occurred in the Crossopterygii of the geological past. The skeletal elements were present in these fishes, which apparently used their pectoral fins as supporting structures when resting on the bottom. Here are environmental factors common to terrestrial and aquatic habitats: the 
force of gravity and a solid substratum. But when the ancestral fishes emerged from the water, the stimulus of a dense fluid medium was lost. Presumably the fringe of the fins disappeared, but we have no reason to suppose that the power to produce a complete fin was lost in these early terrestrial fishes. They were, however, subject to new stimuli on land, stimuli which favored the realization of latent possibilities of their fins which could never have been brought out by an aquatic environment, and the pentadactyl appendage is the result. In most terrestrial vertebrates its importance is so great that reversion is unthinkable; it is a positive adjustment to positive environmental conditions, many of which could have had no part in its production, and even though subject to the same aquatic environment as the ancestral fin, it presents a different heritage and so gives a different result in the course of evolution, as in the flippers of the seals. But it can be reduced, like the fore limbs of the kangaroos, or lost completely as in the snakes.

It seems entirely logical to expect reversibility in the response of a heritage to an environmental stimulus during the initial stages of stimulation, but when the heritage has been subjected to the stimulus for many generations, or to a gradually increasing stimulus, until a cumulative response has been brought to an extreme expression, the 
condition may well be different. Add to this the possible successive incidence of different stimuli and we have the assemblage of environmental conditions which may be operative in nature. If a heritage can be brought to an expression whose latitude is beyond that of its previous state, it may still be reversible through an equally slow process, but it may have a different and potent effect within the organism while maintained in its new condition, and either it or some results of its new development may respond to an environmental stimulus toward which it was previously inert. The latter condition would make probable the persistence of the character through its relation to the second stimulus even after the cessation of the first. Such an assumption is, of course, highly speculative, but the conditions involved are unavoidable in the circumstances of life, and when we take into consideration the internal environmental factors, it is of great significance.

Among the many attempts to demonstrate the inheritance of acquired characters in the past, these fundamental considerations have in no case been met. It is not difficult to find organisms, both simple and complex, which respond to environmental conditions through demonstrable functional adjustment or through visible structural change, nature of pigmentation, or habits. Leaving out mutilation and mechanical malformation, 
experiments have dealt with organic responses of these kinds. In every case some hereditary capacity has been involved, and the degree of its expression has been controlled by artificially controlling the environment. The procedure followed has involved the subjection of the organisms to a given stimulus through several generations in all of the experiments known to me, and the return of the stock, finally, to the normal ancestral environment. In no case have I found a record of an attempt to determine the effect of a gradual increase of a stimulus over a succession of generations, and in no case has the experiment dealt with the usefulness of a character under other conditions than those which determined its production.

The various conditions suggested here for the possible modification of living things through individual response to environment present very different possibilities for experimental verification. The time element is always important in such studies, but probably to the greatest degree in those experiments which involve the modification of a simple character in response to a simple environmental condition. Such a response may be adaptive or it may be incidental, but in any case we can scarcely expect it to carry the development of a character quickly beyond its former latitude of response, if at all. It is conceivable that an increasing or decreasing' stimulus may ultimately accomplish this 
result, but probably at such a slow rate that it may not be experimentally demonstrable except in very favorable cases. It is much more probable that an induced change, if it can be brought into relationship with other factors of the environment than those which caused it to appear, may be fixed in the species through experiments of sufficient duration to afford convincing evidence of its importance in evolution. The relation of such characters to selective processes is a more delicate matter, since any selection makes it necessary to distinguish carefully between the heritage and the somatic characters as the basis for selection. The relationship is a valid field of inquiry in the general process of evolution, but a dangerous one for the study of acquired characters.

The limited duration of experiments in this field has been a necessity which will probably continue to be felt. It has been possible to follow organisms of short life through many generations, and for this reason they are desirable material, but unfortunately experimental material must be sought among species which show some capacity for varied response to environment, whether or not their other characteristics are favorable. Duration is certainly an important factor in evolution, but it may not be an unavoidable obstacle. Certainly we cannot expect to work important changes in a species in a few generations when individuals may 
be called upon in the natural state to adjust themselves many times to fluctuations of the environment, so we must avoid this condition as far as possible.

The behavior of the offspring of animals kept for several generations under unusual conditions has varied in the work of different investigators. It is unfortunate that so many of these experiments have been conducted without adequate checks, as, for example, Schröder's studies of the habits of the willow moth, ${ }^{5}$ for while any room for objection is left by the experimenter he may be certain that it will be forthcoming. Nevertheless, the available experimental data strongly support the points suggested above. The permanence of characters is in proportion to the length of treatment in some cases, and a return to normal within one or two generations of the renewal of normal environment is a common result. Apparent persistence of a character is reported by Guyer and Smith in their work with cytolysins, ${ }^{6}$ but, without denying the positive value of these results, I feel that normal responses to artificially modified external environments are the most desirable materials for this work.

The theoretical possibilities of individual responses have not been adequately tested by experi-

5 Verh. d. Zool. Ges., Vol. XIII, p. 158, 1903.

'Jn. Exp. Zool., Vol. XXXI, p. 171, 1920. 
ment. In view of the fact that they have as great logical appeal as the mutations which have demanded so much of our attention, and even more harmony with the apparent course of evolution, they seem worthy of more attention and more careful and thorough experimentation than have hitherto been accorded them, but we cannot expect greater success in our experiments than has resulted in the past unless they are undertaken with a clear idea of the probable part of individual response in evolution. No one factor in so complex a process can be responsible for all of the results, and until we know all factors and recognize their interaction we must remain ignorant of the total process.

Any experiment which embodies the essential factors of individual response to environment as stated above will give useful results, but for the thorough investigation of the problem we must first determine the nature of individual response through a reasonably long succession of generations. Response is cumulative in the individual, but is there any possibility of cumulative response through several generations? Guyer and Smith have given us the nearest approach to a sound investigation of this question in their studies of typhoid agglutinins in rabbits. " "The young of immunized mothers can, without further immuni-

${ }^{7}$ Jn. Inf. Diseases, Vol. XXX, (6), p. 498, 1923. 
zation, transmit agglutinating ability to their own offspring," and successive generations are able to build up increasing degrees of immunity. But the possibility that these results are due to "a placental rather than a truly hereditary transmission" is a serious difficulty in a study of evolution. I feel that the experiments have evolutionary significance in either case, for placental transmission is a normal factor in mammalian life, but for the establishment of individual responses as a factor in evolution generally, the possibility of prenatal influence must be eliminated. Mammals are therefore barred as experimental subjects, and it is very desirable to confine experiments to species in which no association between parents and offspring exists beyond the production of the fertilized ovum or other reproductive unit.

It is further necessary that the individual response to a fixed stimulus over an extended period of time, and to a gradually increasing stimulus, be determined. In succeeding generations it is desirable to determine how the young of treated parents respond to a continuation of the initial stimulus and to an increase of it, with adequate provision against the possibility of natural selection. Are the young able to adjust themselves successfully to a more extreme condition than their parents could meet? If so, the influence of individual response upon the reproductive cells is definitely 
established, and with scarcely less certainty we may say that the germinal chromosomes are affected. There is, however, no more reason to suppose that the condition will persist after a few generations if the inciting stimulus is removed than to conclude a priori that such a cumulative change may not occur. If cumulative change does not take place, then studies of individual response are not likely to have value in evolution, but the available experimental evidence does not point to this end.

Given a cumulative response of considerable degree, it is desirable next to build it up to a maximum. It is conceivable that the degree of development attained may become a factor of such importance in the internal environment that internal coördination may, after a time, guarantee its perpetuation. The factor of time appears to be important here, and may be an insurmountable obstacle for experimentation if we can judge by the long geological periods which have been occupied by the evolution of known species. There is, however, no reason to rule this possibility out; directly adaptive responses must be inherited in this way, if at all. Such a result would be the inheritance of acquired characters in a very simple form.

It is more probable that the factor of usefulness in relation to other than the inciting stimuli may 
play a part in successful experimentation. For this reason a second stage of investigation should be undertaken to relate the artificially developed character with some condition of the external environment as an adaptive character. It is more than likely that the attainment of this end will be difficult, but it is essential to a thorough study of the problem.

With a character developed artificially by modification of the environment through several generations, and an adaptive association established between it and some other environmental condition, the possibility arises of new development through use, in the ordinary sense of the word, of the previously indifferent character. The essential condition to be investigated, however, is the potency of the adaptive value of the character to maintain it even in the absence of the environmental condition under which it originally developed. Maintenance of the adaptive association in an artificial environment and the abatement, at the same time, of the original stimulus, would determine this point.

These are the conditions necessary for an acceptable and final investigation of the inheritance of acquired characters. Whether they can be completely attained remains to be determined. It is certain that the attainment will be difficult, for the available organisms have had many years in which to adjust themselves to the natural environ- 
ment which we know and to gain the degree of independence which is characteristic of their kind. The individual responses which are commonly known are of slight degree. Even if developed to a maximum it is possible that they will still lack adaptive value under any available conditions. But stranger things than this have been accomplished and we may yet see all of these conditions realized. It is certain that the previous method of subjecting organisms to a stimulus for a few generations and then removing them to the original environment is hopelessly inadequate for the investigation of such a complex subject as the process of evolution. Succeed or fail, it is better by far to follow a method which promises success than one which is obviously inadequate.

Finally I would note again that this proposal does not deny in the slightest degree the efficacy of other factors in evolution. The inheritance of acquired characters is emphasized because it demands investigation more than any other subject, but it is broader than the term usually implies. Natural selection, isolation, and other processes of less importance, are also potential sources of change in species, once we have a variable heritage on which they may work. Our task is largely to determine the source of variation in an originally homogeneous heritage, and the response of the individual to its environment is too igmificant 
to be denied investigation. Mutation certainly does not explain; it is a recognition of a type of variation, rather than of the underlying causes, and until we have determined what causes heritable variations we have not exhausted the available field of investigation. 


\section{INDEX}

Abnormal abdomen, 94

Acquired characters, 4, 149, 164, 204, 219

Adaptation, 14, 59; process and result, 60 ; adjustment of, 62 ; process of, 62; and natural selection, 114; and Lamarckian theory, 135

Adjustment, need for, 197

Agar, W. E., 157

Agglutinins, 223

Albino, 64, 203

Alcohol, 203, 205

Alcoholism, 146

Alexander, J., 81, 97

Alimentary tract, 90

Altitude, 19; effect on blood, 19; effect on environment, 49

Amblystoma punctatum, 38

Animals, and organic environment, 20; responses of, 186

Ant-eater, 134

Ants, 69

Appendage, pentadactyl, 217

Ascaris, 78

Autocatalysis, 13, 14, 81

Autonomy, 48, 178

Babcock, E. B., 58

Bacteria, 28

Baldwin, J. M., 116

Barnes, W., 42

Bateson, W., 26, 53

Beebe, W., 69
Bees, bumble-, 187; honey-, 32, 187

Belief, in science, 109

Bessey, C. E., 26

Boas, J. E. V., 168

Bolley, H. L., 158

Bones, 168; development of, 166; sesamoid, 168

Borodin, N. A., 161

Boveri, T., 78

Brain, 184

Bridges, C. B., 81

Butterflies, 61, 95, 119, 180

Camels, 165

Camponotus macilentus, 70

Carbon dioxide, 36

Catalysis, 12

Caterpillars, 49

Cave animals, 59

Cell, organization of, 28

Centrifuging, 79

Centro-epigenesis, 139

Cephalochordata, 166

Change, in genes, 96; foundations of, 147; cumulative, 174, 205, 207

Characters, acquired, 63, 98, 158,204 , 219; addition of, 74; complexity of, 215; degree of development, 73; hereditary, 67; indifferent, and selection, 117, 118; modification of, 74; new, 174; non-adaptive, 61; origin of, 61 ; stability of, 154 
Child, C. M., 181, 202

Chromatin, 86; of Ascaris, 78

Chromosomes, 89, 206; as controlling center, 79; dependence of, 79, 91; and heredity, 77; use and disuse in, 208, 211

Circulus, 31

Climate, and altitude, 49; and rainfall, 50; and geological change, 51

Clupea, 161

Cockerell, T. D. A., 163

Coincident selection, 116

Colonies, 32

Conger, G. P., 1

Conklin, E. G., 5, 56, 62, 79, 80, $82,85,97$

Constancy of organism, 92

Continuity, of germ plasm, 92, 104, 209; of somatic tissues, 210

Controversy, 201

Cook, O. F., 34

Cope, E. D., 138

Corpuscles, red, 80, 99

Cowdry, E. V., 84

Coyote, 151

Cretinism, 37

Crossopterygii, 134, 166, 180, 217

Cuénot, L., 125, 130, 133, 214

Cunningham, J. T., 62, 91, 97, 141, 149

Cytolysins, 155

Cytoplasm, 87, 206; compared with soma, 87; constancy of, 89 ; dependence of, 84 ; differentiation in eggs, 85 ; in heredity, 77, 84; necessity of, 82; and nucleus, 78
Daphnia, 66, 155

Darwin, Charles, 23, 53, 70, 113, $114,124,136,137,139,199$

Darwinian school, 113

Darwinism, compared with Lamarckism, 138

Deer-mice, 153

De Mol, W. E., 74

Dendy, A., 35

Depression and climate, 51

Devaux, E., 120, 175

Development, degrees of, 73; of muscles, 207

DeVries, H., 81, 127, 128, 132

Dispersal, 68, 121, 160; and adaptation, 50

Dixey, F. A., 95

Drosophila, 58, 73, 74, 92, 94, $101,128,144,148$

Duration of experiments, 221

Edelweiss, 36

Élan vital, 9

Elephants, 165

Elevation and climate, 51

Embryology, 85

Emergents, 169

Endocrine glands, 90, 216

Enucleation, 99

Environment, 5, 35, 87, 178, 181, 201, 203; effect of change, 72; complexity of, 17; control by man, 191; in evolution, 147, 151, 193; external, 58; internal, $21,57,215$, 225; and mutation, 94, 98; organic, 20; phases of, 18; physical, 18; of species, 41 ; source of life, 14

Enzymes, 81, 97

Epigenesis, 202 
Erythrocytes, 80, 99

Evening primrose, 127

Evolution, emergent, 150, 168, 181,212 ; and past environment, 165; not an inherent tendency, 191; scope of, 1; starting point of, 150

Experiment, duration of, 221; Lamarckian, 141; need for, 199

Eyes, 59

Factors, localization, 102

Fell, H. B., 103

Finches, 69

Fins, 217

Fishes, 215

Fittest, survival of, $7 \mathbf{1}$

Flavones, 36

Flax, 158

Flipper, 217

Foods, response to, 56

Foot, 217

Forces, 47

Friction, response to, 56

Frog, change of color, 10; parthenogenesis, 37

Functions, latitude of, 197

Galápagos, 69, 122

Ganoids, lobe-finned, 61; see Crossopterygii

Gaskell, Augusta, 8

Genes, $76,77,80,104$; action of, 204; duration of activity, 100; sphere of activity, 100; dependence of, 91 ; modification of, 96 ; perpetuation of, 81 ; rôle in acquired characters, 99 ; stability of, 95 ; use and disuse of, 105; and $\mathrm{X}$-rays, 144

Genetics, 76, 194

Geological changes, 51

Germ cells, 91, 209

Germinal selection, 115

Germ plasm, 87, 97, 98, 210; continuity of, 92, 209

Gifford, E. W., 69

Glands, 194; endocrine, 90, 216

Goldschmidt, R., 81

Goodrich, E. T., 149

Gopher, 151

Gowen, J. W., 101

Green plants, 18

Gregory, J. W., 31

Guyer, M. F., 136, 155, 171, 222, 223

Hagedoorn, A. L. and A. C., 6

Hand, 217

Harrison, R. G., 38

Henderson, L. J., 36

Henneguy, L. F., 41

Herbert, S., 116

Heredity, Mendelian, 76; and mitochondria, 83; and cytoplasm, 77, 84

Heritage, $5,35,87,178,181,201$; in acquired characters, 149; in evolution, 147; fluctuations of, 51 ; independence of, 37 ; modification of, 203; reassortment in, 52 ; in species, 41 ; tendency of, 194

Herrick, C. J., 183, 184

Herrings, 161

Hesperioidea, 61

Heterocatalysis, 81

Heteroploidy, 74 
Hingston, R. W. G., 187

Hinny, 84

Hogben, L. T., 10

Honey-bee, 32, 187

Horses, 165

Hybrid interpretation of mutants, 128

Hypotheses, see Theories

Immunity, 223

Individual, adaptive processes in, 135 ; and reproduction, 105 ; and species, 29

Individual response, $67,98,155$, 172

Induction, parallel, 140

Inheritance, cytoplasmic, 87

Injury, results of, 56

Insects, mental processes of, 186

Instincts, of insects, 186; origin of, 189

Integument, 90

Intelligence, 196, 197; of insects, 188; of man, 188; and evolution, 189, 191, 193

Intraselection, 116

Iodine, 65,181

Irreversibility, 216

Irritability, 184

Isolation, 69, 119, 160, 227; geographic, 120, 122; limitations of, 126; organic, 120; results of, 124

Johanssen, W., 127

Johnstone, J., 110, 111

Jordan, D. S., 152

Just, E. E., 84

Kangaroo, 218

Kepner, W. A., 185
Kidneys, 90

Kinetogenesis, 138

Lamarck, J. B., 23, 136, 199; laws of, 136, 137; work of, 138

Lamarckian school, 118

Lamarckian theory, 135; compared with Darwinism, 138; failure of, 164; modern attitude, 136; experiment, 141; insufficiency of support, 141

Lawrence, W., 91

Lead, 48

Le Dantec, F., 173

Life, 7, 182; and external conditions, 49 ; origin of, 178

Light, response to, 56

Lillie, F. R., 84

Lindsey, A. W., 26, 42

Linneon, 129

Living substance, characteristics, 12; plasticity of, 175

Locomotion, 50

Loeb, J., 37

Lotsy, J. P., 129

Lungs, 61

MacDougal, D. T., 43, 66

Mammals, 224

Man, 192, 195; control of environment, 191; intelligence of, 188

Marshall, G. A. K., 95

Mason, F., 31

Materials, 47

McClung, C. E., 207

Mechanism, 111

Meiosis, 73

Melanin, 208

Mendelian heredity, 76 
Metabolism, 14

Mice, 73; California deer-, 153; white, 60,156

Mind, 67, 183; and thyroid, 181

Mitochondria, 83

Mneme theory, 139

Mocking birds, 69

Modifications, 56, 64

Molluses, 61

Monkeys, Mona, 162

Montgomery, 'T. H., 26, 31

Moore, J. E. S., 161

Morgan, T. H., 38, 80, 83, 93

Morphine, 205, 207

Moth, willow, 222

Mule, 84

Muller, H. J., 58, 98, 143

Mutant, abnormal abdomen, 94; wingless, 73

Mutations, 6, 57, 127, 143, 163, $175,223,228$; cause of, 132; and acquired characters, 145 ; cumulative, 130, 131; degree of, 128; definition, 148; and environment, 74, 146; explanation of, 132; importance and effects, 130; of eye, 101; gene, 74; kinds of, 170; reverse, 128; and selection, 130; somatic, 101; usefulness of, 144

Mutation theory, 127, 164

Mutilations, 63

Nageli, Carl von, 131

Narcotics, tolerance for, 205

Natural selection, 6, 70, 112, 227; criticism of, 126

Neovitalism, 110

Newman, H. H., 131
Novelty in organisms, 165

Nucleus, as controlling center, 78 ; and cytoplasm, 78; compared with germ plasm, 87; necessity of, 82

\section{Oenothera, 128}

Opportunism, 179, 193

Organic selection, 116

Organism, 47, 202, 210; adjustment of, 196; capacity for change, 134; complexity of, 16 ; constancy of, 194 ; independence of environment, 16; limitations of, 206; multicellular, 28; product of heritage and environment, 22; source of energy, 15 ; tendency to be constant, 92

Orthogenesis, 6, 131

Osborn, H. F., 9, 55, 116, 161, 194

Overproduction, 118

Oxygen, 36

Palaeontology, 164, 216

Pancreas, 10

Pangenesis, 139

Panmixia, 115

Papilio ajax, 72

Paramecium, 192

Parasitism, 20

Parental care, 178

Parthenogenesis, artificial, 37

Patterson, J. T., 101

Pawpaw butterfly, 72

Pentadactyl appendage, 166, 217

Peromyscus maniculatus, 153

Petrunkevitch, A., 37, 98

Pharyngeal pouches, 215 
Physico-chemical basis of life, 10, 11

Pieris octavia-seramus, 41

Pigeon, passenger, 29

Pigmentation, 40; in butterflies, 95,180 ; in man, 94,204

Pike, F. H., 90

Pituitary gland, 10

Plants, and organic environment, 20; xerophytic, 134

Plastids, 83

Plebeius melissa, 119

Poisons, response to, 56

Polarity, 85

Polled Hereford, 73

Polyploidy, 74

Powers, J. H., 26

Prairie, 19

Preadaptation, 125, 133, 159, 214

Prescience, 185

Pressure, 19

Primates, 195

Primordial living substance, 13

Primrose, evening, 127

Promorphology, 85

Protophyta, 28

Protozoa, 28; enucleate, 80; responses of, 185

Pure lines, 27, 127

Pyrgus centaureae, 123

Pyrgus tessellata, 42

Rabaud, E., 5, 7

Rabbits, 151, 155, 223

Races, 42, 69; geographic, 152; of deer-mice, 153

Radiation, disintegrative, 48; in evolution, 146, 151; terrestrial, 58
Rays, 89, 212; see X-rays

Reassortment, 68

Recapitulation theory, 167

Recombination, 57

Relationship of nucleus and cytoplasm, $\mathbf{7 7}$

Rensch, B., 152, 162

Response, 56; adaptive, 64, 204; of bumble-bees, 187; through generations, 223; of higher animals, 186; of honey-bees, 187; individual, 67, 155, 172; of Protozoa, 185

Resultants, 168, 169

Reversibility, 218

Rignano, E., 139

River, analogy with species, 30

Roux, W., 36, 116

Ruthven, A. G., 161

Salmo fario, 153

Salmo ferox, 153

Schröder, C., 222

Schwarz, E., 162

Scott, E. L., 90

Scrophularia leporella, 43

Scrotum, 91

Seal, 218

Secretin, 10

Selection, 159, 194; coincident, 116; germinal, 115; and isolation, 117; limitations of, 126; and mutations, 130; natural, $70,113,227$; organic, 116; results of, 118, 124; sexual, 70, 114

Self-determination, 182, 195

Semon, R. W., 139

Sense organs, 90 
Sewertzoff, A. N., 3

Sex reversal, 103

Sexual selection, 70, 114

Simocephalus vetulus, 157

Skinner, H., 42

Smith, E. A., 155, 222, 223

Smith, John B., 42

Snakes, garter, 161

Social organization, 20

Soma, 87, 90, 209

Specialization, 90

Speciation, 161

Species, 22, 26, 39; change in, 68 ; elementary, 27 ; and individual, 29, 135; instability of, 33; Lotsy's, 129; reality of, 29 ; and reproduction, 105; scope of, 44; uniformity of, 181

Spencer, W. P., 102

Spermatozoa, 80, 91

Spontaneous generation, 14

Stature, 67

Stimulus, 224

Subspecies, 69

Sumner, F. B., 60, 66, 73, 148, 153,156

Survival of the fittest, 71

Symbiosis, 20

Taenia solium, 37

Temperature, $36,56,89$; effect on mice, 60 ; regulation, 21

Tetrakinetic theory, $\mathbf{5 5}$

Theories : centro-epigenesis, 139; coincident selection, 116; germinal selection, 115; intraselection, 116; isolation, 119; kinetogenesis, 138; Lamarck- ian, 127; mneme, 139; mutation, 127; orthogenesis, 131; pangenesis, 139; panmixia, 115; parallel induction, 140; preadaptation, 125, 133; recapitulation, 167 ; tetrakinetic, 55; use and disuse in chromosomes, 208

Thinking, 183

Thyroid, 37, 65, 181

Translocation, 170

Transplantation, 38

Tree hoppers, 61

Troland, L. T., 81, 97

Tropisms, 188, 196

Trout, 152

Tulips, 74

Typhoid, 223

Unit characters, 40

Uranium, 48

Use and disuse, 137; results of, 56

Usefulness, 70

Variation, cause of, 53; of environment, 49; geographic, 42; of heritage, 49, 52; seasonal, 41

Varieties, 69; of $C$. macilentus, 70

Vertebrates, terrestrial, 218

Vitalists, 108

Vitamines, 65

Wagner, A., 110

Wagner, M., 119

Water, 36, 50

Weismann, A., 92, 103, 115, 125, 209 


\section{INDEX}

Wells, H. G., 205

Wheeler, W. M., 69

Whitman, C. O., 199

Williams, R. C., Jr., 42

Willow moth, 222
Woltereck, R., 66, 155, 216

Worms, parasitic, 37

$\mathrm{X}$-rays, 48, 58, 74, 92, 101, 144, 203 





